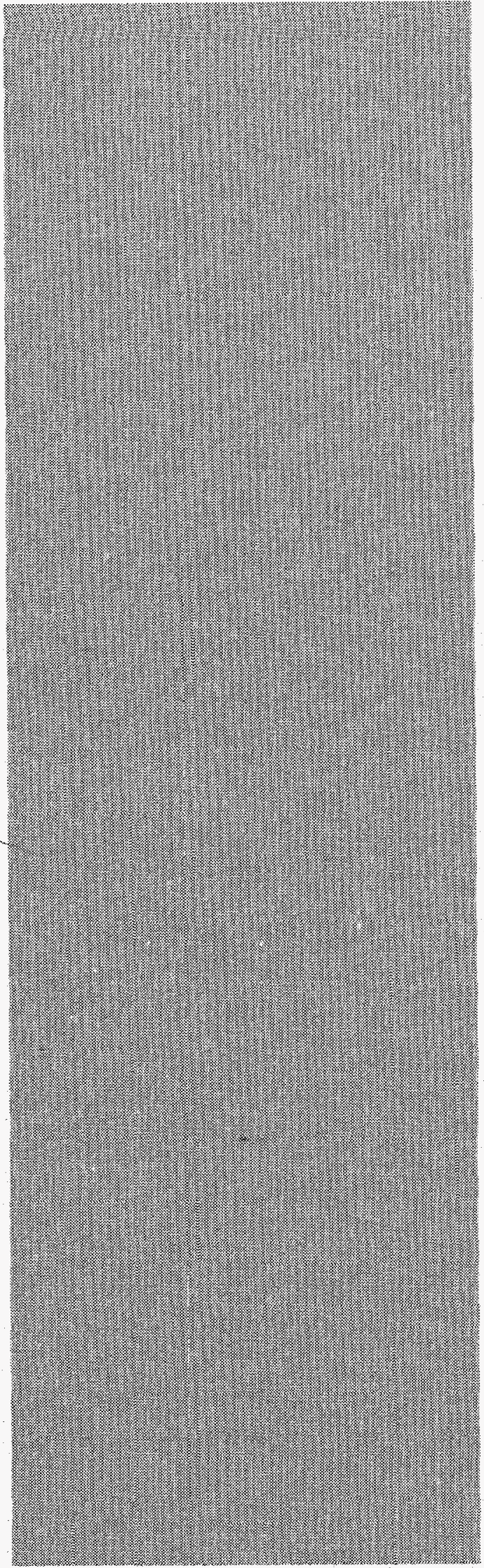

\title{
HENC Performance Evaluation and Plutonium Calibration
}

$$
\begin{aligned}
& \text { RECEIVED } \\
& \text { DEC } 291997 \\
& \text { OSTI }
\end{aligned}
$$

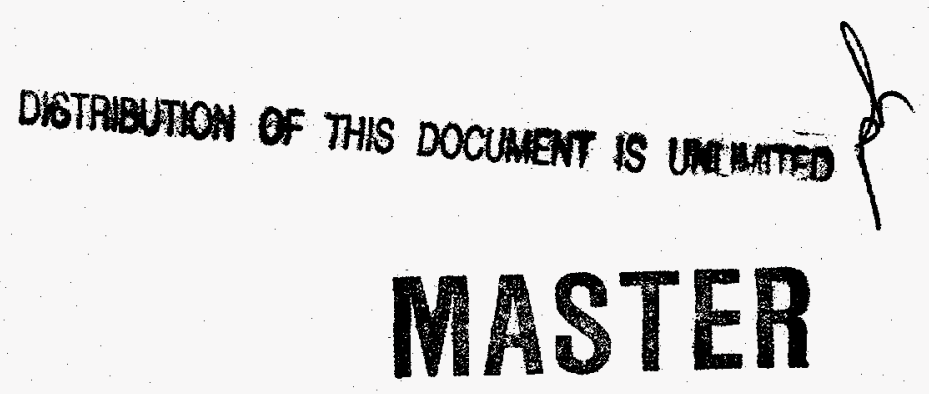

\section{Los Alamos}

Los Alamos National Laboratory is operated by the University of California for the United States Department of Energy under contract W-7405-ENG-36. 
This work was supported by the U.S. Department of Energy, Office of Nonproliferation and National Security, Office of Safeguards and Security, and Canberra Industries, Meriden, CT.

Edited by Jeff Skiby, Group CIC-1

Prepared by Celina Ortiz, Group NIS-5

An Affirmative Action/Equal Opportunity Employer

This report was prepared as an account of work sponsored by an agency of the United States Government. Neither The Regents of the University of California, the United States Government nor any agency thereof, nor any of their employees, makes any warranty, express or implied, or assumes any legal liability or responsibility for the accuracy, completeness, or usefulness of any information, apparatus, product, or process disclosed, or represents that its use would not infringe privately owned rights. Reference herein to any specific commercial product, process, or service by trade name, trademark, manufacturer, or otherwise, does not necessarily constitute or imply its endorsement, recommendation, or faooring by The Regents of the University of California, the United States Government, or any agency thereof. The views and opinions of authors expressed herein do not necessarily state or reflect those of The Regents of the University of California, the United States Government, or any agency thereof. Los Alamos National Laboratory strongly supports academic freedom and a researcher's right to publish; as an institution, however, the Laboratory does not endorse the viewpoint of a publication or guarantee its technical correctness. 


\section{DISCLAIMER}

Portions of this document may be illegible electronic image products. Images are produced from the best available original document. 


\section{HENC Performance Evaluation} and Plutonium Calibration
H. O. Menlove
J. Baca
J. M. Pecos
D. R. Davidson*
R. D. McElroy*
D. B. Brochu* 


\section{CONTENTS}

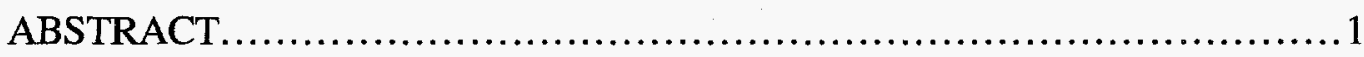

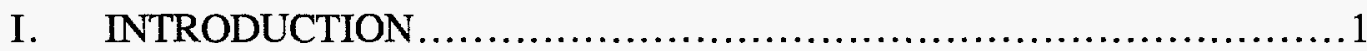

II. MECHANICAL DESIGN ...........................................

III. PERFORMANCE TESTS ............................................... 3

A. High Voltage Bias.............................................

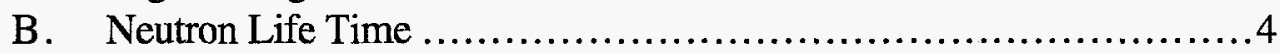

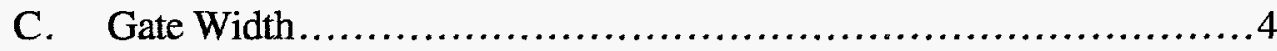

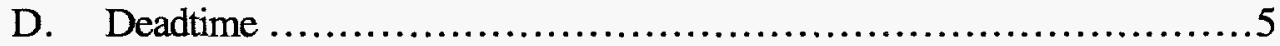

E. Efficiency ................................................... 6

F. Coincidence Gate Fractions.......................................... 9

G. Multiplication Constant....................................... 9

H. Calibration Options .......................................... 10

IV. BACKGROUND MEASUREMENT .................................. 10

A. Cosmic-Ray Backgrounds ................................... 11

B. Statistical Filter for Cosmic-Ray Rejection....................... 11

V. RESPONSE PROFILES................................................ 12

A. Axial Profiles ................................................... 12

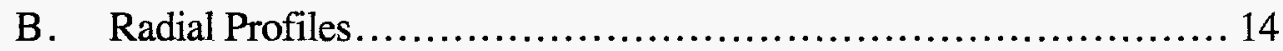

VI. ADD-A-SOURCE MATRIX CORRECTIONS .......................... 14

A. Add-a-Source Procedures..................................... 16

B. Matrix Materials ................................................... 17

C. Results with the Detector Bank Off .............................. 17

D. All Banks on Results ...................................... 18

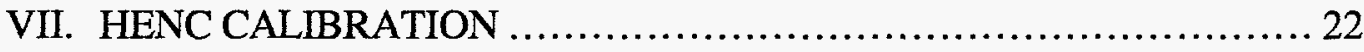

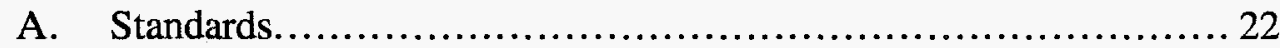

B. Calibration Procedure.......................................... 24

C. Calibration Results......................................... 24

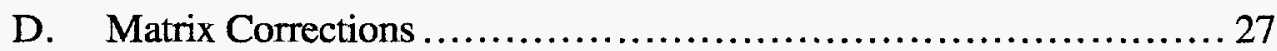

VIII. MEASUREMENT PRECISION AND BACKGROUNDS ............... 28

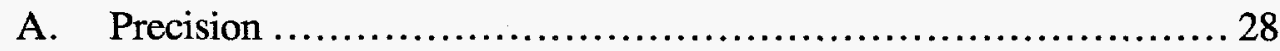

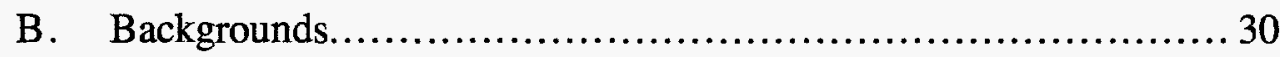

C. Background Reduction by Statistical Filters ...................... 32

1. NAS Software ................................................ 32

2. NCC Software............................................... 34

D. Spallation Background Tests ..................................... 36

E. HENC Backgrounds in 200-L Drums ........................... 38 


\section{CONTENTS (cont.)}

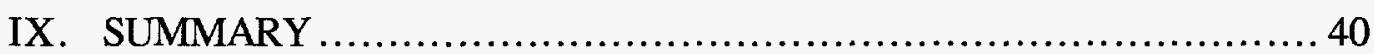

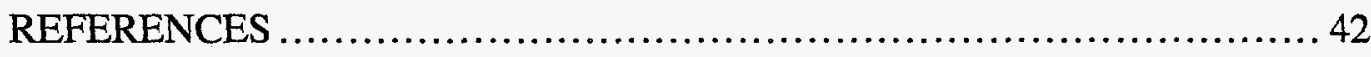

APPENDIX A ............................................................... 43

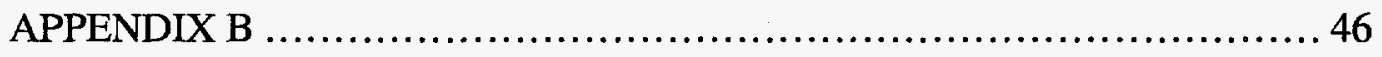

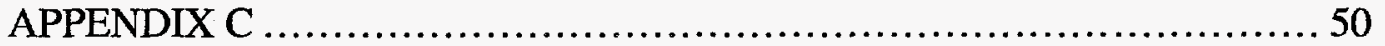




\title{
HENC PERFoRMANCE EVAlUATION AND PLUTONIUM CALIBRATION
}

\author{
by
}

H. O. Menlove, J. Baca, J. M. Pecos, D. R. Davidson, R. D. McElroy, and D. B. Brochu

\begin{abstract}
We have designed a high-efficiency neutron counter (HENC) to increase the plutonium content in 200-L waste drums. The counter uses totals neutron counting, coincidence counting, and multiplicity counting to determine the plutonium mass. The HENC was developed as part of a Cooperative Research and Development Agreement between the Department of Energy and Canberra Industries. This report presents the results of the detector modifications, the performance tests, the add-a-source calibration, and the plutonium calibration at Los Alamos National Laboratory (TA-35) in 1996.
\end{abstract}

\section{INTRODUCTION}

This report gives a summary of the performance tests and calibrations that were performed on the high-efficiency neutron counter (HENC) that was designed as part of the Cooperative Research and Development Agreement (CRADA) between Canberra Industries and the Department of Energy (DOE). The design and fabrication of the HENC was completed in early 1996.

The initial characterization of the HENC was performed by Canberra in April 1996 and results are documented elsewhere. ${ }^{1}$ Small design modifications were made at the Los Alamos National Laboratory (Los Alamos), and the system was calibrated for plutonium. The add-asource (AS) matrix correction calibration was made to reflect the final moderator configuration.

\section{MECHANICAL DESIGN}

The HENC was fabricated out of high-density polyethylene (HDPE) with 10-cm-thick detector banks backed by $30-\mathrm{cm}$-thick HDPE shielding. The sample cavity size is $82 \mathrm{~cm}$ wide by $109 \mathrm{~cm}$ high by $77 \mathrm{~cm}$ deep. There are $113{ }^{3} \mathrm{He}$ tubes in the system with uniform coverage on the four sides, the top, and the bottom. Figure 1 shows the complete system and Fig. 2 shows the sample cavity. There are doors on both the front and back of the system for the potential of having the drums pass through the system. Figure 3 shows the electronics cabinet with the computer, printer, and the CI2150 multiplicity electronics. The system uses 16 AMPTEK amplifiers.

A complete system description is provided in Canberra's technical manual. ${ }^{2}$ 


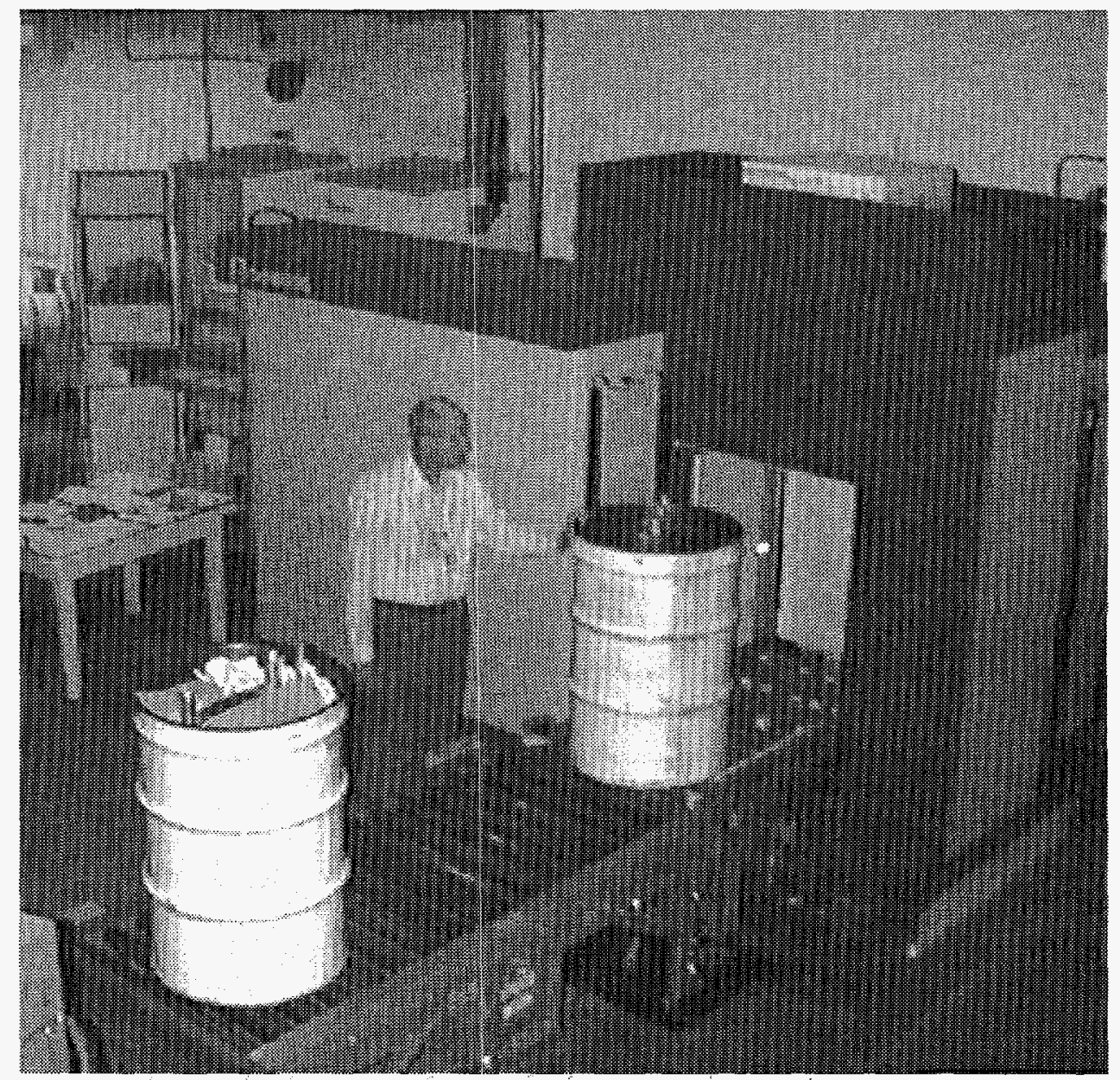

Fig. 1. Photograph of complete HENC.

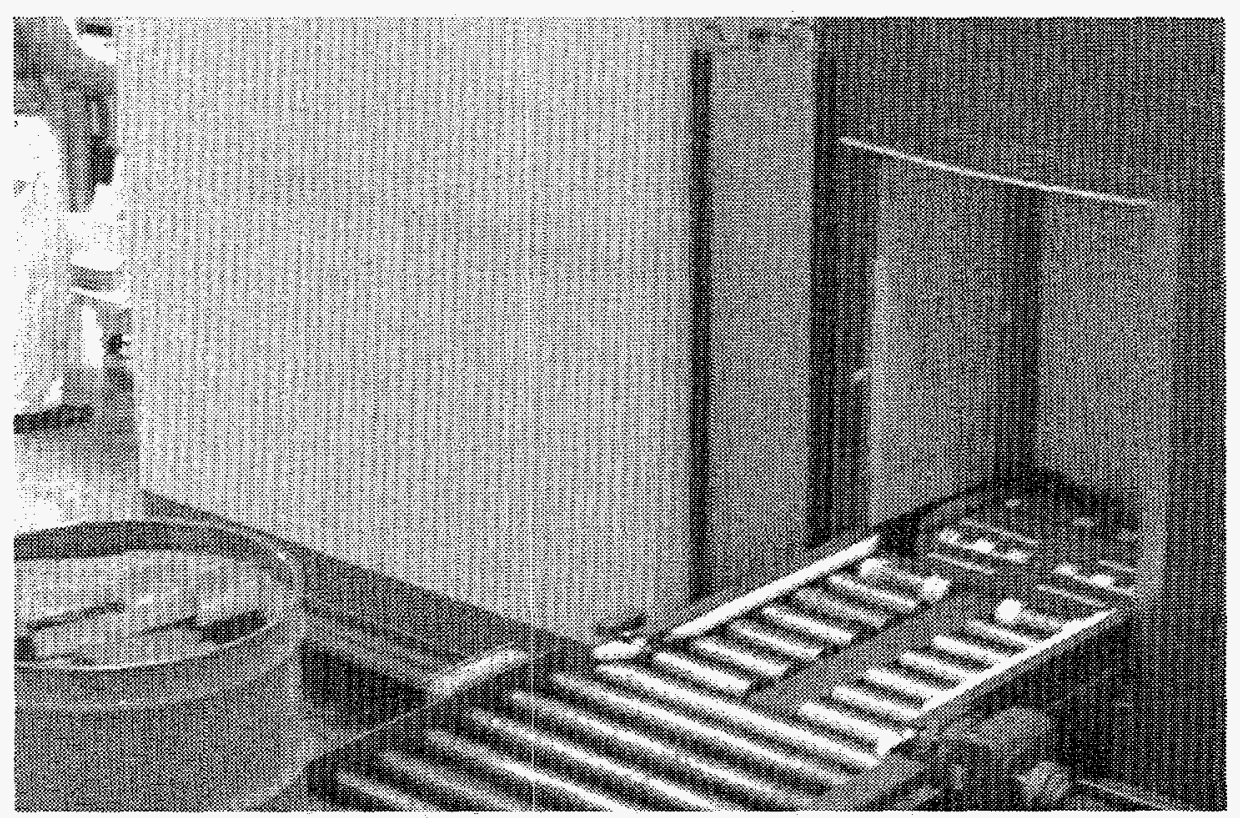

Fig. 2. Sample cavity of HENC. 


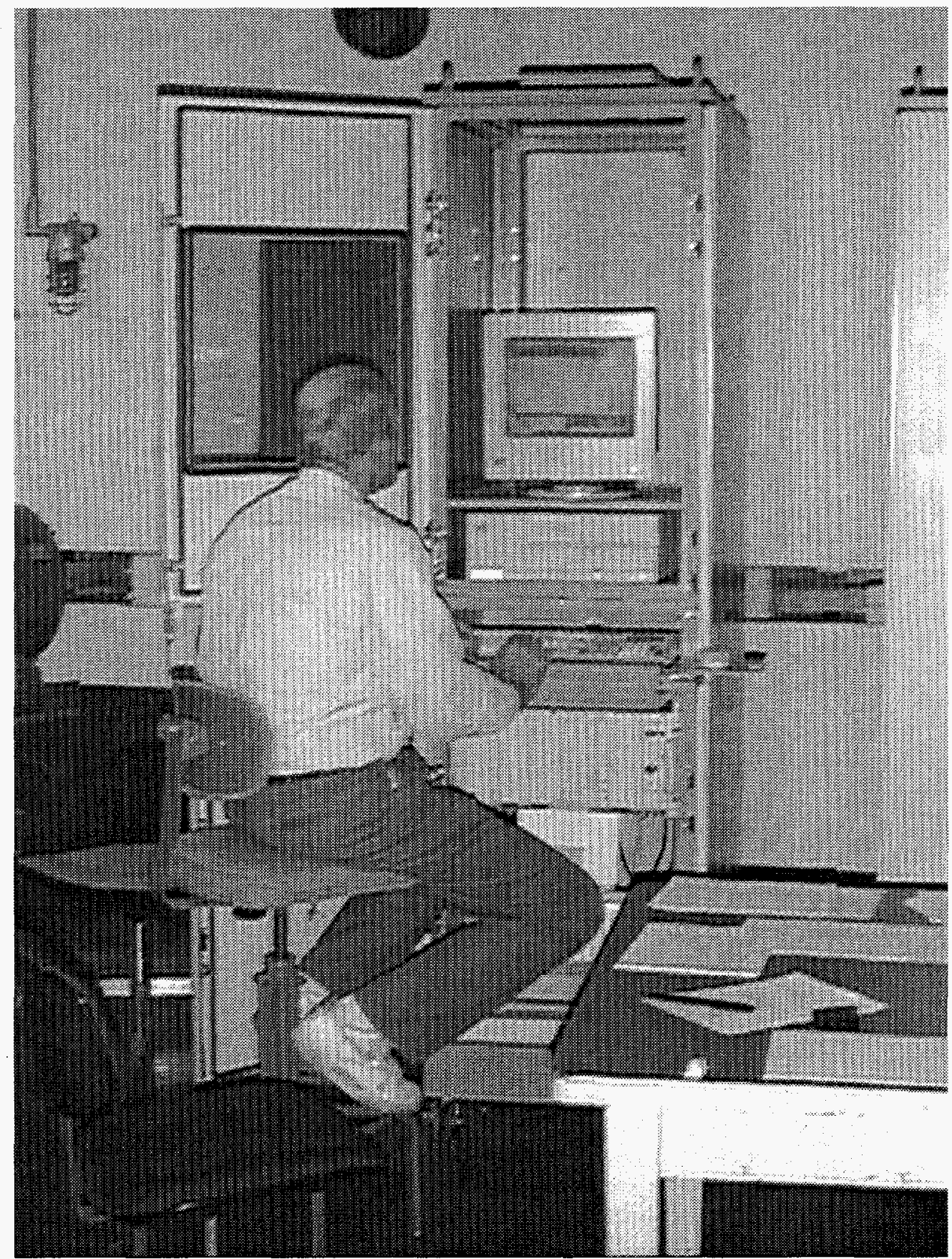

Fig. 3. Electronic cabinet for HENC showing the personal computer (PC) and the CI2150 multiplicity module.

\section{PERFORMANCE TESTS}

\section{A. High Voltage Bias}

The neutron counting rate vs high voltage was measured in Ref. 1 and the results are shown in Fig. 4. The operating voltage was set at $1720 \mathrm{~V}$. 


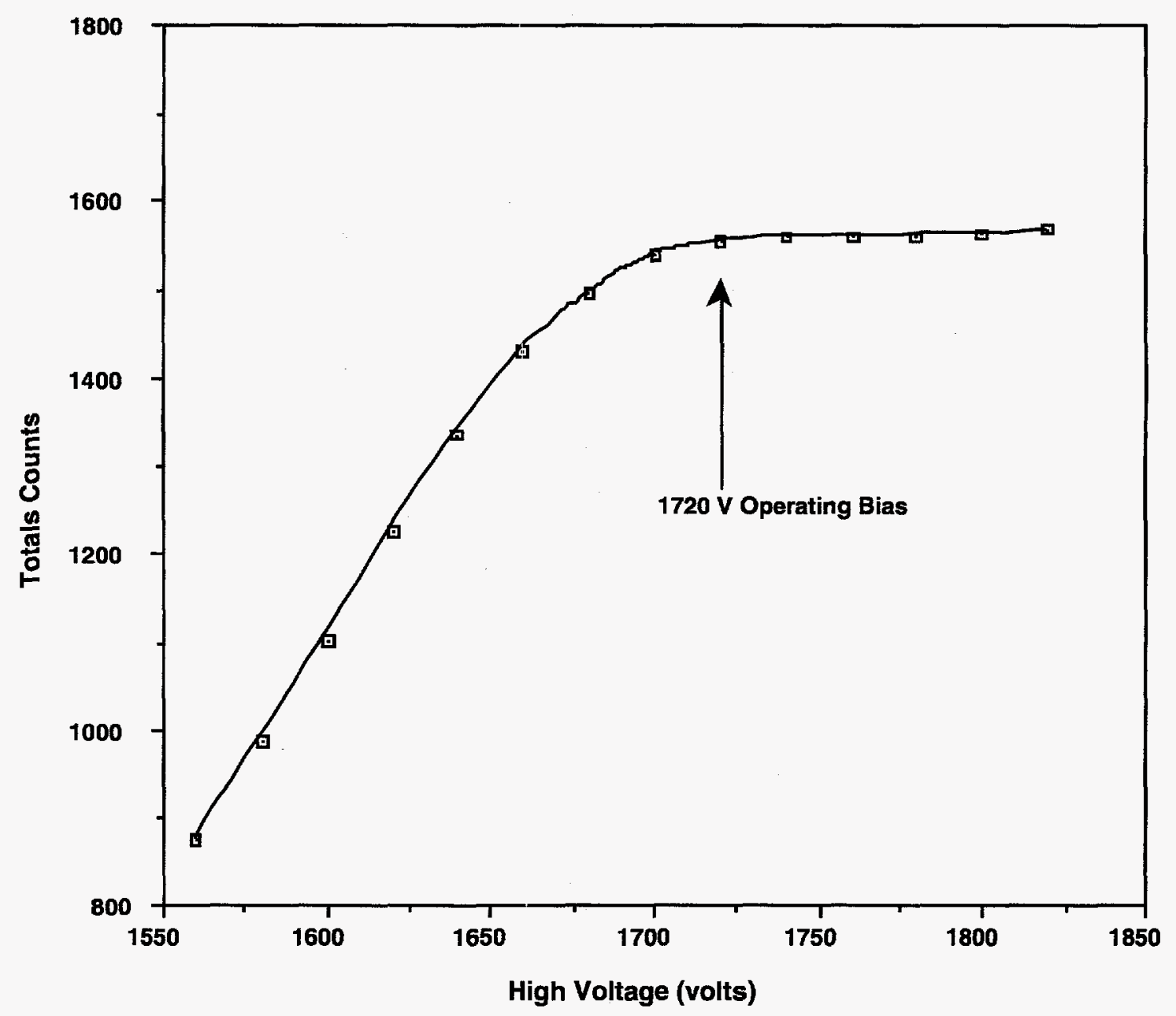

Fig. 4. Detector high voltage plateau for the HENC.

\section{B . Neutron Life Time}

The neutron life time was measured using a ${ }^{252} \mathrm{Cf}$ source and different gate lengths. The dieaway time is smaller for short gate settings and larger for long gate settings. We operate the HENC at a gate of $128 \mu \mathrm{s}$, and the die-away time of $50 \mu \mathrm{s}$ is representative of the gate times of 64 to $128 \mu \mathrm{s}$.

\section{Gate Width}

Long gate settings are desirable to get a large fraction of the neutrons in the coincidence gate. However, at higher counting rates, the long gate settings give a large accidental counting rate and this increases the statistical error on the reals. For waste quantities of plutonium, the totals rates are low and we have selected a gate setting of $128 \mu \mathrm{s}$. For plutonium masses greater than $100 \mathrm{~g}$, the appropriate gate setting would be $64 \mu \mathrm{s}$ but this is outside the normal range for waste drums. The ratio of the doubles rate at a gate of $128 \mu$ s to $64 \mu \mathrm{s}$ is 1.320 . Figure 5 shows the relative statistical error vs gate setting for a $3-\mathrm{g}$ plutonium sample $\left(6 \%{ }^{240} \mathrm{Pu}\right)$. 


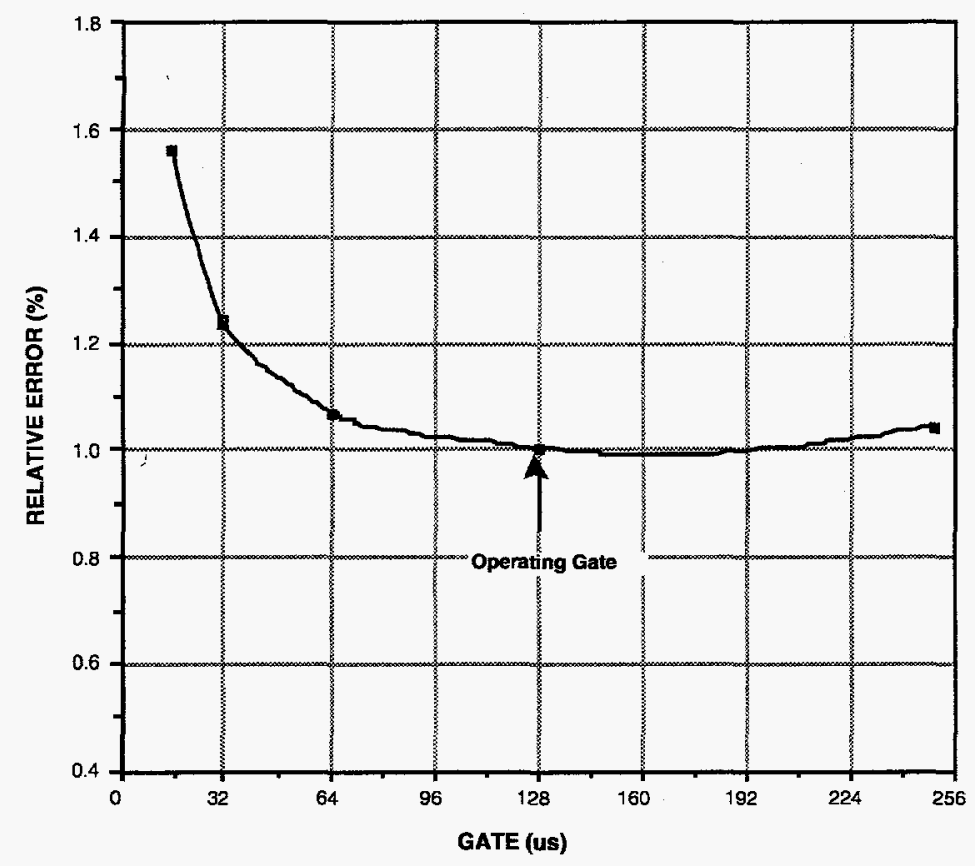

Fig. 5. Normalized measurement error vs gate setting for a $3-g$ plutonium sample.

\section{Deadtime}

The deadtime was measured using multiple ${ }^{252} \mathrm{Cf}$ sources at Canberra and at Los Alamos. The results agreed within the statistical errors and we have used the average values shown in Table I.

The deadtime correction is slightly different for the two software codes that can be used to operate the HENC. The Canberra code Neutron Assay System (NAS) ${ }^{3}$ uses the standard correction for the Reals $(\mathrm{R})$ and the Totals $(\mathrm{T})$ and it uses the multiplicity deadtime with linear corrections ( $\mathrm{c}$ and $\mathrm{d})$ for the doubles, and triples. ${ }^{1}$

\begin{tabular}{|l|l|}
\hline \multicolumn{2}{|l|}{ TABLE I. Performance Specification for the HENC. } \\
\hline \hline Parameter & Value \\
\hline \hline Neutron efficiency for ${ }^{240} \mathrm{Pu}$ & $31 \%$ \\
\hline Neutron die away-time & $50 \mu \mathrm{s}$ \\
\hline Deadtime (a) $\quad 0.50 \mu \mathrm{s}$ \\
\hline \multicolumn{1}{|c|}{ x 10 $\left.0^{-6}\right)$} & $0.161 \mu \mathrm{s}$ \\
\hline Multiplicity deadtime & $171 \mu \mathrm{s}$ \\
\hline correction coefficient c & $0.147 \mu \mathrm{s}$ \\
\hline correction coefficient d & $0.147 \mu \mathrm{s}$ \\
\hline Coincidence gate & $128 \mu \mathrm{s}$ \\
\hline Predelay & $3.0 \mu \mathrm{s}$ \\
\hline Doubles calibration coefficient & 53.8 counts $/ \mathrm{s}^{\circ} \mathrm{g}{ }^{240} \mathrm{Pu}$ \\
\hline Multiplication constant $\left(\rho_{0}\right)$ & 0.178 \\
\hline
\end{tabular}


The Los Alamos software NCC ${ }^{4}$ uses the same corrections for T and R as NAS, but it uses the same corrections for the singles (S) and doubles (D) as were used for $T$ and $R$. The multiplicity deadtime is only used for the triples rate together with the linear correction (d).

In practice, these differences in the deadtime corrections are completely negligible for waste quantities of plutonium.

\section{E. Efficiency}

The efficiency of the HENC was measured at Canberra giving the results of $29.5 \%$ for ${ }^{252} \mathrm{Cf}$. This efficiency was remeasured at Los Alamos after shipment giving an efficiency of $29.6 \%$ for ${ }^{252} \mathrm{Cf}$ in the center of an empty drum. The volume-averaged efficiency was $30.2 \%$ because the counts at the perimeter of the drum are slightly higher than at the center. Subsequent corrections in the absolute yields of the ${ }^{252} \mathrm{Cf}$ calibration sources has reduced the measured efficiencies by a few percent.

Initial measurements with polyethylene shavings in the drum gave a significant increase in efficiency indicating that the HENC had a wall thickness that was too thin for matrix independence. A series of measurements were performed to determine the optimum wall thickness. Figure 6 shows the measurement geometry that was used to evaluate the efficiency change with the polyethylene thickness at the sample. The HDPE thickness was increased and the counting rate for a small ${ }^{240} \mathrm{Pu}$ sample was measured at each thickness. The results are shown in Fig. 7 when the rates have been normalized to the original as-built condition. We see that the efficiency increases up to a thickness of about $1.8 \mathrm{~cm}$. The doubles rates peak before the singles rates because the thermalized neutrons at the sample location do not make it into the coincidence gate because of the long flight time to the ${ }^{3} \mathrm{He}$ tubes.

The addition of polyethylene at the sample location has a different effect than the addition on the wall near the detector. On the detector wall, the HDPE moderates the direct neutrons from the sample as well as the reflected neutrons from the other interior walls. The HDPE at the sample location has less impact on the efficiency than the HDPE on the detector wall. Figure 8 shows the efficiency increase with the addition of the HDPE on the detector walls. With the addition of $\sim 0.6 \mathrm{~cm}$ of HDPE on the four sides and top of the cavity walls, we see a $3 \%$ increase in the ${ }^{240} \mathrm{Pu}$ counting efficiency. When we increase the thickness to $\sim 1.2 \mathrm{~cm}$, the efficiency is approximately the same as for the $0.6-\mathrm{cm}$ increase so we used the $0.6-\mathrm{cm}$ thickness to leave the detector slightly under moderated.

After the addition of $0.6 \mathrm{~cm}$ to the wall, we added HDPE at the sample location and we got the results shown in Fig. 9. With the HDPE on the wall, the sample HDPE thickness to get the peak efficiency is $\sim 0.5 \mathrm{~cm}$ so the detector is still slightly under moderated.

In summary, the addition of $0.6 \mathrm{~cm}$ of HDPE to the wall increased the efficiency to $30 \%$ for

${ }^{252} \mathrm{Cf}$ and $31 \%$ for ${ }^{240} \mathrm{Pu}$. The system also has less matrix sensitivity for low hydrogen loadings in waste drums. 


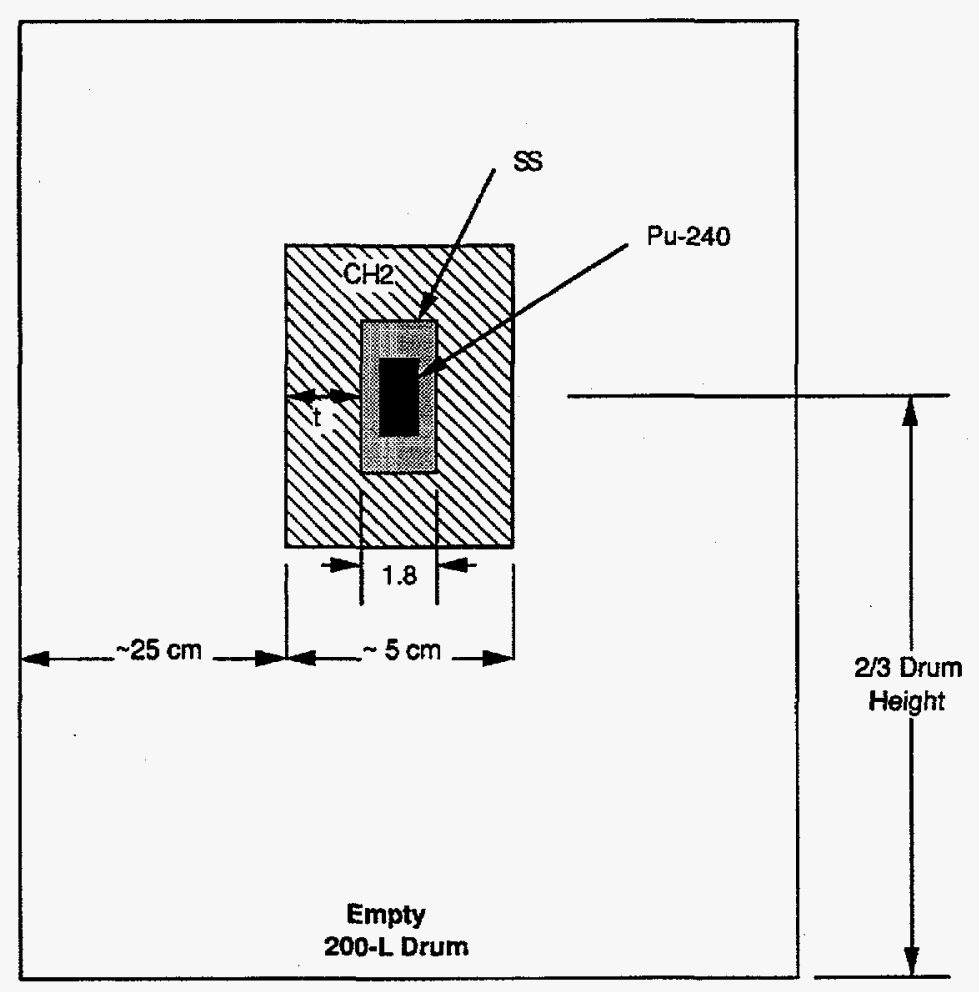

Fig. 6. Geometry for adding HDPE around $a^{240} \mathrm{Pu}$ sample to measure neutron moderation and absorption.

Fig. 7. Change in singles and doubles counting rate as a function of HDPE thickness around the plutonium sample.

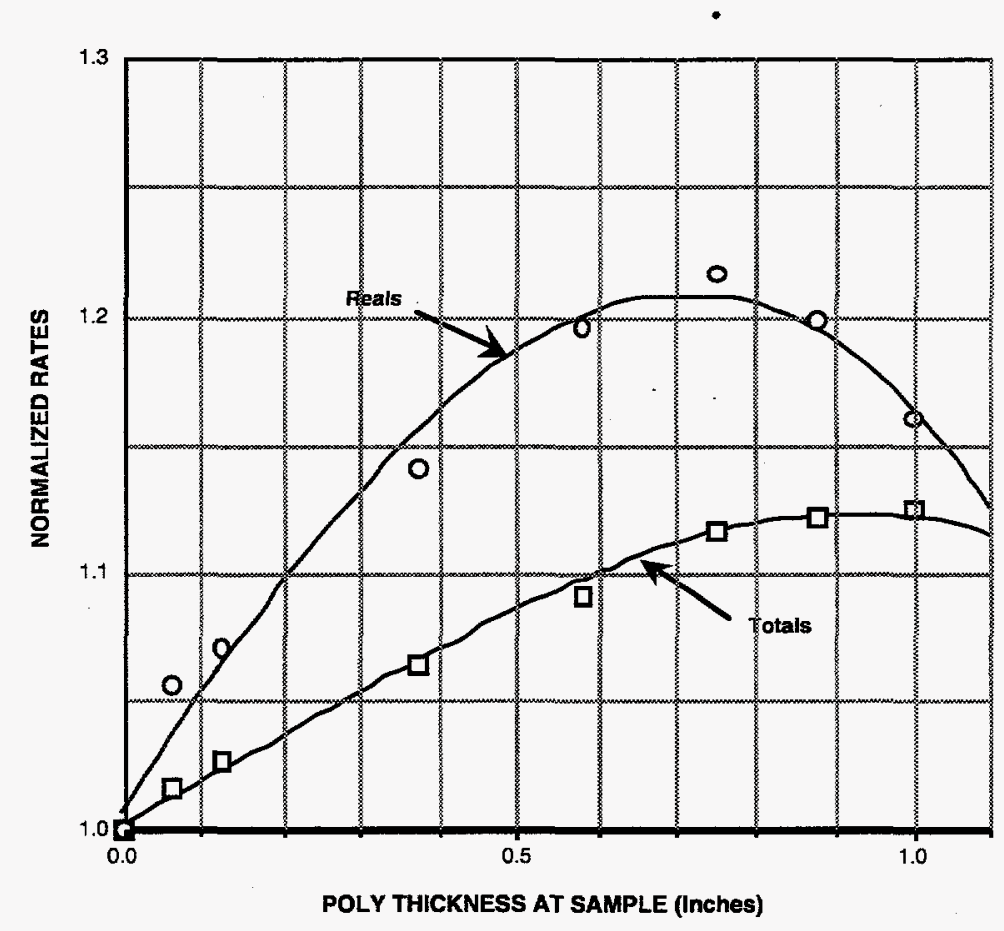




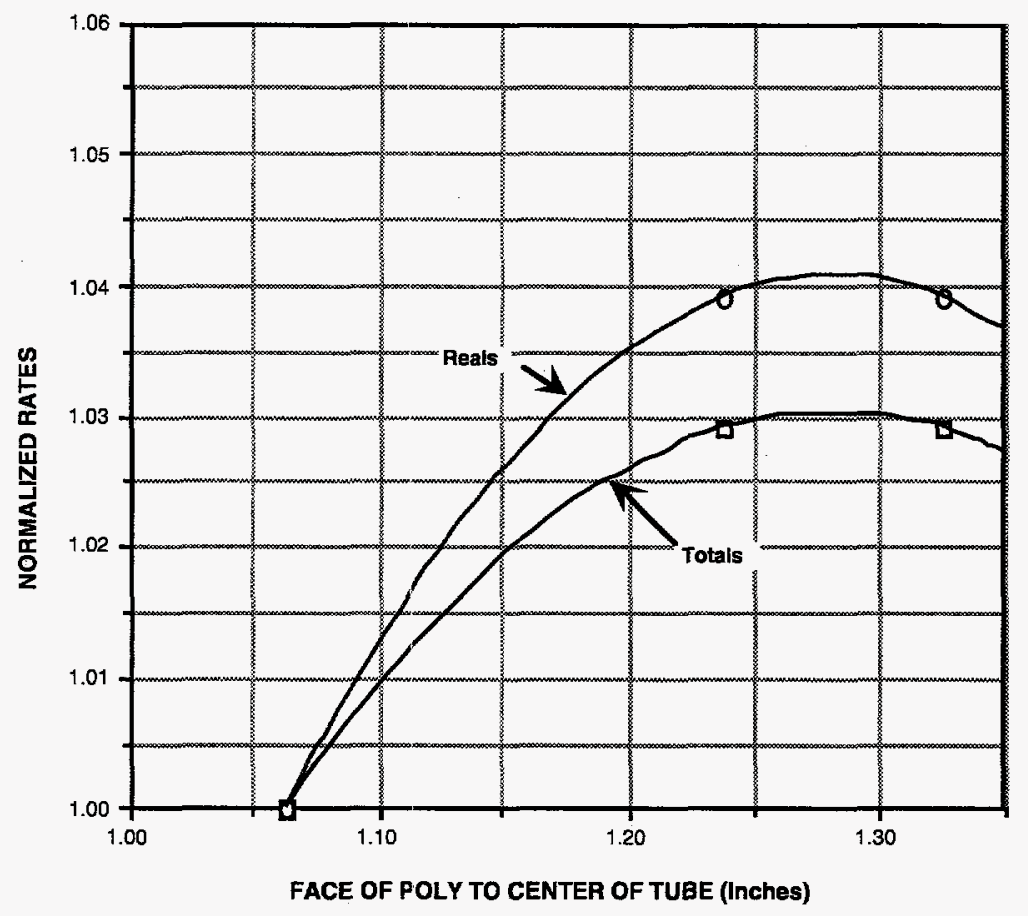

Fig. 8. Normalized singles and doubles counting rate as a function of HDPE added to the sample cavity walls.

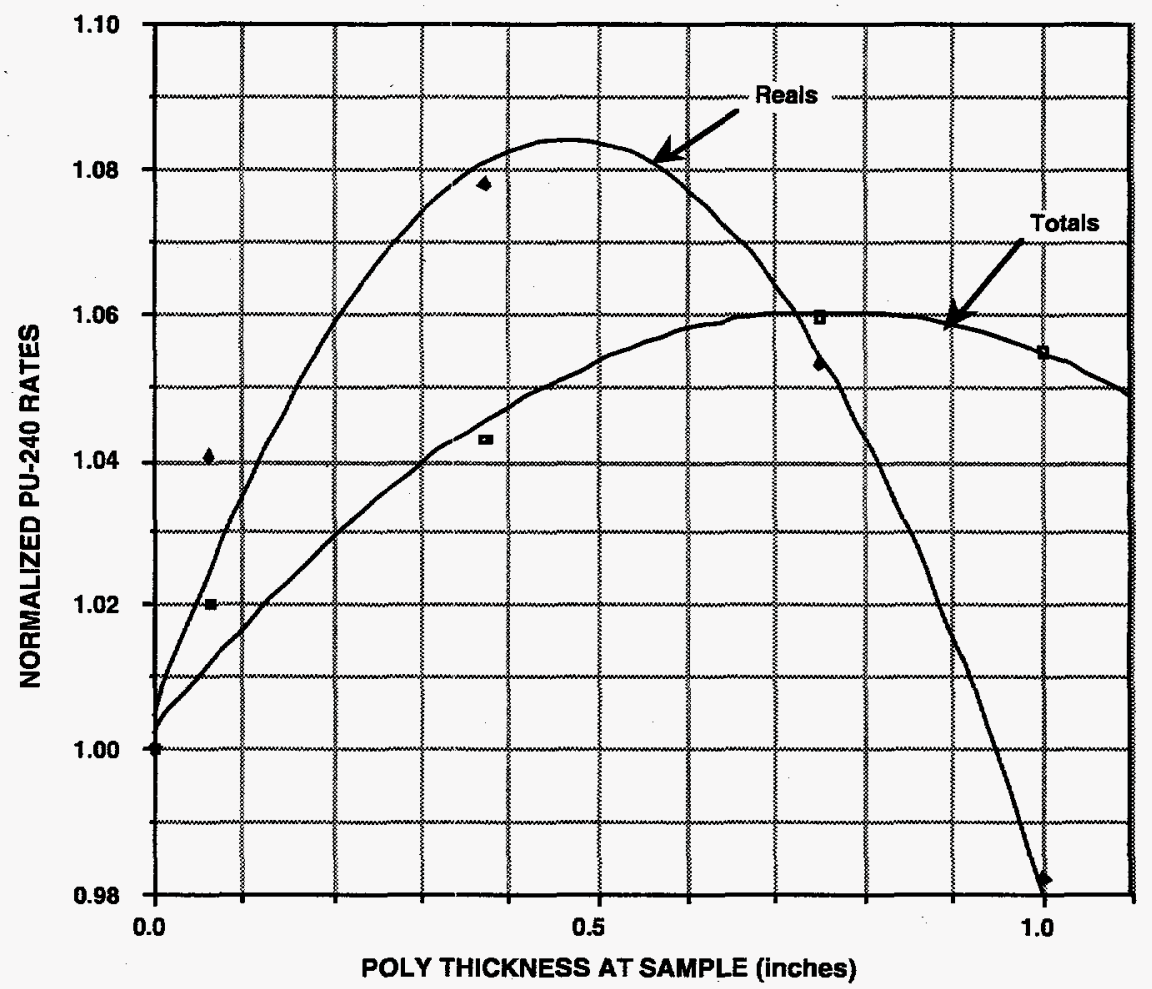

Fig. 9. Normalized singles and doubles counting rate as a function of HDPE added around the sample after $0.6 \mathrm{~cm}$ of HDPE was added to the detector walls. 


\section{F. Coincidence Gate Fractions}

The fraction neutrons that fall within the doubles coincidence gate can be calculated or measured. The calculated value is

$$
f_{g}=e^{\frac{-P D}{\tau}}\left(1-e^{\frac{-G}{\tau}}\right),
$$

where

$$
\begin{aligned}
\mathrm{PD} & =\text { Predelay }=3.0 \mu \mathrm{s} \\
\mathrm{G} & =\text { Gate }=128 \mu \mathrm{s} \\
\tau & =\text { Die-away time } \approx 50 \mu \mathrm{s} .
\end{aligned}
$$

The doubles gate fraction calculation gives

$$
f_{g}=0.869 \text {, }
$$

and the triples gate fraction is approximately the square of the doubles gate fraction.

$$
f_{\mathrm{g}} \text { (triples) }=(0.869)^{2}=0.755 \text {. }
$$

These fractions can be measured using ${ }^{252} \mathrm{Cf}$ source together with the nuclear decay constants for ${ }^{252} \mathrm{Cf}$. The measured gate doubles fraction was

$$
f_{g} \text { (doubles) } \sim 0.70 \text {. }
$$

The gate fractions are not used for the normal AS applications, but they are used for passive multiplicity counting if plutonium standards are not available. The triples gate fraction is adjusted to give the correct ${ }^{240} \mathrm{Pu}$ mass when standards are available.

\section{G. Multiplication Constant}

For two-parameter passive coincidence counting, a multiplication constant is defined as

$$
\rho_{0}=\frac{R_{0}}{T_{0}}(1+\alpha),
$$

where

$R_{0}=$ Doubles rate for a nonmultiplying sample,

$T_{0}=$ Totals rate for a nonmultiplying sample, and

$\alpha=$ Ratio of $(\alpha, n)$ neutrons to spontaneous fission neutrons.

To measure $\rho_{0}$, we used a small $(0.705 \mathrm{~g}){ }^{240} \mathrm{Pu}$ sample to give 


$$
\rho_{0}=\frac{37.87}{246.8}(1+0.142)=0.178
$$

\section{H. Calibration Options}

The calibration of the HENC is normally performed for the doubles rate; however, the singles and triples rates can also be used for the calibration. The singles rate gives the most sensitive response but it is subject to variations in $\alpha$. The triples rate is less sensitive than the doubles for low mass assays.

\section{BACKGROUND MEASUREMENT}

The neutron backgrounds in the HENC originate from nuclear materials stored nearby, such as waste drums and from cosmic-ray spallation reactions. The net reals come exclusively from cosmic-ray spallation.

The HENC has 30-cm-thick HDPE on the outside of the 10-cm-thick detector banks and this effectively eliminates the room source neutrons. However, the $30 \mathrm{~cm}$ of shielding has a negligible reduction in the cosmic-ray coincidence neutrons. The spallation neutrons originating in the floor and room walls are eliminated; however, the HDPE shield creates additional spallation neutrons next to the detector banks.

The effectiveness of the HENC shield for room neutrons was measured in Ref. 1 by placing $\mathrm{a}^{252} \mathrm{Cf}$ source inside the sample cavity and then outside the cavity at different distances from the system. Table II shows the normalized singles rates as a function of distance. The doubles background was negligible.

\begin{tabular}{|c|c|}
\hline \multicolumn{2}{|c|}{$\begin{array}{l}\text { TABLE II. Room Background Rate vs } \\
\text { Distance to HENC for } \mathrm{a}^{252} \mathrm{Cf} \\
\text { Source. }\end{array}$} \\
\hline Distance to HENC (m) & Normalized Totals Rate \\
\hline $\begin{array}{l}\text { Inside } \\
0.3 \\
0.91 \\
1.52 \\
2.29 \\
3.05 \\
\end{array}$ & $\begin{array}{l}1.00 \\
1.09 \times 10^{-3} \\
0.69 \times 10^{-3} \\
0.43 \times 10^{-3} \\
0.29 \times 10^{-3} \\
0.22 \times 10^{-3}\end{array}$ \\
\hline
\end{tabular}

One conclusion of Table II is that a drum containing $\sim 10 \mathrm{~g}$ of plutonium placed $\sim 2.3 \mathrm{~m}$ from the outside of HENC would give a singles count equivalent to $<3 \mathrm{mg}$ of plutonium inside the HENC. The doubles rate from the drum's background would be negligible. If the totals rate is used to measure low mass samples, it is necessary to measure the totals background near the time of the sample measurement. 


\section{A. Cosmic-Ray Backgrounds}

The dominant source of neutron background is the neutrons from cosmic-ray spallation. To investigate the effectiveness of the external HDPE shield on the cosmic rays, we placed a portable coincidence counter ${ }^{5}$ near the HENC and then measured the singles and doubles backgrounds as a function of HDPE shielding thickness.

Table III gives the results of the measurements where the detector background was first measured in the 12-m-deep basement of Building 27, TA-35 at Los Alamos. The detector was then moved adjacent to the HENC and the cosmic-ray background was measured.

\begin{tabular}{|l|c|c|c|}
\hline \multicolumn{5}{|c|}{ TABLE III. Cosmic-Ray Background for INVS. } \\
\hline \hline Location & $\begin{array}{c}\text { Shielding } \\
\text { (cm) }\end{array}$ & $\begin{array}{c}\mathrm{S} \\
\text { (counts/s) }\end{array}$ & $\begin{array}{c}\mathrm{D} \\
\text { (counts/s) }\end{array}$ \\
\hline \hline Los Alamos, Bldg. 27 & 0 & 1.72 & 0.013 \\
(12 m below surface) & 10 & 1.09 & 0.014 \\
Los Alamos, Bldg. 27 & 0 & 9.41 & 0.100 \\
(surface) & 10 & 4.88 & 0.100 \\
& 20 & 4.20 & 0.098 \\
\hline
\end{tabular}

We conclude from the measurements that the singles and doubles rates increased by factors of 5.47 and 7.21, respectively, at the surface compared with the basement. The 20-cm-thick HDPE shielding decreased the singles background by a factor of 2.24 and the doubles background by only a few percent.

The cosmic-ray backgrounds for HENC at Meriden, CT were a factor of 3 and 4 less for singles and doubles, respectively, compared to Los Alamos.

\section{B . Statistical Filter for Cosmic-Ray Rejection}

The cosmic-ray spallation events have a higher average multiplicity than the spontaneous fission events. The detectability limit is a function of the neutron time-correlation background from cosmic rays, and we have reduced the background by eliminating the cosmic-ray spallation events that produce high-multiplicity neutrons by using a statistical filter. The cosmic-ray events can be counted as prompt charged-particle reactions in the detector tubes or as spallation-source neutrons that extend in time over the slowing-down time of the detector body. The predelay $(3.0 \mu \mathrm{s})$ eliminates the first category because they are short lived and the predelay ${ }^{6}$ vetoes them from the coincidence gate. The spallation neutrons fall within the coincidence gate but often with high multiplicity. We use the data collection software to isolate the high-multiplicity events and to eliminate them from the data averages. We are currently using statistical techniques to accomplish this.

Our statistical filter for background reduction consists of 2.4-3.0 $\sigma$ rejection threshold from the average of multiple, short data intervals. The normal counting time for a drum is $600 \mathrm{~s}$, and we divide this into 60 intervals of $10 \mathrm{~s}$ each. If any interval is more than $\pm 2.4-3.0 \sigma$ out of the average, we reject that interval from the average. The software statistical quality control (QC) 
filter $^{4}$ at the $2.4 \sigma$ rejection level decreased the doubles background by a factor of 1.35 and it gave a negligible reduction in the singles rate. This type of filter does not interfere with the routine assay of drums with significant plutonium loadings.

The HENC has such a large singles and doubles background rate at Los Alamos that the statistical filter has less benefit than at the lower counting rates. The average doubles background rate is $\sim 2.5$ counts/s so a 60 -s counting interval contains $\sim 138$ counts. Thus, a cosmic-ray burst with high multiplicity is diluted by the 138 average counts. To help this problem, we decreased the counting intervals to $10 \mathrm{~s}$ so the average number of counts is $2.3 \times 10=23$ and more of the burst events can be eliminated. There is much less of a problem at sea level because the doubles rate of $\sim 0.6$ counts/s would result in an average of 6 counts in a 10-s interval and the burst events can be more effectively eliminated.

The triples rate is more effective at eliminating burst events because the average triples rate is about an order of magnitude less than the doubles rate so the cosmic-ray burst stands out above the background.

\section{RESPONSE PROFILES}

\section{A. Axial Profiles}

The vertical response profiles for the singles and doubles rates were measured for the HENC with the original wall thickness and again after the addition of $0.6 \mathrm{~cm}$ of HDPE to the upper sections of the sample cavity.

$\mathrm{A}^{252} \mathrm{Cf}$ source was measured as a function of distance above the bottom of a $200-\mathrm{L}$ drum and the results are given in Fig. 10 for the original wall thickness. The source was positioned at a radius of $20 \mathrm{~cm}$ in a rotating drum to give a volume-averaged response. After the addition of the $0.6 \mathrm{~cm}$ of HDPE to the upper walls of the sample cavity, the response was more uniform as shown in Fig. 11. 


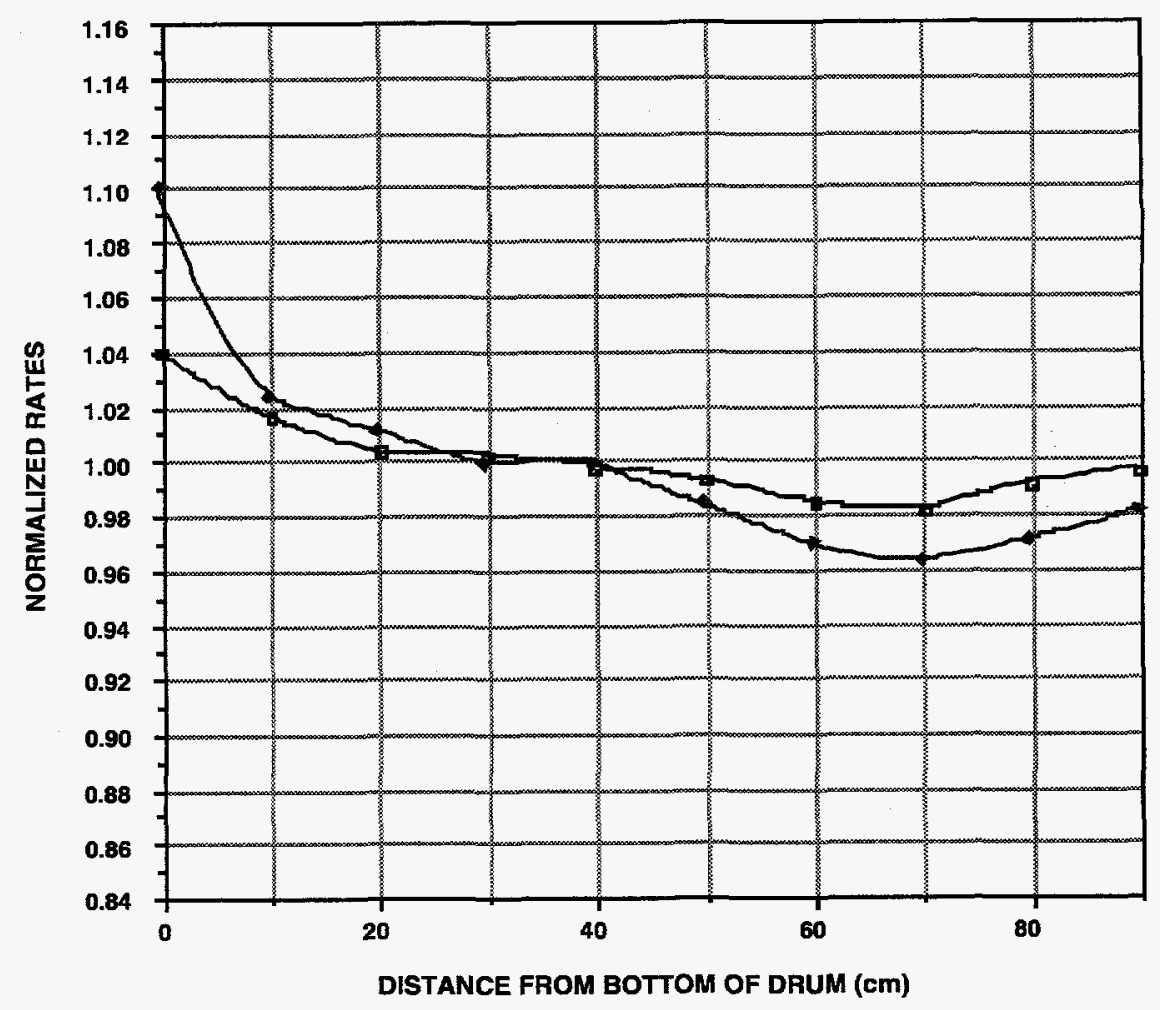

Fig. 10. Vertical response profiles for singles and doubles rates for HENC prior to adding $0.6 \mathrm{~cm}$ HDPE to the cavity walls.

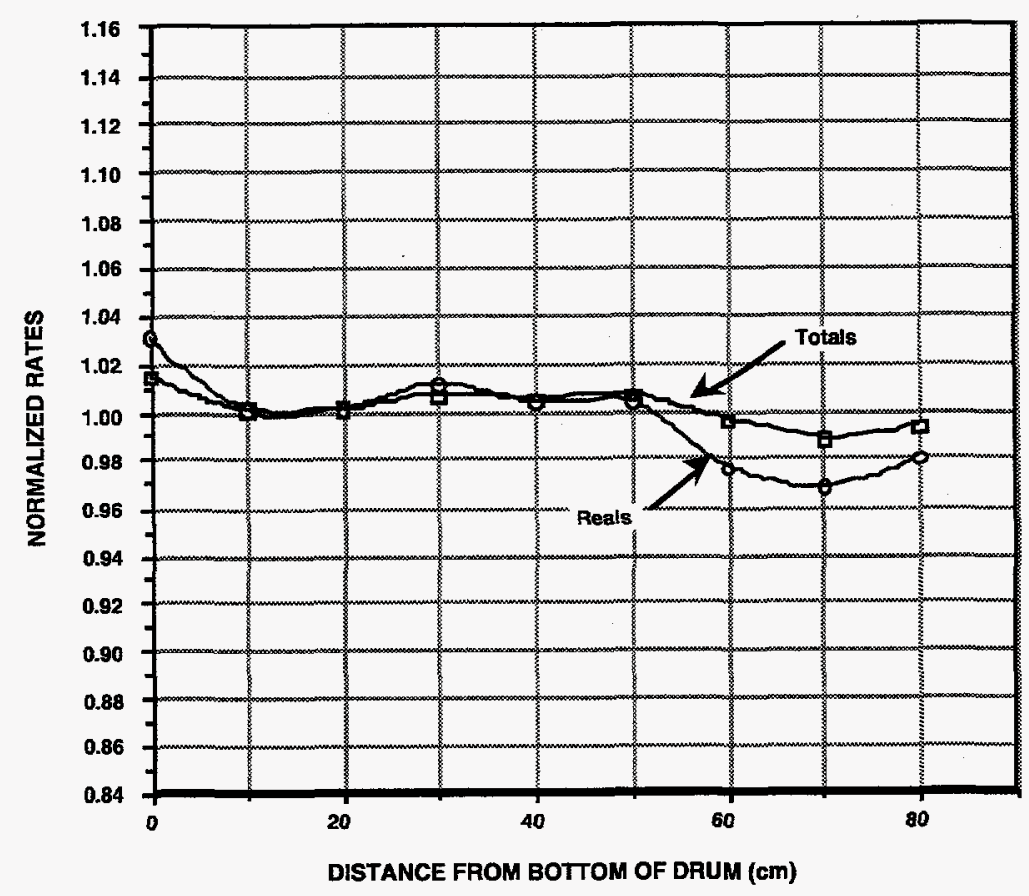

Fig. 11. Vertical response profiles for singles and doubles rates after adding $0.6 \mathrm{~cm}$ of HDPE to the upper sections of the HENC detector walls. 


\section{B . Radial Profiles}

The radial response profiles were measured using $\mathrm{a}^{252} \mathrm{Cf}$ source at the midplane of a rotating 200-L drum. The normalized totals and reals rates are shown in Fig. 12. The rates are higher near the perimeter of the drum because of the higher counting efficiency near the sides of the HENC. The volume averaged response was used for the calibrations.

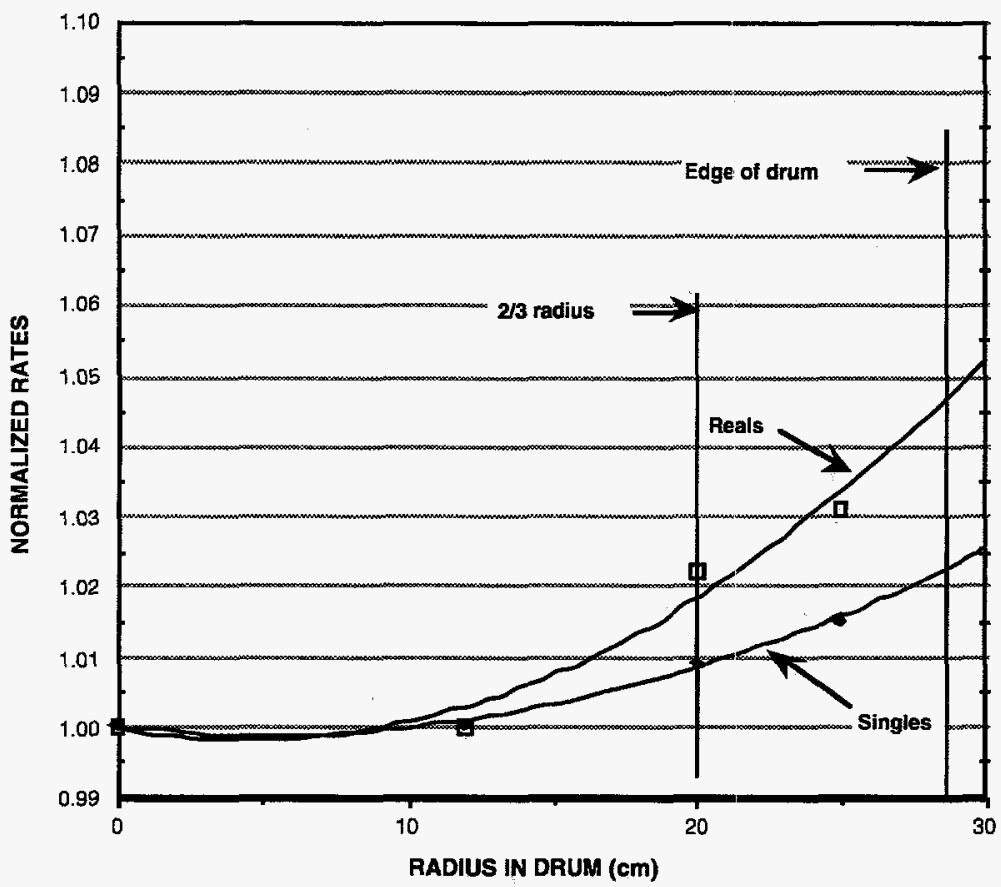

\section{ADD-A-SOURCE MATRIX CORRECTIONS}

The HENC was designed to obtain a maximum figure of merit. However, it is also necessary to make the system insensitive to matrix variations in the drum. The initial measurements with HENC showed that the system was under moderated so the additional $0.6 \mathrm{~cm}$ of HDPE was added to the walls. This addition changed the AS calibration that was performed in Ref. 1. The AS calibration was measured at Los Alamos for the modified unit.

The basis of the AS method is to measure the matrix perturbation to the counting rate from a small ${ }^{252} \mathrm{Cf}$ source $\left(9 \times 10^{4} \mathrm{n} / \mathrm{s}\right)$ on the outside of the sample and to use the information to correct for the matrix perturbation on the inside of the sample. For the present case, we have positioned the AS neutron source at three positions on the side of the 200-L drum. Figure 13 shows a schematic diagram that illustrates the technique in which the AS neutrons originate from ${ }^{252} \mathrm{Cf}$ and that is stopped at three positions along the side of the drum. The plutonium neutrons originate from the drum's interior. 


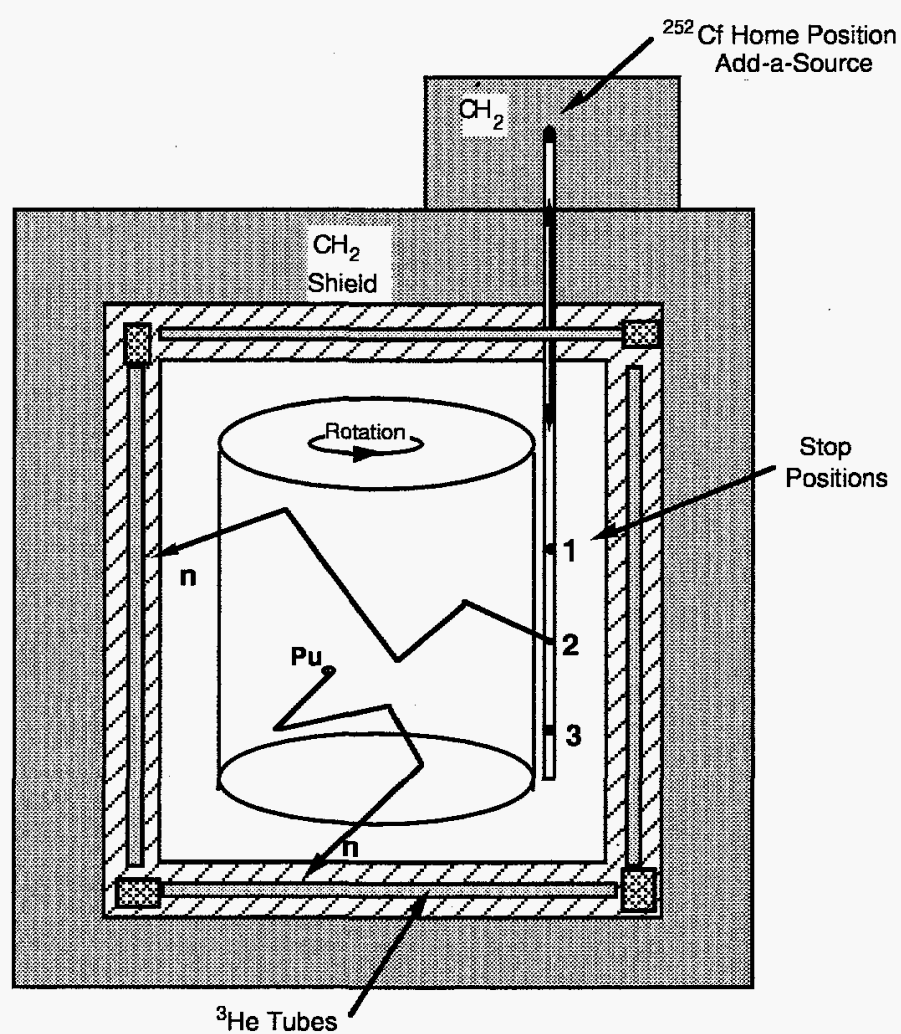

Fig. 13. Schematic diagram of the HENC AS positions for a rotating 200-L drum.

To correct for the matrix perturbation on the neutron signal, the AS method measures each drum both with and without the ${ }^{252} \mathrm{Cf}$ source on the outside of the drum. The measured quantities are

$T_{0}, R_{0}=\quad$ Totals and reals rates from ${ }^{252} \mathrm{Cf}$ for an empty drum.

$T, R=$ Totals and reals rates from a sample drum without ${ }^{252} \mathrm{Cf}$.

$T(\mathrm{Cf}), R(\mathrm{Cf})=$ Totals and reals rates from a sample drum with the ${ }^{252} \mathrm{Cf}$.

The net ${ }^{252} \mathrm{Cf}$ reals rate for the ${ }^{252} \mathrm{Cf}$ and a loaded sample drum is

$R(\mathrm{Cf})-R=R($ net $)$.

We use the ratio of the empty drum (after source decay correction) to the net loaded drum to make the matrix correction as follows:

$$
\left(\frac{R_{0} \mathrm{e}^{-\lambda t}}{R(\mathrm{net})}-1\right)=x
$$

and the correction factor $(C F)$ is defined as 


$$
C F=1+f(x),
$$

where $f(x)$ is a polynomial function of $x$ based on empirical measurements. The measured $R$ for a drum is corrected to give

$R($ corrected $)=R$ (measured) $C F$.

The functional relationship between the AS perturbation $x$ and the volume-averaged sample perturbation $f(x)$ was determined empirically by measuring a large variety of matrix loadings with the AS.

A separate ${ }^{240} \mathrm{Pu}$ neutron source was counted at six positions in the drum to give a volume averaged matrix effect. The average of the six positions was then ratioed to the empty drum case to give the volume averaged perturbation

$\left[\frac{R_{0}^{\prime}(\text { empty vol })}{R^{\prime} \text { (matrix vol) }}-1\right]=y($ vol av perturbation $)$,

where

$R_{0}^{\prime}=$ reals rates averaged over the volume of an empty drum and

$R^{\prime}=$ reals rates averaged over the volume of the drum with matrix material.

\section{A. Add-a-Source Procedures}

To obtain the volume-averaged matrix response, the small ${ }^{240} \mathrm{Pu}$ sample $\left(0.700 \mathrm{~g}{ }^{240} \mathrm{Pu}\right.$-eff. $)$ was counted as six positions in the drum. The neutron source was positioned at two heights (20 $\mathrm{cm}$ and $40 \mathrm{~cm}$ ), and three radial positions $(12,20$, and $25 \mathrm{~cm})$. At each position, the source was measured for $10 \mathrm{~min}$ in the passive mode.

The ${ }^{252} \mathrm{Cf}$ AS measurements were made at three positions along the outside of the drum. These positions are given in Table IV.

\begin{tabular}{|c|c|c|c|}
\hline \multicolumn{5}{|c|}{ TABLE IV. AS Positions for the HENC. } \\
\hline \hline & Steps & $\begin{array}{c}\text { Distance from Home } \\
(\mathrm{cm})\end{array}$ & $\begin{array}{c}\text { Distance from Bottom of Drum } \\
(\mathrm{cm})\end{array}$ \\
\hline \hline 1 & 2745 & 139.7 & 51.8 \\
2 & 3079 & 156.7 & 34.8 \\
3 & 3413 & 173.7 & 17.8 \\
\hline
\end{tabular}

The AS positions did not continue to the top of the drum to avoid measuring air with partially filled drums. 


\section{B . Matrix Materials}

The matrix materials that were used in the calibration are listed in Table V. The primary variable that requires the matrix correction is the hydrogen density. The other atoms such as carbon, nitrogen, oxygen, silicon, and aluminum have very little effect on the passive neutron measurement. Thermal-neutron poisons such as boron and chlorine reduce the totals rate but not the reals rate because the thermal neutrons in the drum are eliminated by the coincidence time gate.

Two AS measurement procedures were evaluated. They were

(1) all detector banks operational and

(2) the detector banks directly behind the AS position turned off.

The reason for procedure (2) was to enhance the AS perturbation by increasing the fraction of neutrons that interact with the drum.

\begin{tabular}{|l|l|}
\hline TABLE V. Matrix Loadings in 200-L Drums Used for AS Calibration. \\
\hline \hline Sample & \\
\hline \hline Empty drum & Empty metal drum weighing $20 \mathrm{~kg}$ \\
\hline Polyethylene drum liner $(9.1 \mathrm{~kg})$ & 5 -mm thick polyethylene liner on inside wall of drum \\
\hline Boron glass $(173 \mathrm{~kg})$ & Raschig rings \\
\hline Concrete/rubble $(220 \mathrm{~kg})$ & High-density concrete block mixed with $10 \mathrm{~kg}$ paper \\
\hline Sand $(290 \mathrm{~kg})$ & Dry sand \\
\hline Iron metal $(196 \mathrm{~kg})$ & Iron pieces $(\sim 170 \mathrm{~kg})$ mixed with aluminum $(\sim 26 \mathrm{~kg})$ \\
\hline Polyethylene shavings $(7.2 \mathrm{~kg})$ & Low-density polyethylene shavings \\
\hline Polyethylene tubes $(32.5 \mathrm{~kg})$ & Chopped polyethylene tubes \\
\hline Paper $(38.4 \mathrm{~kg})$ & Low-density paper \\
\hline Paper $(53.9 \mathrm{~kg})$ & Medium-density paper \\
\hline Paper $(71 \mathrm{~kg})$ & High-density paper \\
\hline Wood $(51 \mathrm{~kg})$ & Wood pieces \\
\hline Polyethylene beads/vermiculite $(66 \mathrm{~kg})$ & $\begin{array}{l}\text { Polyethylene beads }(41 \mathrm{~kg}) \text { plus vermiculite }(22 \mathrm{~kg}) \\
\text { plus borax }(\sim 31 \mathrm{~kg})\end{array}$ \\
\hline
\end{tabular}

\section{Results with the Detector Bank Off}

The results with the detector bank off (procedure 2) are given in Table VI. We see that the nonhydrogeneous matrices such as sand and iron, scatter neutrons with negligible absorption. This scattering reflects the AS neutrons back into the detector bank that has been turned off. However, the scattering increases the volume-averaged response. Thus, the AS perturbation has the opposite sign as the plutonium volume-averaged response. To avoid this ambiguity, we did not use the bank-off procedure. 


\begin{tabular}{|c|c|c|c|c|c|c|c|c|c|c|}
\hline Sample & S av & $\mathrm{D}$ av & $\mathrm{T}$ av & So/S & $\mathrm{Do} / \mathrm{D}$ & $\mathrm{To} / \mathrm{T}$ & As S av & AS D av & $\mathrm{AS} \mathrm{So} / \mathrm{S}$ & AS Do/D \\
\hline Empty drum & 246.8 & 37.87 & 4.3 & 1 & 1 & 1 & 25823 & 7420 & 1 & 1 \\
\hline $\begin{array}{l}\text { Polyethylene drum liner } \\
(9.1 \mathrm{~kg})\end{array}$ & 248.3 & 37.55 & 3.97 & 0.994 & 1.008 & 1.083 & 26082 & 7400 & 0.99 & 1.003 \\
\hline Boron glass $(173 \mathrm{~kg})$ & 237.4 & 38.54 & 4.24 & 1.04 & 0.982 & 1.014 & 23130 & 6670 & 1.116 & 1.112 \\
\hline Concrete/rubble $(219.5 \mathrm{~kg})$ & 257.8 & 38.49 & 4.22 & 0.957 & 0.984 & 1.019 & 24741 & 6640 & 1.044 & 1.118 \\
\hline Sand $(290 \mathrm{~kg})$ & 265.3 & 47.39 & 6.1 & 0.93 & 0.799 & 0.705 & 24542 & 7166 & 1.052 & 1.035 \\
\hline Iron metal $(196 \mathrm{~kg})$ & 259 & 44.45 & 6.2 & 0.953 & 0.852 & 0.694 & 25291 & 7586 & 1.021 & 0.976 \\
\hline $\begin{array}{l}\text { Polyethylene shavings } \\
(7.2 \mathrm{~kg})\end{array}$ & 258.4 & 39.89 & 4.67 & 0.955 & 0.949 & 0.92 & 25948 & 7170 & 0.995 & 1.035 \\
\hline $\begin{array}{l}\text { Polyethylene tubes } \\
(32.5 \mathrm{~kg})\end{array}$ & 231.6 & 26.84 & 2.44 & 1.066 & 1.411 & 1.76 & 23010 & 5022 & 1.122 & 1.478 \\
\hline Paper $(38.4 \mathrm{~kg})$ & 253.8 & 35.32 & 3.44 & 0.972 & 1.072 & 1.25 & NA & NA & $\mathrm{NA}$ & $\mathrm{NA}$ \\
\hline Paper $(53.9 \mathrm{~kg})$ & 246.6 & 32.71 & 3.09 & 1.001 & 1.158 & 1.392 & 24185 & 5790 & 1.068 & 1.282 \\
\hline Paper $(71 \mathrm{~kg})$ & 228.1 & 25.84 & 2.35 & 1.082 & 1.466 & 1.83 & 22872 & 5062 & 1.129 & 1.466 \\
\hline Wood $(50 \mathrm{~kg})$ & 247.7 & 31.96 & 2.84 & 0.996 & 1.185 & 1.51 & 24400 & 5867 & 1.058 & 1.265 \\
\hline $\begin{array}{l}\text { Polyethylene } \\
\text { beads/vermiculite }(66 \mathrm{~kg})\end{array}$ & 202.2 & 21.6 & 1.392 & 1.221 & 1.74 & 3.09 & 19003 & 4434 & 1.36 & 1.669 \\
\hline $\begin{array}{l}\text { Half polyethylene and half } \\
\text { aluminum }\end{array}$ & 100.7 & 4.58 & 0.133 & 2.45 & 8.27 & 32.33 & NA & 2900 & $\mathrm{NA}$ & 2.56 \\
\hline
\end{tabular}

\section{All Banks on Results}

To obtain the correct scattering results for nonhydrogenous matrix materials, we have used the results with all detector banks turned on. The measurement results and the perturbation summary are given in Table VII.

The AS calibration curve are shown in Fig. 14 and the results with both the bank on and off is shown in Fig. 15. We see that the AS perturbation is increased by the bank-off procedure; however, the results in the negative domain for metals and sand are ambiguous.

The maximum volume-averaged plutonium perturbation was 0.76 for the drum containing $47 \mathrm{~kg}$ of polyethylene beads plus $19 \mathrm{~kg}$ of vermiculite and borax. This is a higher hydrogen density than can be found in normal combustible matrix materials.

The polynomial fit to the AS calibration data gave the following coefficient for the function:

$$
y=a_{0}+a_{1} \mathrm{x}+a_{2} x^{2}+a_{3} x^{3}
$$

where

$$
\begin{aligned}
& a_{0}=-0.0131, \\
& a_{1}=1.378, \\
& a_{2}=1.916, \text { and } \\
& a_{3}=5.86
\end{aligned}
$$


TABLE VII. AS Calibration Data with all Detector Banks On.

\begin{tabular}{|c|c|c|c|c|c|c|c|c|c|c|}
\hline Sample & S av & $\mathrm{D}$ av & T av & $\mathrm{So} / \mathrm{S}$ & $\mathrm{Do} / \mathrm{D}$ & $\mathrm{To} / \mathrm{T}$ & As $S$ av & AS D av & $\mathrm{AS} \mathrm{So} / \mathrm{S}$ & $\mathrm{AS} \mathrm{Do} / \mathrm{D}$ \\
\hline Empty drum & 246.8 & 37.87 & 4.3 & 1 & 1 & 1 & 29820 & 10030 & & 1 \\
\hline $\begin{array}{l}\text { Polyethylene drum liner } \\
(9.1 \mathrm{~kg})\end{array}$ & 248.3 & 37.55 & 3.97 & 0.994 & 1.008 & 1.083 & 30253 & 10148 & 0.986 & 0.988 \\
\hline Boron glass $(173 \mathrm{~kg})$ & 237.4 & 38.54 & 4.24 & 1.04 & 0.982 & 1.014 & 28080 & 9778 & 1.062 & 1.026 \\
\hline $\begin{array}{l}\text { Concrete/rubble } \\
(220 \mathrm{~kg})\end{array}$ & 257.8 & 38.49 & 4.22 & 0.957 & 0.984 & 1.019 & 30047 & 9925 & 0.992 & 1.013 \\
\hline Sand $(290 \mathrm{~kg})$ & 265.3 & 47.39 & 6.1 & 0.93 & 0.799 & 0.705 & 30220 & 10985 & 0.987 & 0.913 \\
\hline Iron metal $(196 \mathrm{~kg})$ & 259 & 44.45 & 6.2 & 0.953 & 0.852 & 0.694 & 29940 & 10696 & 0.996 & 0.94 \\
\hline $\begin{array}{l}\text { Polyethylene shavings } \\
(7.2 \mathrm{~kg})\end{array}$ & 258.4 & 39.89 & 4.67 & 0.955 & 0.949 & 0.92 & 30397 & 10055 & 0.981 & 0.997 \\
\hline $\begin{array}{l}\text { Polyethylene tubes } \\
(32.5 \mathrm{~kg})\end{array}$ & 231.6 & 26.84 & 2.44 & 1.066 & 1.411 & 1.76 & 27798 & 7540 & 1.073 & 1.33 \\
\hline Paper $(38.4 \mathrm{~kg})$ & 253.8 & 35.32 & 3.44 & 0.972 & 1.072 & 1.25 & 29798 & 9278 & 1.001 & 1.081 \\
\hline Paper $(53.9 \mathrm{~kg})$ & 246.6 & 32.71 & 3.09 & 1.001 & 1.158 & 1.392 & 29389 & 8500 & 1.015 & 1.181 \\
\hline Paper $(71 \mathrm{~kg})$ & 228.1 & 25.84 & 2.35 & 1.082 & 1.466 & 1.83 & 27858 & 7711 & 1.07 & 1.3 \\
\hline Wood $(51 \mathrm{~kg})$ & 247.7 & 31.96 & 2.84 & 0.996 & 1.185 & 1.51 & 29203 & 8594 & 1.021 & 1.167 \\
\hline $\begin{array}{l}\text { Polyethylene beads/ } \\
\text { vermiculite }(66 \mathrm{~kg})\end{array}$ & 202.2 & 21.6 & 1.392 & 1.221 & 1.753 & 3.09 & 25650 & 6942 & 1.163 & 1.448 \\
\hline $\begin{array}{l}\text { Half polyethylene and } \\
\text { half aluminum }\end{array}$ & 100.7 & 4.58 & 0.133 & 2.45 & 8.27 & 32.33 & 25991 & 7066 & 1.147 & 1.419 \\
\hline
\end{tabular}

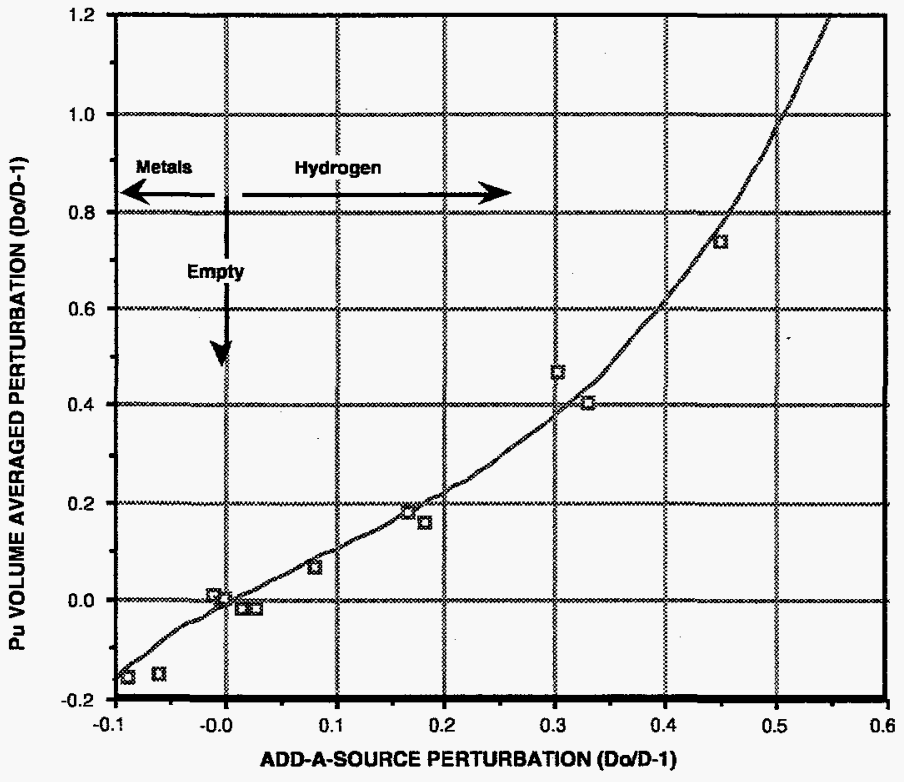

Fig. 14. AS calibration function (all banks on) for the matrix materials listed in Table V. The horizontal axis is the AS perturbations and the vertical axis is the volume averaged ${ }^{240} \mathrm{Pu}$ doubles rate perturbation. 
Fig. 15. AS calibration data with all detector banks on and with one detector bank turned off.

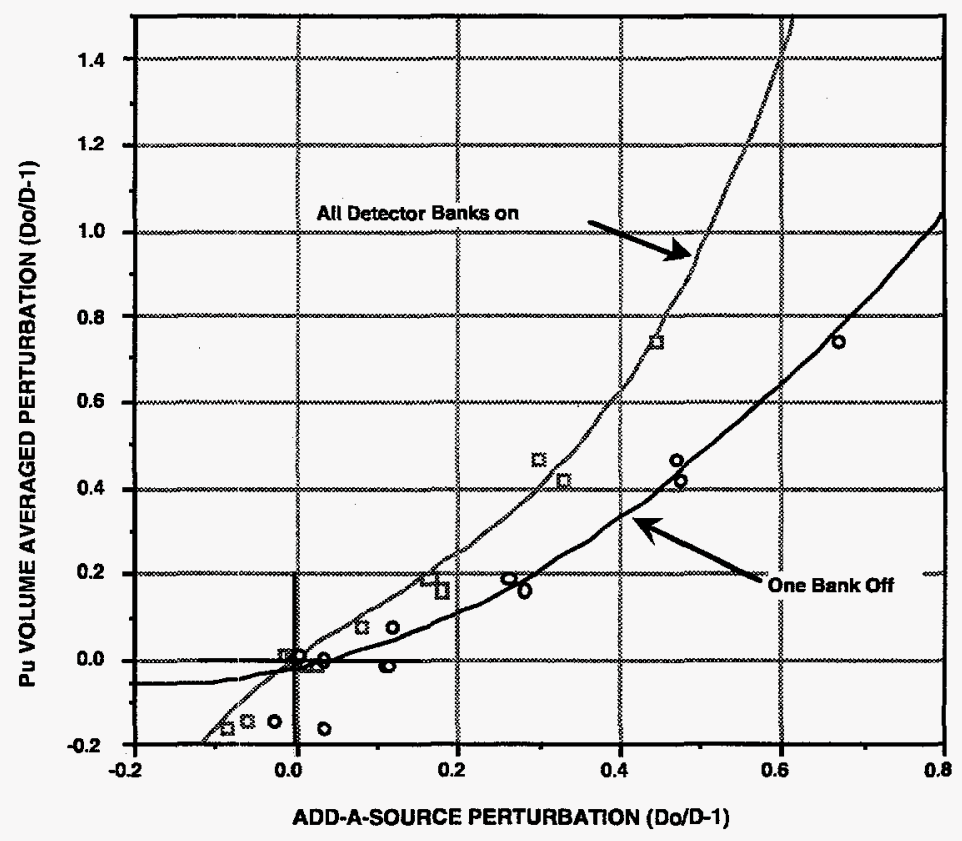

These coefficients are based on a volume-averaged loading pattern. If the loading is concentrated in the central area of the drum as would be the case of a radial-averaged loading, the plutonium perturbation increases more rapidly with hydrogen concentration. For this radialaveraged loading case, the AS correction function coefficients are

$$
\begin{aligned}
& a_{0}=-0.0224, \\
& a_{1}=1.401, \\
& a_{2}=-2.041, \text { and } \\
& a_{3}=8.493 .
\end{aligned}
$$

These coefficients are entered in the software under the AS calibration. An empty drum was counted to obtain the $\mathrm{AS}{ }^{252} \mathrm{Cf}$ reference rate. This rate was measured at TA-35, Bldg. 27 to be

$$
R_{0}=10027 \text { on } 11 / 1 / 96 \text {. }
$$

When the AS correction is applied to the volume-averaged plutonium rates, we get the corrected rates shown in Table VIII and Fig. 16. The corrected values are normalized to the empty drum case so that the empty drum calibration can be used. The average deviation of the corrected rates from the true values was $3.1 \%$. The boron glass matrix (Raschig rings) has very little effect on the reals rate. The heterogeneous mixture of concrete rubble and compacted paper rate agreed with the known value to within $2 \%$. 


\begin{tabular}{|l|l|l|l|l|l|l|c|}
\hline \multicolumn{1}{|l}{ TABLE VIII. AS Corrected Doubles Rate. } & \multicolumn{1}{|l|}{ S av } & D av & Do/D & AS Do/D & CF & DxCF & Norm. D \\
\hline \hline Sample & 246.8 & 37.87 & 1 & 1 & 1 & 37.87 & 1.00 \\
\hline \hline Empty drum & 248.3 & 37.55 & 1.0085 & 0.988 & 1 & 37.55 & 0.99 \\
\hline Polyethylene drum liner (9.1 kg) & 237.4 & 38.54 & 0.9826 & 1.026 & 1.005 & 38.5 & 1.02 \\
\hline Boron glass (173 kg) & 257.8 & 38.49 & 0.9839 & 1.013 & 1 & 38.49 & 1.02 \\
\hline Concrete/rubble (220 kg) & 265.3 & 47.39 & 0.7991 & 0.913 & 0.845 & 40.04 & 1.06 \\
\hline Sand (290 kg) & 259 & 44.45 & 0.852 & 0.94 & 0.892 & 39.6 & 1.05 \\
\hline Iron metal (196 kg) & 258.4 & 39.89 & 0.9494 & 0.997 & 1 & 39.89 & 1.05 \\
\hline Polyethylene shavings (7.2 kg) & 231.6 & 26.84 & 1.411 & 1.33 & 1.437 & 38.57 & 1.02 \\
\hline Polyethylene tubes (32.5 kg) & 253.8 & 35.32 & 1.0722 & 1.081 & 1.069 & 37.78 & 1.00 \\
\hline Paper (38.4 kg) & 246.6 & 32.71 & 1.1577 & 1.181 & 1.19 & 38.92 & 1.03 \\
\hline Paper (53.9 kg) & 228.1 & 25.84 & 1.4656 & 1.3 & 1.377 & 35.58 & 0.94 \\
\hline Paper (71 kg) & 247.7 & 31.96 & 1.1849 & 1.167 & 1.172 & 37.46 & 0.99 \\
\hline Wood (51 kg) & 202.2 & 21.6 & 1.7532 & 1.448 & 1.75 & 37.8 & 1.00 \\
\hline $\begin{array}{l}\text { Polyethylene beads/ } \\
\text { vermiculite (66 kg) }\end{array}$ & 244.85 & 35.27 & & & & 38.31 & 1.01 \\
\hline Average & \pm 16.8 & \pm 7.36 & & & & \pm 1.19 & \pm 0.0316 \\
\hline St dev (counts/s) & \pm 6.88 & \pm 20.9 & & & & \pm 3.10 & \pm 3.12 \\
\hline St dev (\%) & & & & & & & \\
\hline
\end{tabular}




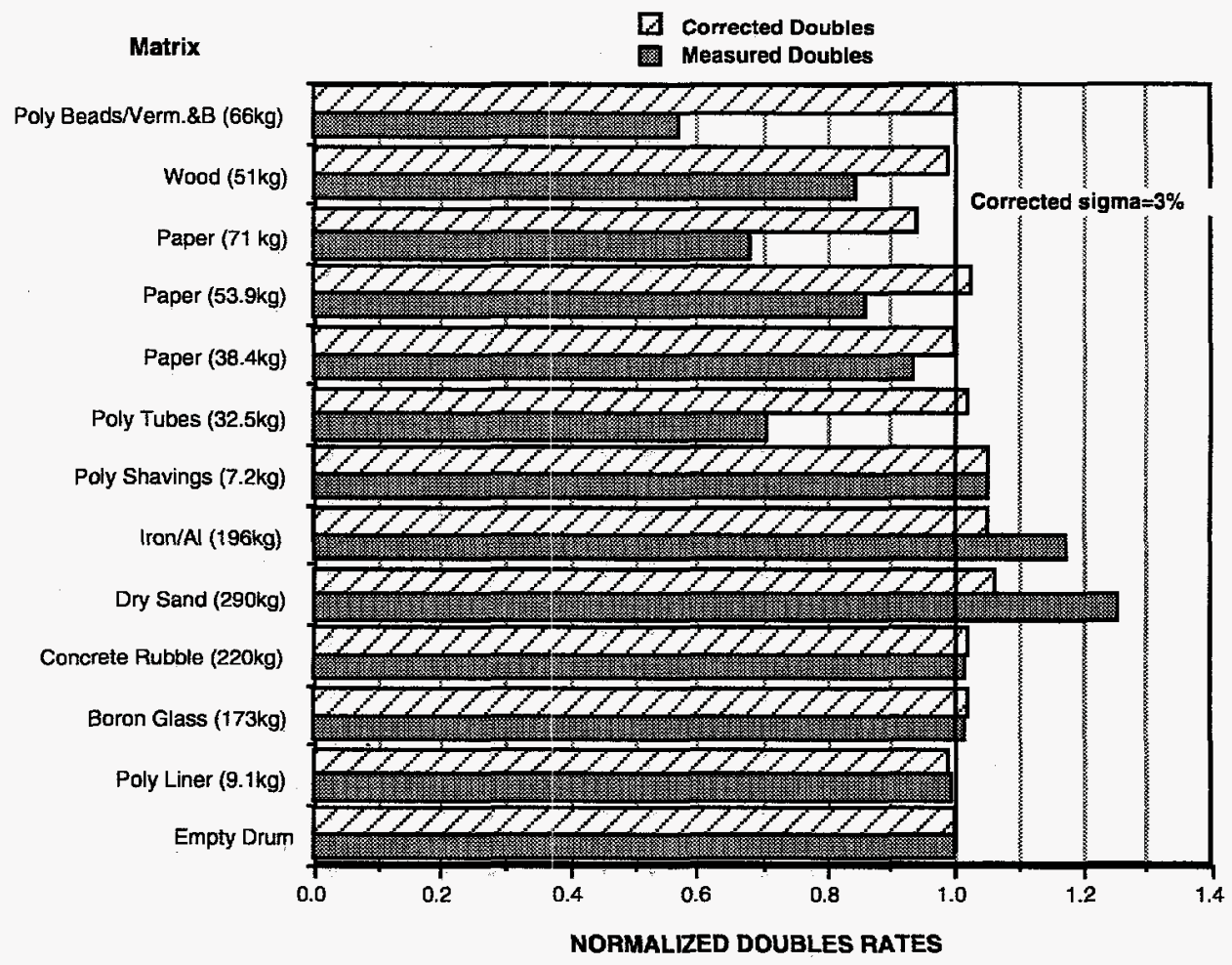

Fig. 16. Normalized doubles rates with before and after the AS correction for the materials listed in Table $V$.

\section{HENC CALIBRATION}

The HENC was calibrated on November 1-3, 1996, using NIS-5 standards. The counter walls were configured with the standard 0.25 -in. HDPE liners and the measurements were performed inside an empty drum using positions to give a volume-averaged response.

\section{A. Standards}

The standards were a set of five MOX pellets and a small ${ }^{240} \mathrm{Pu}$ oxide sample. The MOX pellet standards were prepared by the GE Vallecitos Nuclear Center under contract number LC3-18688-1 in 1973 with traceability to GE fuel batch history and the National Bureau of Standards (NBS). The physical description of the MOX standards is listed in Table IX. The isotopics are listed in Table $\mathrm{X}$ for both the plutonium and uranium.

The ${ }^{240} \mathrm{Pu}$ enriched standard (FZC-158) was prepared at Los Alamos in 1978 and the isotopics and ${ }^{240} \mathrm{Pu}$-eff mass are listed in Table XI. This sample contains less than $1 \mathrm{~g}$ of plutonium and the alpha value was 0.142 on October 26, 1996.

Because of the small fissile masses in the pellet and powder samples, the neutron multiplication is negligible for the waste calibration. 


\begin{tabular}{|c|c|c|c|c|c|c|}
\hline \multirow[b]{2}{*}{ Standard } & \multicolumn{3}{|c|}{ Dimensions (in.) } & \multirow[b]{2}{*}{$\begin{array}{c}\text { Mass } \\
\text { (g) }\end{array}$} & \multicolumn{2}{|c|}{ Density (\% TD)* } \\
\hline & Length & Diameter & Annulus & & Fuel & Bulk \\
\hline A1-066 & 0.4143 & 0.4716 & 0.146 & 10.7721 & 91.67 & 82.88 \\
\hline A1-081 & 0.4133 & 0.4706 & 0.147 & 10.6510 & 91.25 & 82.35 \\
\hline A1-078 & 0.3925 & 0.4719 & 0.148 & 10.1886 & 91.41 & 82.41 \\
\hline A1-089 & 0.4067 & 0.4718 & 0.150 & 10.5145 & 91.60 & 82.34 \\
\hline A1-119 & 0.2508 & 0.1952 & - & 1.2452 & 92.13 & 92.13 \\
\hline
\end{tabular}

$\tilde{\omega}$

TABLE X. Los Alamos MOX Pellets Specifications

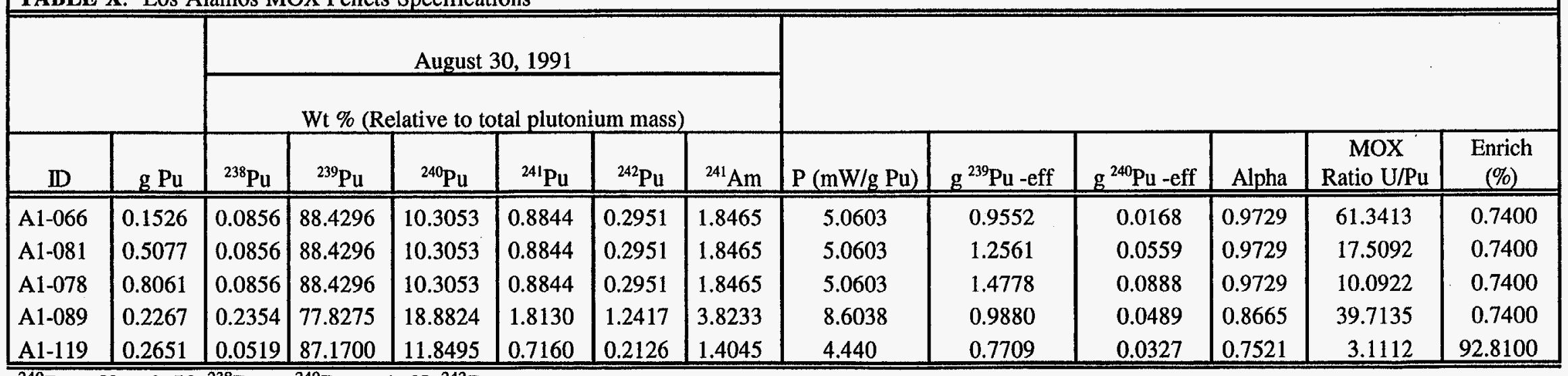

${ }^{240} \mathrm{Pu}$-eff $=2.52{ }^{238} \mathrm{Pu}+{ }^{240} \mathrm{Pu}+1.68{ }^{242} \mathrm{Pu}$. 


\begin{tabular}{|c|c|}
\hline \multicolumn{2}{|c|}{ TABLE XI. FZC-158 Isotopics. } \\
\hline \hline Isotope & Wt \% \\
\hline \hline & $12 / 15 / 78$ \\
\hline${ }^{238} \mathrm{Pu}$ & 0.016 \\
\hline${ }^{239} \mathrm{Pu}$ & 0.955 \\
\hline${ }^{240} \mathrm{Pu}$ & 93.76 \\
\hline${ }^{241} \mathrm{Pu}$ & 0.699 \\
\hline${ }^{242} \mathrm{Pu}$ & 4.56 \\
\hline & \\
\hline${ }^{241} \mathrm{Am}$ & 0.001 \\
\hline & \\
\hline${ }^{240} \mathrm{Pu}$ & $0.705 \mathrm{~g}$ \\
\hline
\end{tabular}

\section{B . Calibration Procedure}

The standards were positioned in the drum to give a volume-averaged response over the interior of the empty drum. The five MOX pellets were attached to a thin aluminum tube to give uniform vertical spacing between 10 and $60 \mathrm{~cm}$ from the bottom of the drum. The radius was set to $12 \mathrm{~cm}$ and the drum was rotated for a $60 \times 30$-s counts. The drum was removed from the counter, the sample radius was increased to $20 \mathrm{~cm}$, and the drum was counted for $60 \times 30-\mathrm{s}$ counts. The drum was removed from the counter, the sample radius was increased to $25 \mathrm{~cm}$, and the drum was counted for $60 \times 30$-s counts. The average of the three positions was used to give a volume-averaged response.

This procedure was repeated with three MOX pellets on the tube and with the FZC-158 standard and the MOX pellets on the tube. In each case, the volume-averaged response was used.

\section{Calibration Results}

The calibration measurement results are listed in Table XII where the room background has been subtracted from the rates. The ${ }^{252} \mathrm{Cf}$ source CR-6 was counted at the same time in the center of the drum to give a reference rate for future normalizations. The AS reference rate is also given in Table XIII.

The HENC can be used in the singles mode (S), the doubles mode (D), and the triples mode (T). All three modes are calibrated and the data are in Table XII. Figure 17 shows the calibration curve for the normal doubles mode and the triples mode. The linear calibration is forced through the origin because the cosmic-ray and room backgrounds have been subtracted. The doubles calibration slope is $53.8 \pm 0.2$ counts $/ \mathrm{s}^{\bullet}{ }^{240} \mathrm{Pu}$-eff.

For high-density matrix materials such as iron, it is necessary to adjust the cosmic-ray background subtraction. The combustible matrix materials have approximately the same background as the empty drum. 
TABLE XII. HENC Calibration Data.

\begin{tabular}{|c|c|c|c|c|c|c|c|c|c|}
\hline Sample & $\begin{array}{c}{ }^{240} \mathrm{Pu} \\
(\mathrm{g})\end{array}$ & $\begin{array}{c}\text { Time } \\
(\mathrm{s})\end{array}$ & $\begin{array}{c}S \\
\text { (counts/s) }\end{array}$ & $\begin{array}{c}\mathrm{D} \\
\text { (counts/s }\end{array}$ & $\begin{array}{c}\text { Sigma } \\
\text { (counts } / \mathrm{s})\end{array}$ & $\begin{array}{c}\mathrm{T} \\
\text { (counts/s) }\end{array}$ & $\begin{array}{l}\text { Alpha } \\
\text { (a) }\end{array}$ & $\frac{S}{(1+a)}$ & $\frac{\mathrm{D}}{\mathrm{g} 240 \mathrm{e}}$ \\
\hline $\mathrm{A} 1-066,081,078$ & 0.161 & $60 \times 30$ & 98.93 & 8.863 & 0.06 & 0.971 & 1.013 & 49.14 & 55.05 \\
\hline $\begin{array}{l}\text { A1-066-078,081, } \\
089,119\end{array}$ & 0.243 & $60 \times 30$ & 143.7 & 13.12 & 0.09 & 1.42 & 1.013 & 71.39 & 53.99 \\
\hline FZC-158 & 0.705 & $60 \times 30$ & 246.8 & 37.87 & 0.28 & 4.3 & 0.142 & 216.1 & 53.72 \\
\hline $\begin{array}{l}\text { A1-066, 078, } 081,089 \\
119, \text { FZC- } 158\end{array}$ & 0.948 & $60 \times 30$ & 390.5 & 50.98 & 0.31 & 5.41 & 0.365 & 286.1 & 53.78 \\
\hline $\begin{array}{l}{ }^{252} \mathrm{Cf}, \mathrm{CR}-6 \\
\text { Centered }(11 / 1 / 96)\end{array}$ & NA & $20 \times 30$ & 2120 & 646.4 & 3.5 & 118.1 & NA & NA & NA \\
\hline PDP1-3.0 & 0.1833 & $40 \times 30$ & 158.5 & 9.8 & 0.1 & 1.25 & $0.787^{b}$ & NA & 53.46 \\
\hline PDP1-3.0. $+0.5^{\mathrm{a}}$ & 0.2138 & $59 \times 10$ & 186.2 & 11.94 & 0.1 & 1.88 & $0.787^{b}$ & NA & 55.84 \\
\hline PDP1-3.0 $+0.5+0.1^{a}$ & 0.2199 & $513 \times 10$ & 189.4 & 11.97 & 0.1 & 1.37 & $0.787^{b}$ & NA & 54.43 \\
\hline
\end{tabular}

${ }^{a}$ The PDP standards were counted at two-thirds radius and half height to approximate a volume-averaged response.

${ }^{\mathrm{b}}$ The effective $\alpha$ is $\sim 1.80$ because of the increase from the diatomaceous earth. 


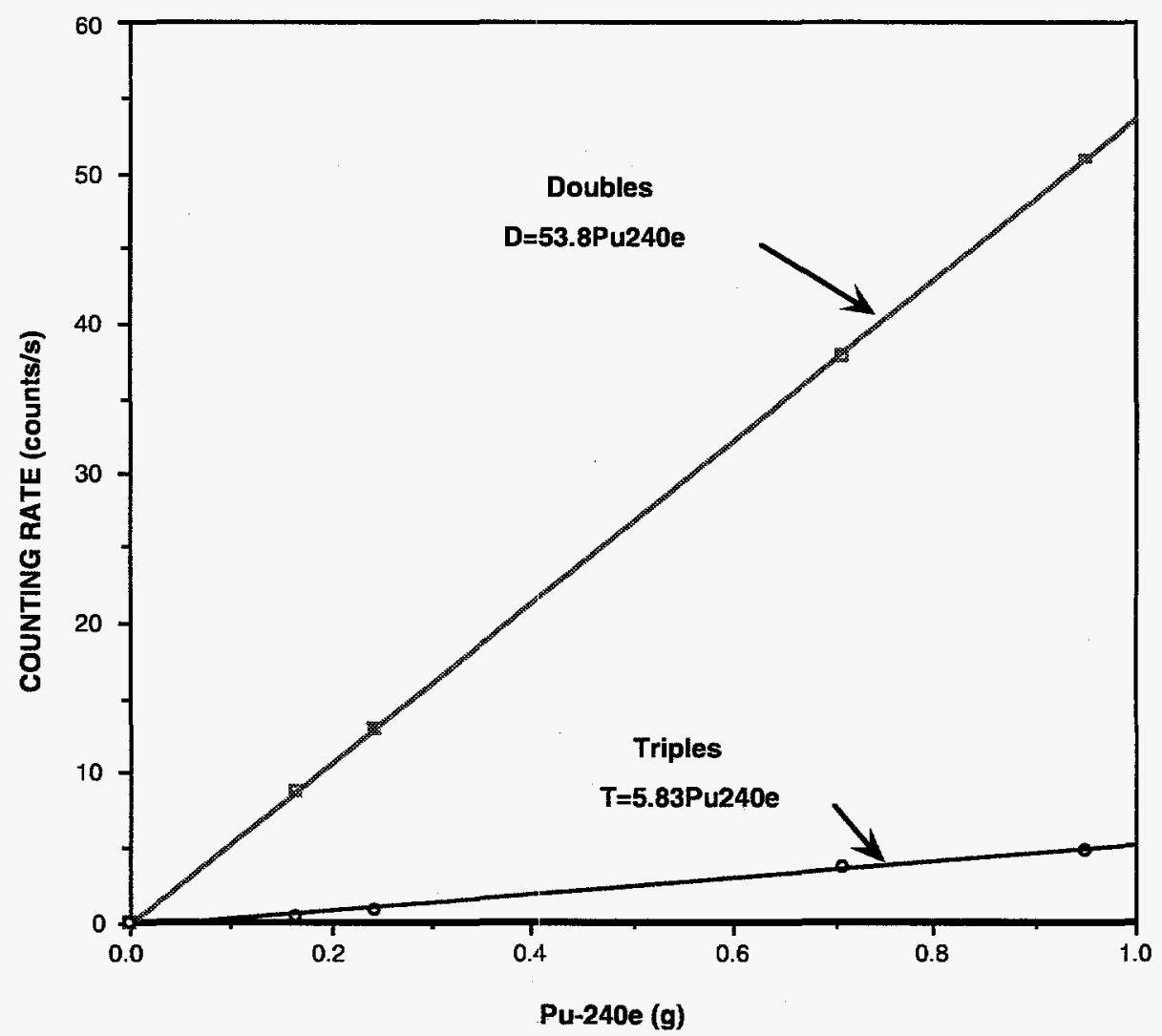

Fig. 17. Doubles and triples rate calibration for the plutonium samples listed in Tables $X$ and IX.

The singles rate calibration is shown in Fig. 18 where the two types of standards give different slopes because of their different alpha values (alpha reaction neutrons/spontaneous fission neutrons). The MOX standards have an alpha of 1.013 , whereas the alpha for the enriched ${ }^{240} \mathrm{Pu}$ is only 0.142 . The alpha of $\sim 1$ is typical of low-burnup plutonium oxide and the calibration slope is approximately 600 counts/s $/{ }^{240} \mathrm{Pu}$-eff. Materials that contain beryllium, boron, fluorine, magnesium, chlorine, and sodium will have a higher alpha value and a higher singles calibration. When the singles calibration is divided by $(1+\alpha)$, all of the oxide standards fall on a straight line as shown in Fig. 19.

The triples calibration is shown in Fig. 17 with the calibration slope of 5.83 counts $/ \mathrm{s}^{\bullet} \mathrm{g}{ }^{240} \mathrm{Pu}$ eff. The triples calibration can be useful when the plutonium mass gets above $\sim 0.2 \mathrm{~g}{ }^{240} \mathrm{Pu}$-eff. The primary use of the triples calibration is to flag matrices that have localized hydrogenous shielding and nonuniform plutonium distributions in the shielding.

The doubles calibration is normally used for quantitative assay and the singles calibration is used to obtain a lower detectability limit. The $30 \mathrm{~cm}$ of external $\mathrm{CH}_{2}$ shielding makes the HENC singles rate relatively insensitive to the variations in the room backgrounds. 


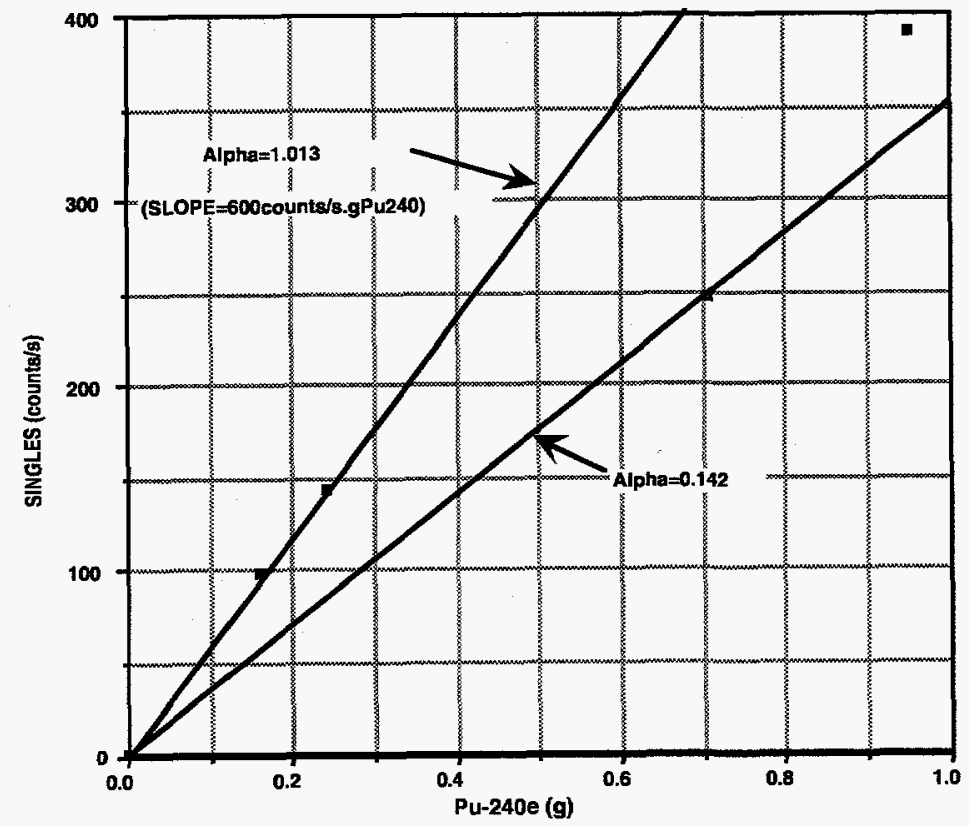

Fig. 18. Singles rate calibration for the plutonium samples listed in Tables IX and XII.

Fig. 19. Singles rate calibration after correcting for the $(\alpha, n)$ reaction neutrons.

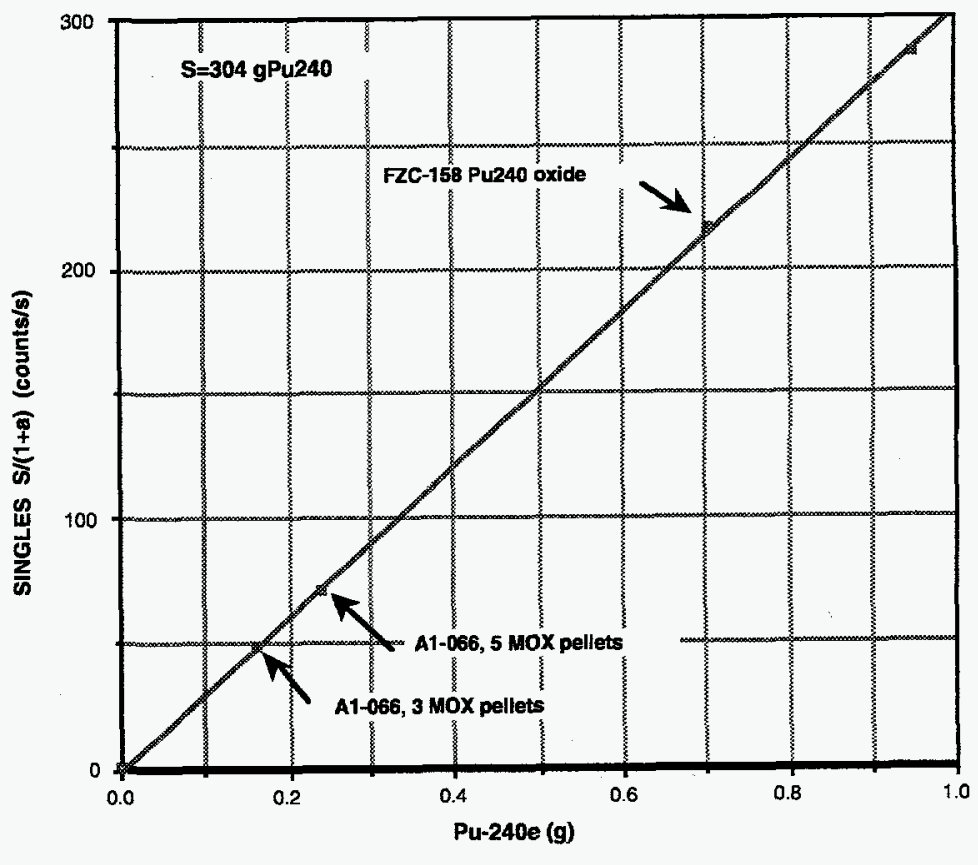

\section{Matrix Corrections}

All of the calibrations are performed relative to the empty $200-\mathrm{L}$ drum case. For drums containing a significantly high loading of hydrogenous matrix materials, the measured response is corrected back to the empty drum calibration condition. The ${ }^{252} \mathrm{Cf} \mathrm{AS}$ measurement is used for this purpose. The AS measurement is made on all drums and the empty drum that was used for the plutonium calibration is the reference condition with no correction. The AS correction is automatically made by the software that is used for routine assay. 
If the plutonium is mixed with materials that have a high $(\alpha, n)$ reaction yield, the singles neutron emission is increased. Plutonium standards $(\alpha=0.787)$ were mixed into diatomaceous earth and the singles rate vs ${ }^{240} \mathrm{Pu}$-eff. mass is shown in Fig. 20 . We see that the yield increases from 600 to 865 counts/s.g ${ }^{240} \mathrm{Pu}$-eff. This corresponds to an $\alpha$ of $\sim 1.8$ for the diatomaceous earth.

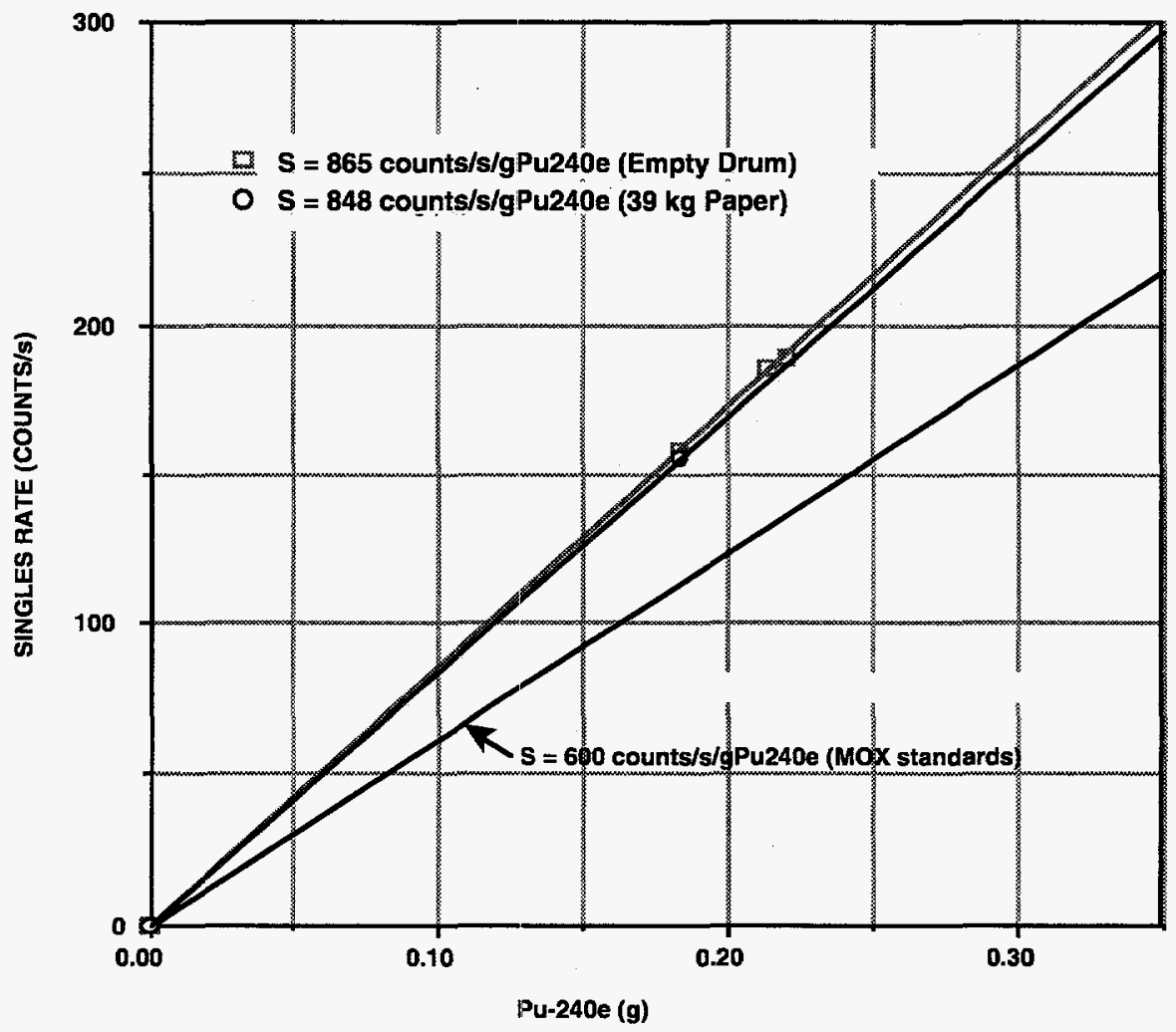

Fig. 20. Singles rate calibration for the plutonium standards mixed in diatomaceous earth.

\section{MEASUREMENT PRECISION AND BACKGROUNDS}

\section{A. Precision}

The measurement time required to reach a given statistical precision are shown in Fig. 21. The measured precisions are based on the standards listed in Table IX with an $\alpha$ of $\sim 1.0$. Figure 22 shows the relationship of the net doubles rate to the statistical error. As the net doubles rate decreases below $\sim 3$ counts/s, the background rate starts to significantly increase the statistical error. 


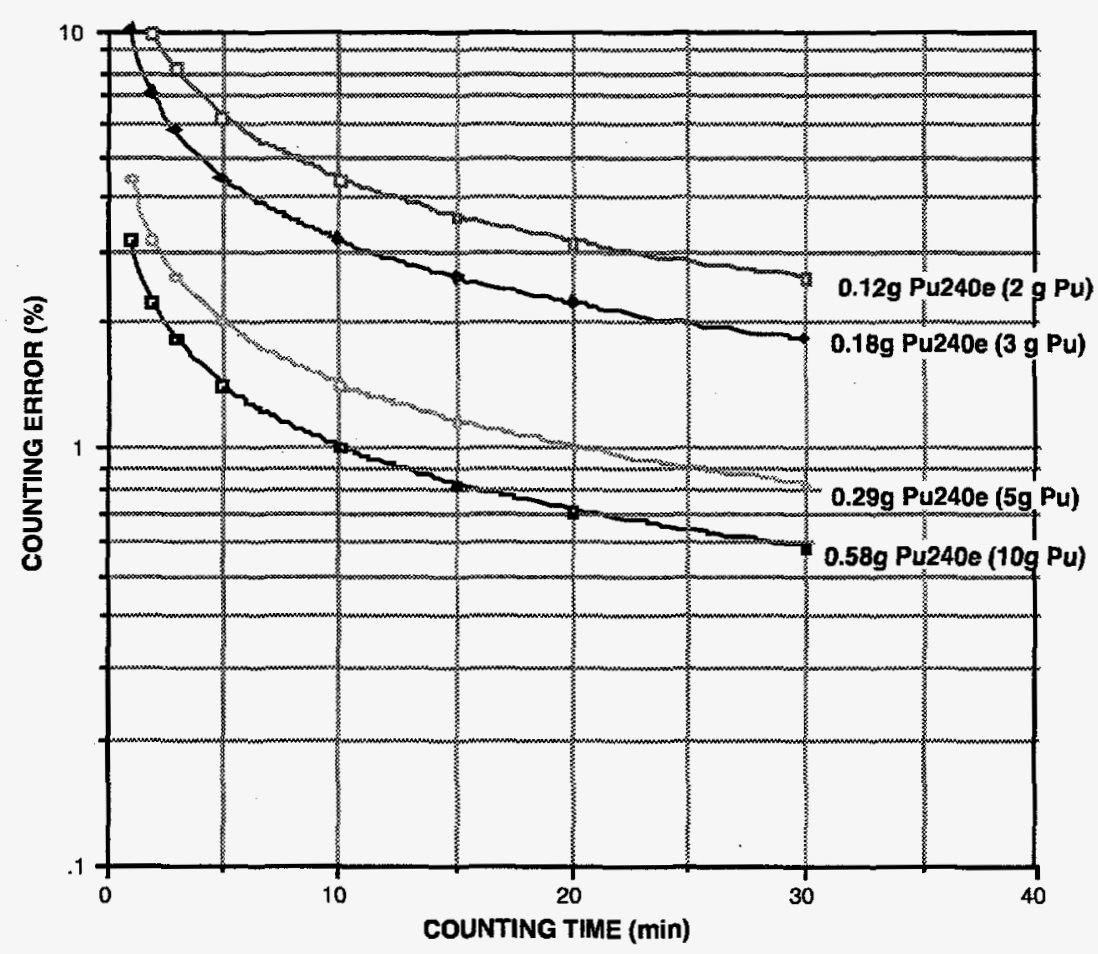

Fig. 21. Counting double error (STD) vs time for different plutonium mass values.

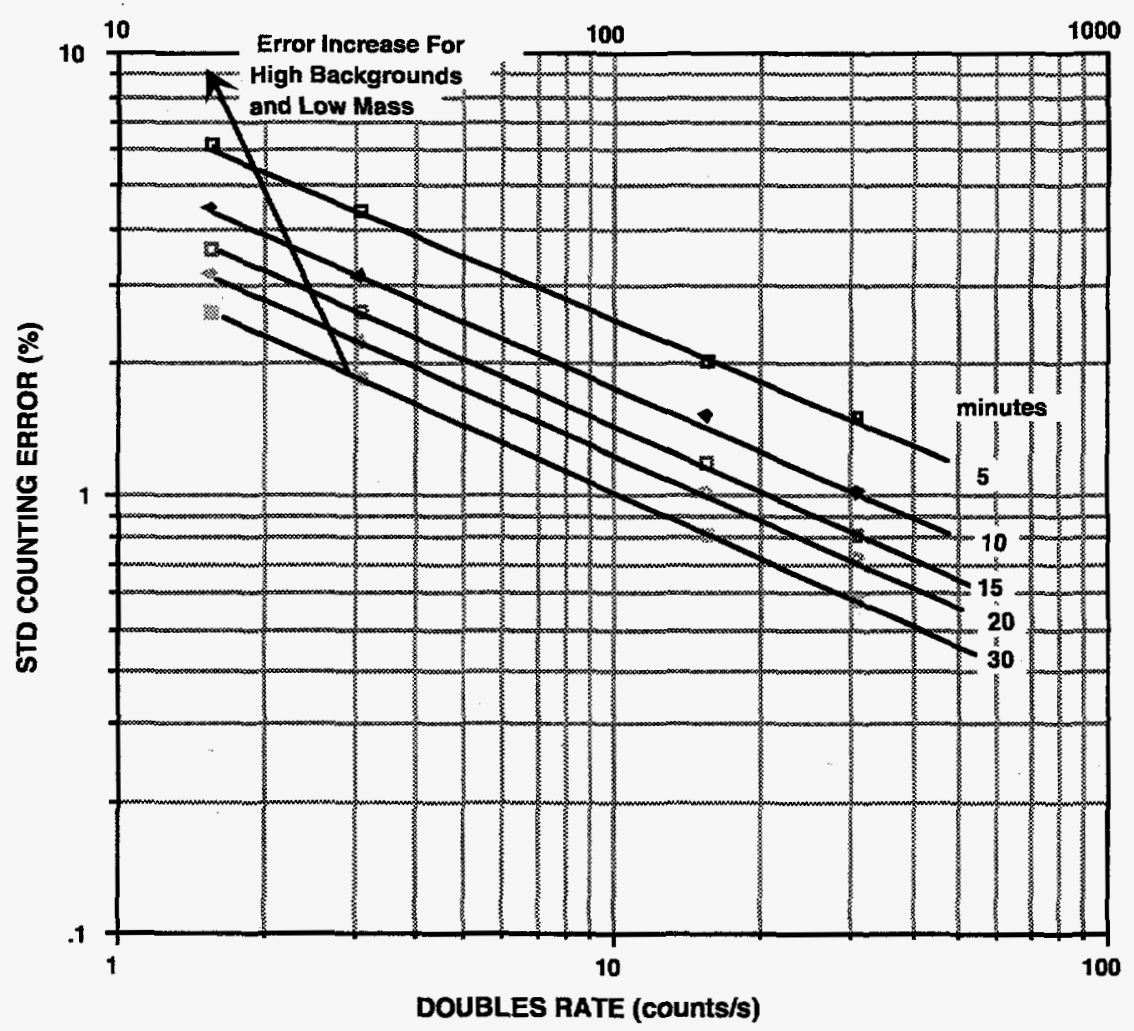

Fig. 22. Net doubles rate vs statistical error for different counting times. 


\section{B . Backgrounds}

The cosmic-ray background varies with the barometric pressure. Figure 23 shows the variation of the singles and doubles rates with time over a five-day period. Both the singles and doubles rates track the inverse of the atmospheric pressure. When the atmospheric pressure is high, the incoming cosmic-ray dose is decreased by absorption in the atmosphere.

The precision for measuring the singles background is much better than the precision for the doubles and triples rates. The precision for the singles background is better than $1 \%$ in $10 \mathrm{~min}$. Thus, we can use the singles rate from a short 10-min measurement to predict the doubles and triples rate for that time period. A long overnight measurement is used to establish the singles, doubles, and triples cosmic-ray background ratios. A typical combustible matrix was used to determine the background ratios shown in Table XIII.

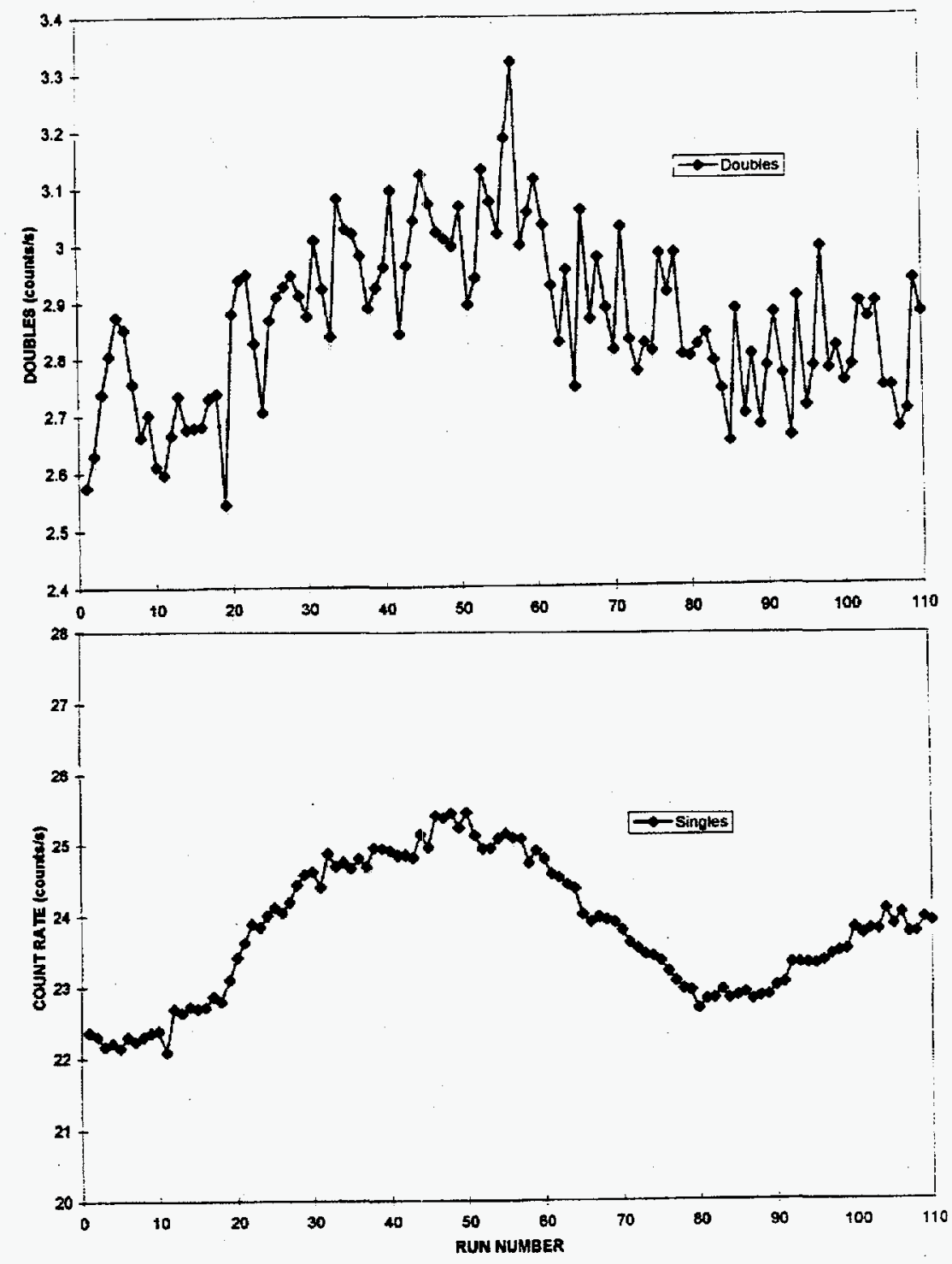

Fig. 23. Variation in background rate with time and barometric pressure change. 


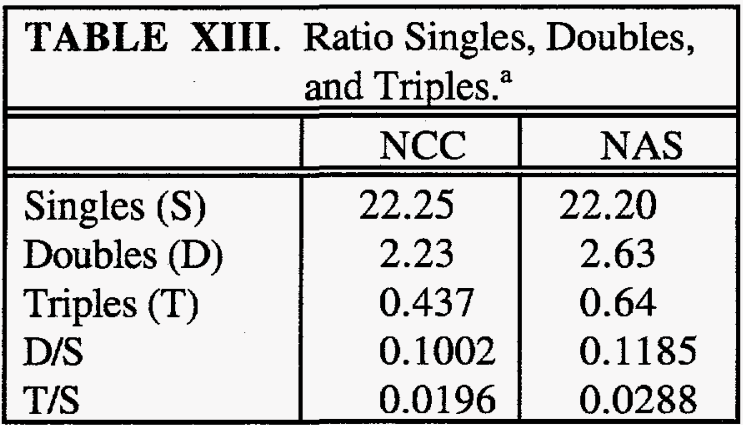

${ }^{a}$ These rates and ratios will change for each new location for the HENC.

The change in the doubles background from different matrix materials is shown in Fig. 24. These measurements were made using the JCC-21 in a well shielded location. We see that the high density materials such as lead and cadmium give a significant increase in the background. The combustible matrices and concrete rubble have essentially the same background as an empty drum. The high hydrogen matrices such as polyethylene have a lower background than the empty drum case because the neutron absorption in the drum is greater than the cosmic-ray neutron production rate.

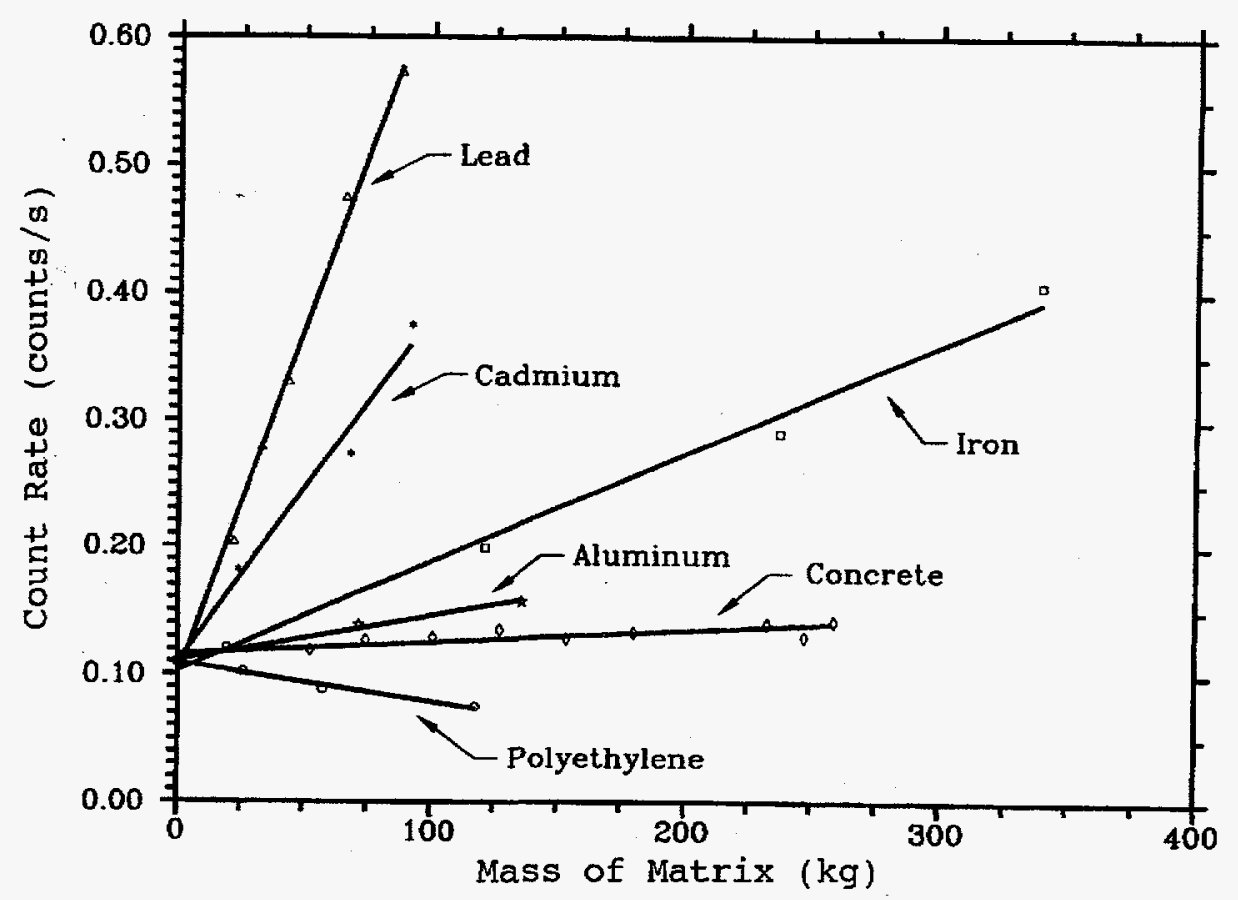

Fig. 24. Doubles background rate vs matrix loading for the JCC-21 in a well-shielded location. 


\section{Background Reduction by Statistical Filters}

The cosmic-ray background neutrons have a higher multiplicity than ${ }^{240} \mathrm{Pu}$ spontaneous fission events. The background counting rates in the HENC are relatively high and this reduces the effectiveness of the statistical QC filter.

1. NAS Software. The NAS software applies the QC test to the singles and doubles rates but not to the triples rates. We performed experiments to study the benefit from using short time intervals and different sigma QC rejection tests. The 10-s time bins gave a slightly lower background than the 30-s time bins. The shorter time bins carry the disadvantage of the lost time (or deadtime) for the data transfer from the multiplicity module (CI2150) to the computer. The large amount of data in the multiplicity distributions require about $3.5 \mathrm{~s}$ for the data transfer at 9600 Baud. Thus the 10-s data collection intervals introduce an $~ 30 \%$ deadtime. Using two CI2150 modules would cut this in half.

Because of the high cosmic-ray background levels at Los Alamos, we used the 10-s time bins to give a better rejection of the large burst events. However, at sea-level locations the background is $\sim 5$ times lower and a time bin of $30 \mathrm{~s}$ would be more appropriate.

We performed measurements with 10-s bins to establish the best sigma level for the QC test. Figure 25 shows the doubles background rate as a function of the signal level for the rejection of an individual run. We selected a 2.4 sigma outlier limit to get a doubles background of 2.63 . counts/s. The doubles background increased to $\sim 3.0$ with the QC test off.

The triples rate background is more sensitive to the QC test than the doubles rate. Figure 26 shows the triples background vs the sigma level for the NAS software. We see that the triples background is $\sim 0.63$ for a 2.4 sigma QC test. The triples background with the $\mathrm{QC}$ test off increases to $\sim 1.3$ counts/s.

It is necessary to set the QC outlier test high enough to pass most of the runs. Figure 27 shows the percent of runs passed as a function of the QC sigma level. The 2.4 sigma level passed $\sim 92 \%$ of the background runs. A higher fraction of the runs are passed when a significant mass of plutonium is in the drum because the cosmic-ray background becomes negligible. 


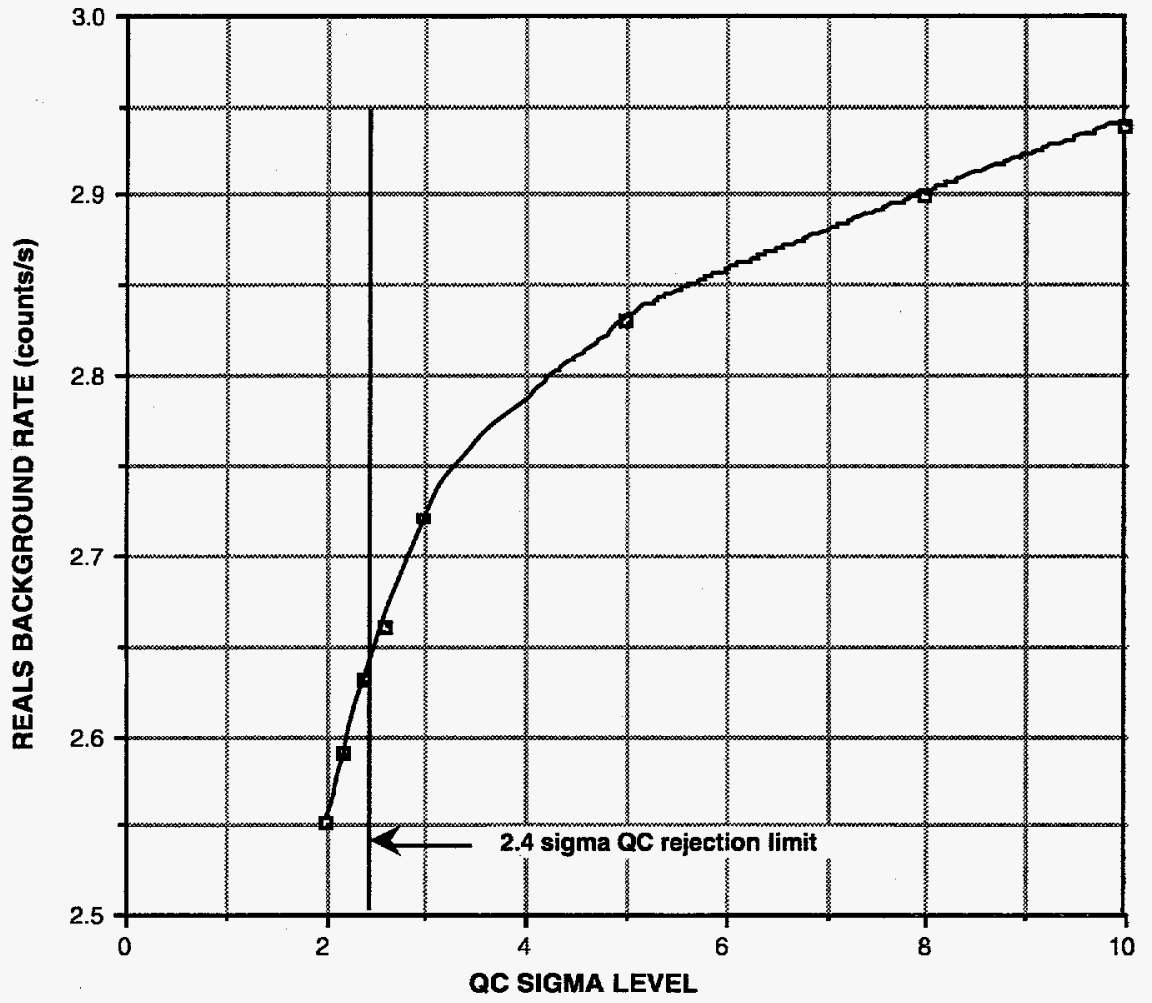

Fig. 25. Doubles background vs outlier sigma test level using NAS software and 10-s time bins.

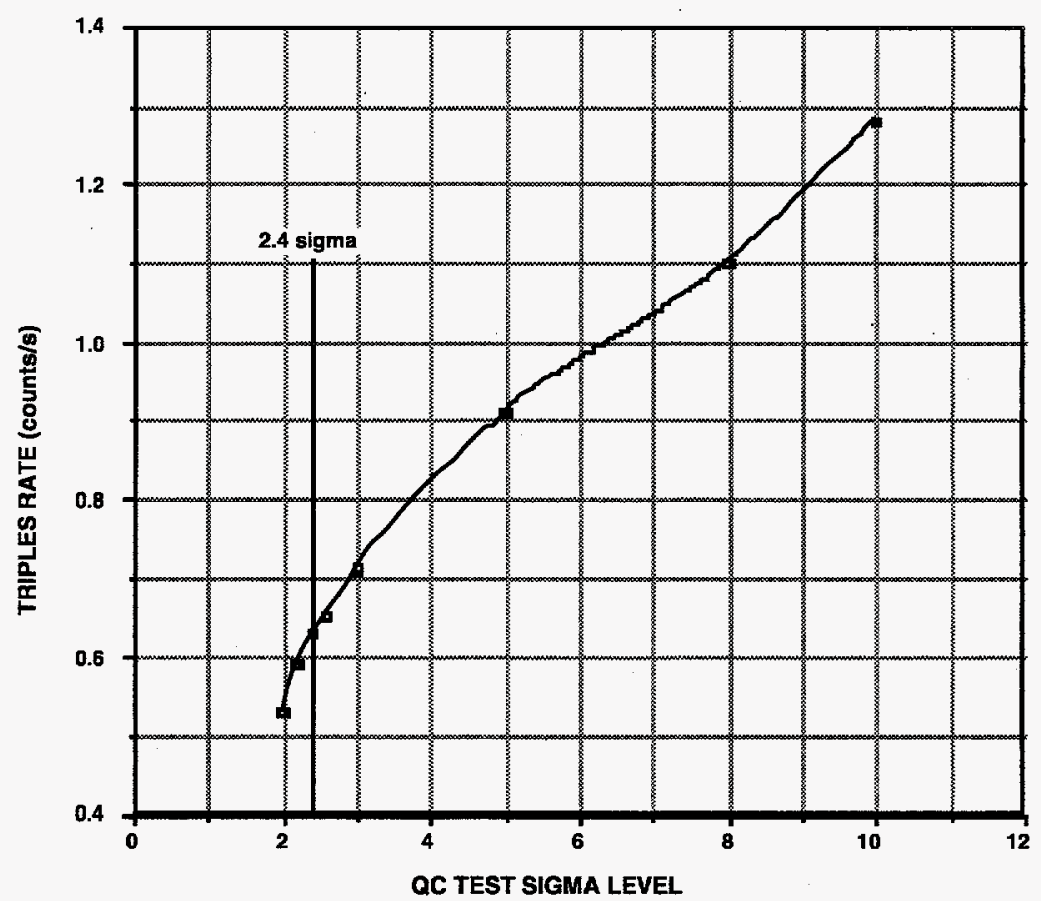

Fig. 26. Triples background vs outlier sigma test level using NAS software and 10-s time bins. 


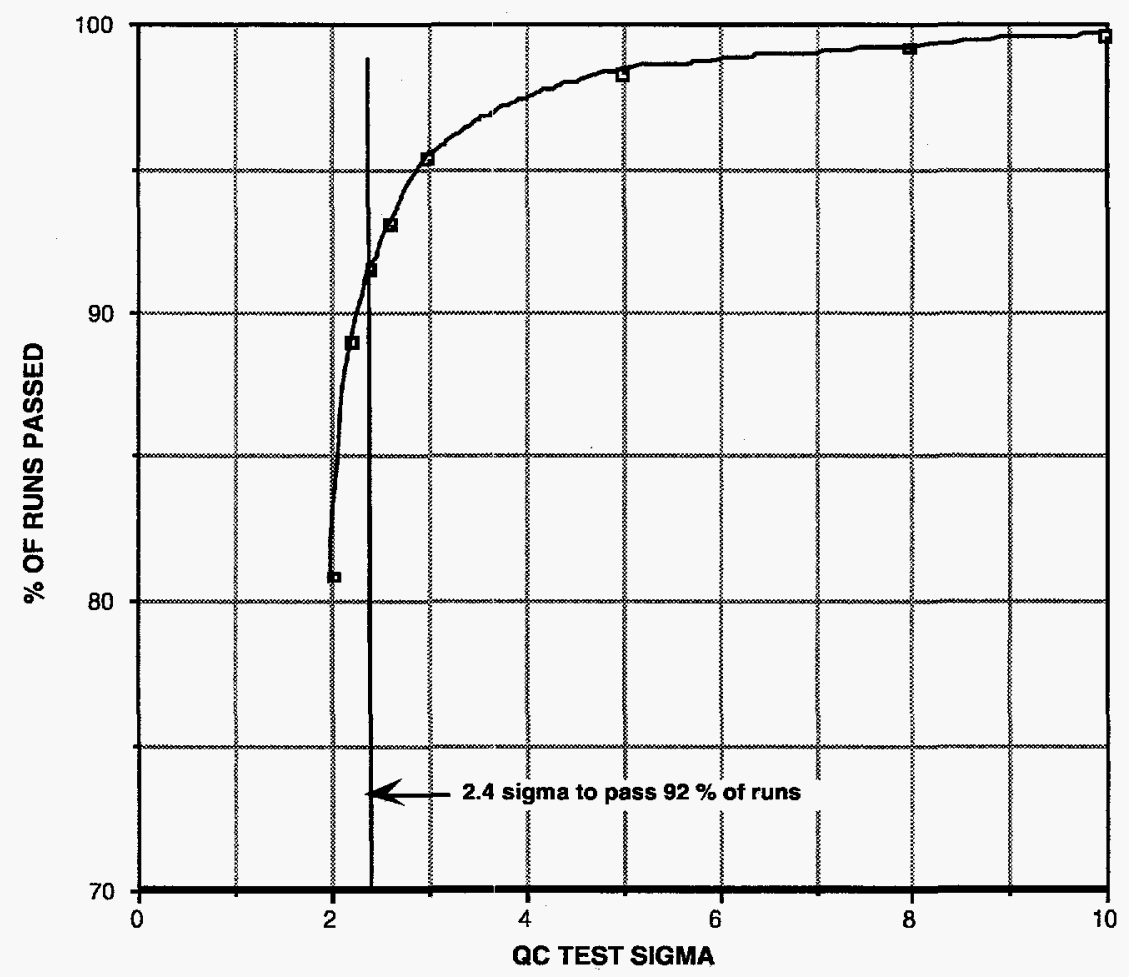

Fig. 27. Percentage of runs passed vs sigma test level for 10-s time bins and NAS software.

2. Neutron Coincidence Counting Software. The QC tests for the Neutron Coincidence Counting (NCC) software are different than for the NAS software because the NCC code applies the QC test to the singles, doubles, and triples; whereas, the NAS does not use the triples rate in the test.

Long background runs were performed with the paper matrix drum $(53.9 \mathrm{~kg})$ to simulate typical combustible drum loadings. Time intervals of $10 \mathrm{~s}, 20 \mathrm{~s}, 30 \mathrm{~s}, 60 \mathrm{~s}$, and $120 \mathrm{~s}$ were used with total run times of 2 to $12 \mathrm{~h}$. Figure 28 shows the triples background rate vs the sigma level for different data time bins. We see that the triples rate drops to 0.44 counts/s for a 3 sigma QC test. This level is significantly below the 0.63 counts/s using the NAS software. The reason for the difference is that the NCC software performs the QC test on the triples rate.

The NCC doubles background vs the sigma level is shown in Fig. 29 and we see that the rate is 2.23 counts/s for a 3 sigma QC test. This can be compared with the 2.63 counts/s doubles background for the NAS software. The 10-s time bin is significantly better than the larger counting time bins. However, in lower background (doubles) locations, the time bins should be increased to $\sim 30$ s to reduce the data transfer time losses.

The percentage of runs passed vs the sigma test level are shown in Fig. 30. We see that $\sim 90 \%$ of the runs are passed at the 3 sigma level and 10-s time bins.

For routine operation at Los Alamos, we recommend 10-s runs with a 3 sigma outlier test for NCC software and a 2.4 sigma test for NAS software. 


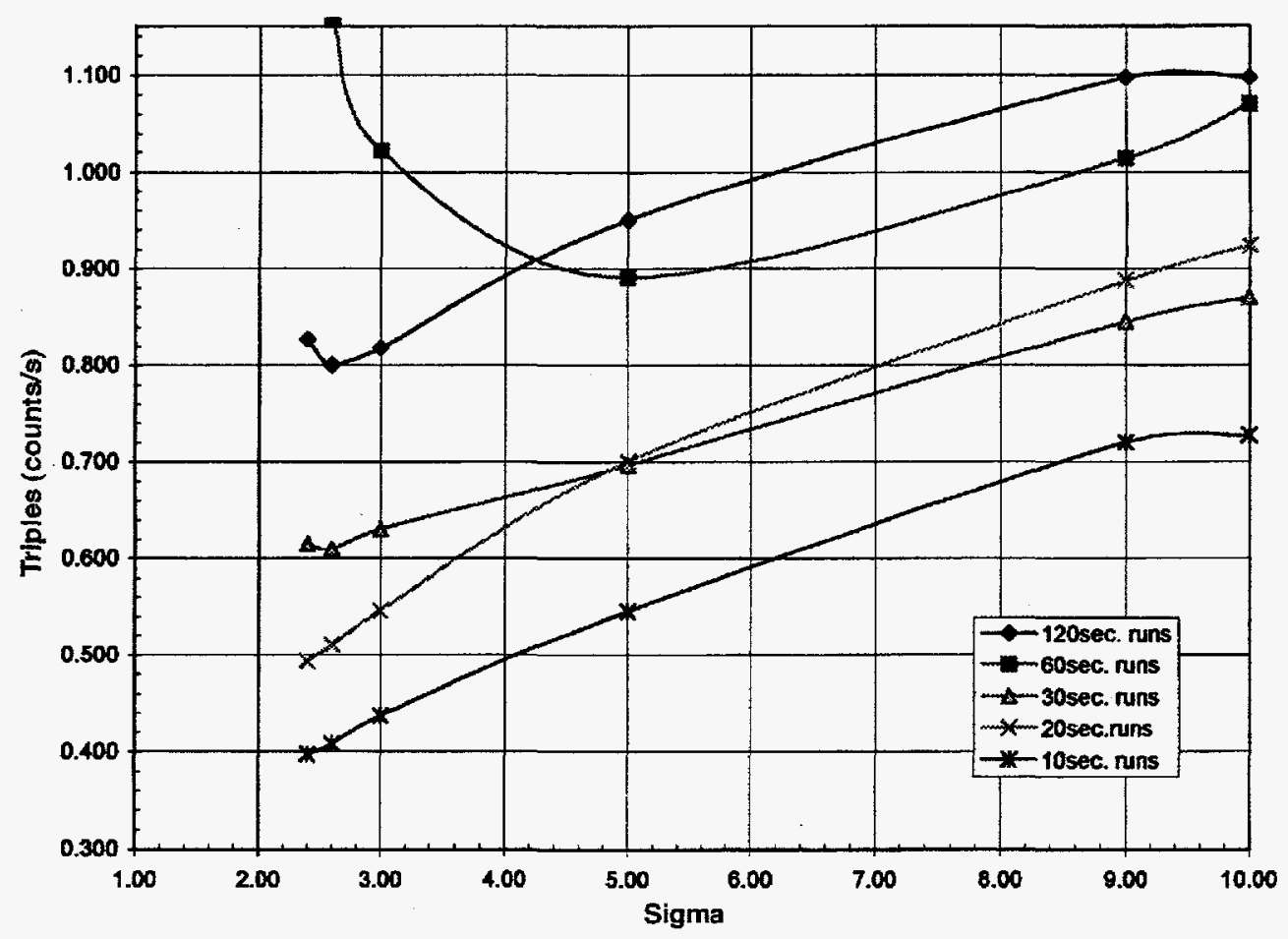

Fig. 28. Triples background rate vs outlier sigma test level for different data collection time bins using NCC software.

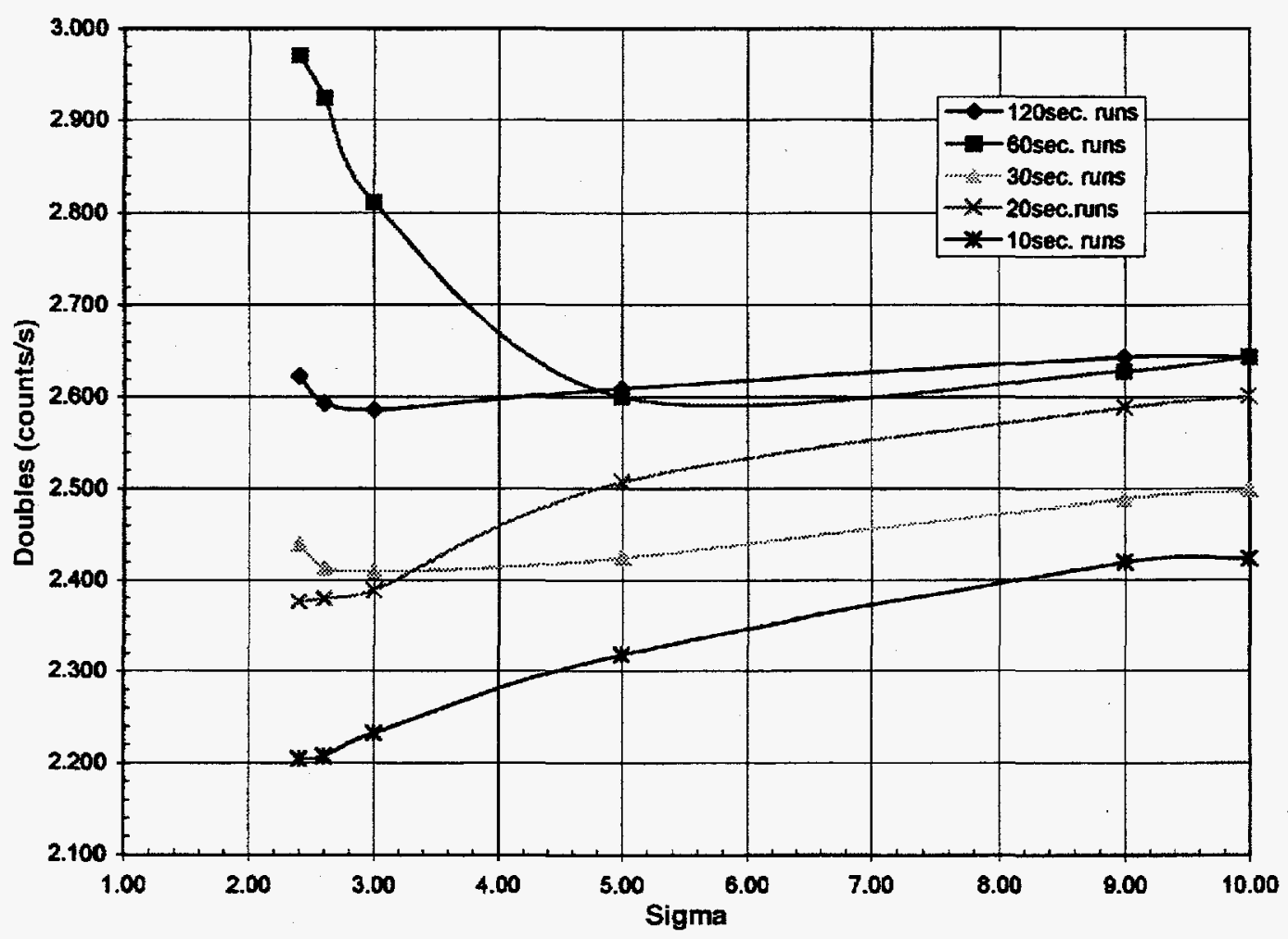

Fig. 29. Doubles background rate vs outlier sigma test level for different data collection time bins using NCC software. 


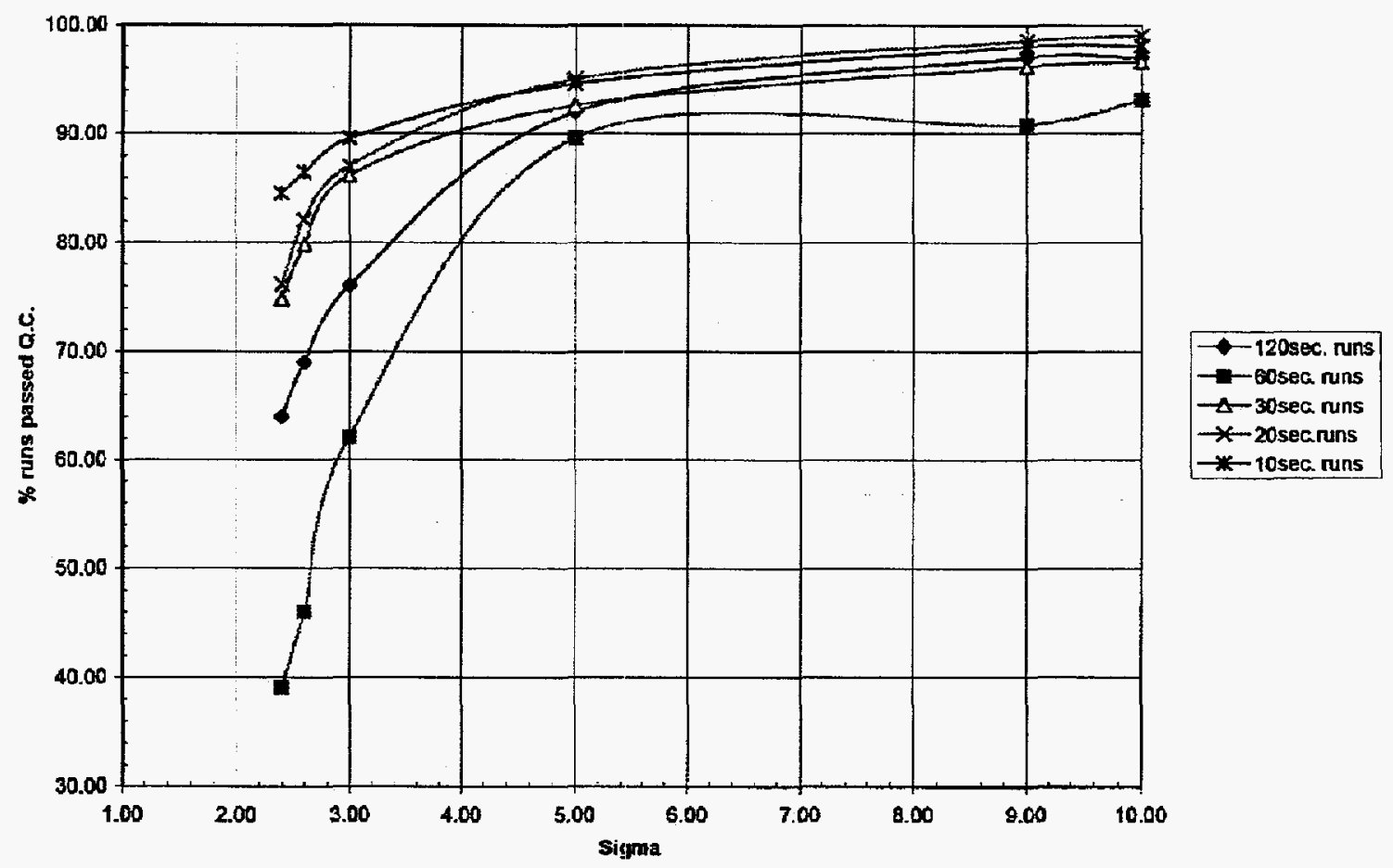

Fig. 30. Percentage of runs passed vs sigma level for different data time bins using NCC software.

\section{Spallation Background Tests}

The spallation background rate in the HENC is a function of the shielding location, cavity size, moderator materials, and construction materials.

A series of measurements were performed to evaluate the background contribution from the moderator and construction materials. Three different multiplicity counters were used for the study.

1. the HENC (LANL, TA-35, Bldg. 27)

2. the $\mathrm{HCAS}^{7}$ (hot cell AS system)

3. the portable neutron MOX scanner

The HCAS uses a composite moderator of polypropylene and Delrin with two rows of ${ }^{3} \mathrm{He}$ tubes. The total volume of the composite moderator is $\sim 0.34 \mathrm{~m}^{3}$, and the mass is $\sim 340 \mathrm{~kg}$. The HCAS is located in an underground hot cell with over an order of magnitude less cosmic-ray background than the HENC that is located at the surface level at Los Alamos. The MOX Scanner is a portable multiplicity counter that can be moved to the locations of the HENC and the HCAS to compare the cosmic-ray backgrounds. The MOX Scanner has an efficiency of $50 \%$ and a mass of $\sim 60 \mathrm{~kg}$. It can be placed by the side or inside both the HENC and the HCAS to sample the background levels at the two locations.

Table XIV gives the counting rates measured at the different locations in Bldg. 27, TA-35 at Los Alamos. The HENC background rates at Meriden, CT are listed for comparison. The 


\begin{tabular}{|c|c|c|c|c|}
\hline Detector and Location & Time(s) & Totals & Doubles & Triples \\
\hline$\underline{1 \text { st floor high bay }}$ & & & & \\
\hline HENC empty bkg (QC off) & $>100,000$ & 23.8 & 2.97 & 4.1 \\
\hline HENC empty bkg (QC on) & $>100,000$ & 23.8 & 2.24 & 0.44 \\
\hline HENC FZC-158 $\left(0.705 \mathrm{~g}{ }^{240} \mathrm{Pu}\right)(\mathrm{QC}$ on $)$ & $30 \times 10$ & 246.8 & 37.87 & 4.11 \\
\hline MOX Scanner by HENC (QC off) & $2 \times 100,000$ & 9.21 & 0.11 & NA \\
\hline MOX Scanner by HENC ( $20 \mathrm{~cm} \mathrm{CH}_{2}, Q C$ off $)$ & $600 \times 30$ & 4.21 & 0.098 & NA \\
\hline MOX Scanner inside HENC (QC off) & $3 \times 10,000$ & 3.69 & 0.075 & NA \\
\hline 2nd floor hot cell & & & & \\
\hline HCAS empty bkg (QC off) & $2000 \times 10$ & 45.3 & 1.175 & 0.581 \\
\hline HCAS empty bkg (QC on) & $2000 \times 10$ & 45.2 & 0.978 & 0.023 \\
\hline HCAS FZC-158 (QC on) & $30 \times 10$ & 235.2 & 30.26 & 2.73 \\
\hline MOX Scanner by HCAS back (QC off) & $3 \times 100,000$ & 2.08 & 0.0061 & NA \\
\hline MOX Scanner by HCAS side (QC off) & $2 \times 10,000$ & 7.53 & 0.0058 & NA \\
\hline MOX Scanner inside HCAS (QC off) & $2 \times 50,000$ & 2.96 & 0.0039 & NA \\
\hline 3rd floor low bkg area & & & & \\
\hline MOX Scanner (QC off) & $2 \times 1000$ & 0.68 & 0.001 & NA \\
\hline $\begin{array}{l}\text { Meridian. CT } \\
\end{array}$ & & & & \\
\hline HENC empty bkg (QC off) & $500 \times 60$ & 7.35 & 0.70 & 0.21 \\
\hline$\frac{\text { Summary }}{\text { HENC/HCAS rate ratios for }{ }^{240} \mathrm{Pu}}$ & Ratios & 1.049 & 1.26 & 1.51 \\
\hline HENC/HCAS sample cavity vol. ratio & 1.293 & & & \\
\hline HENC/HCAS sample cavity surface ratio & 1.174 & & & \\
\hline HENC/HCAS iron mass ratio $=75 \mathrm{~kg} / 126 \mathrm{~kg}$ & 0.60 & & & \\
\hline HENC/HCAS doubles iron bkg increase $1.68 / 2.3$ & 0.73 & & & \\
\hline $\begin{array}{l}\text { Normalized doubles bkg ratio HCAS/HENC } \\
\begin{array}{lll}(0.978 / 2.24) & (1.26) \quad(17.9) \quad(0.73) \quad(1.17)= \\
\text { (D bkg rates) } & \text { (eff.) (location) (metal) (size) }\end{array}\end{array}$ & & & 8.4 & \\
\hline
\end{tabular}

standard plutonium sample FZC-158 was counted in both counters to give a comparison of the efficiency. We see that the singles efficiency of the HENC and HCAS are similar but the doubles and triples efficiencies of the HENC are significantly higher than for HCAS because of the larger gate fractions for the HENC resulting from the shorter die-away times in the HENC.

The MOX Scanner was used to get a ratio of backgrounds between the hot cell and the surface. The measured doubles ratio for the two locations was $\sim 18$. 
To estimate the relative cosmic-ray backgrounds for the HCAS and the HENC, it is necessary to make corrections for the intrinsic efficiency, the detector size, the location, and the iron inside the two systems.

Both the HCAS and the HENC contain much more iron than is desirable for low-background systems. We estimated that the HCAS has $\sim 75 \mathrm{~kg}$ of iron inside the cavity and the HENC has $\sim 126 \mathrm{~kg}$ of iron in the rotator and reflector. We used Fig. 24 to estimate a background increase of $\sim 2.3$ for the HCAS and $\sim 1.7$ for the HENC caused by the iron in both systems.

To compare the backgrounds in the two systerns we need to combine the following ratios:

$$
\frac{\mathrm{HCAS}}{\mathrm{HENC}}=\underbrace{\left[\frac{0.97}{2.24}\right]}_{\text {meas. bkg rates }} \times \underbrace{[1.26]}_{\text {doubles efficiency }} \times \underbrace{[18]}_{\text {doubles location }} \times \underbrace{\left[\frac{1.7}{2.3}\right]}_{\text {interior iron }} \times \underbrace{[1.17]}_{\text {cavity size }}=8.4
$$

We see that the normalized background rate in the HCAS is $\sim 8$ times higher than for HENC. Most of this increase probably comes from the increased spallation rate in the double row composite moderator materials. Compounding the problem is the background increase from the long transport distance for cosmic-ray source neutrons in the high carbon plastics.

\section{E. HENC Backgrounds in 200-L Drums}

We loaded 200-L drums with a series of matrix materials to determine the background levels for the HENC at the Los Alamos surface location. Table XV lists the measured backgrounds. We see that the high carbon graphite loading has a significantly higher doubles background than the pure polyethylene case. Figure 31 shows the doubles backgrounds, and Fig. 32 shows the triples backgrounds for different matrix materials.

For routine applications, a typical combustible matrix should be used to establish the background. A long overnight run is used to get accurate ratios for the S/D and $S / T$ and subsequently short $\sim 10-\mathrm{min}$ runs can be used to get a current $\mathrm{S}$ rate. The S/D and S/T ratios (see Table XIII) are then used to calculate $\mathrm{D}$ and $\mathrm{T}$, which can be entered manually into the background file in the software. For measurements that are near the detectability limit, the appropriate matrix loading should be used for the background subtraction. 
TABLE XV. Cosmic-Ray Backgrounds as a Function of Matrix Loading.

\begin{tabular}{|c|c|c|c|c|}
\hline \multicolumn{2}{|c|}{ Background matrix effects data } & \multirow[b]{2}{*}{$\begin{array}{c}\text { Singles } \\
\text { (counts/s) }\end{array}$} & \multirow[b]{2}{*}{$\begin{array}{c}\text { Doubles } \\
\text { (counts/s) }\end{array}$} & \multirow[b]{2}{*}{$\begin{array}{c}\text { Triples } \\
\text { (counts/s) }\end{array}$} \\
\hline Matrix & $\begin{array}{c}\text { Mass } \\
(\mathrm{kg})\end{array}$ & & & \\
\hline Empty & 0 & 23.67 & 2.61 & 0.551 \\
\hline Paper & 53.9 & 22.58 & 2.23 & 0.437 \\
\hline Polyethylene beads/vermiculite & 66 & 22.25 & 2.24 & 0.460 \\
\hline Polyethylene tubes & 32.5 & 22.99 & 2.30 & 0.463 \\
\hline Polyethylene shavings & 7.2 & 23.34 & 2.40 & 0.492 \\
\hline Wood & 51 & 23.44 & 2.40 & 0.521 \\
\hline Boron glass & 173 & 24.54 & 2.94 & 0.668 \\
\hline Concrete rubble & 220 & 26.05 & 2.97 & 0.678 \\
\hline Graphite block & 126.6 & 26.96 & 3.13 & 0.743 \\
\hline Sand & 290 & 27.53 & 3.68 & 1.003 \\
\hline Iron & 196 & 30.38 & 5.70 & 2.191 \\
\hline
\end{tabular}

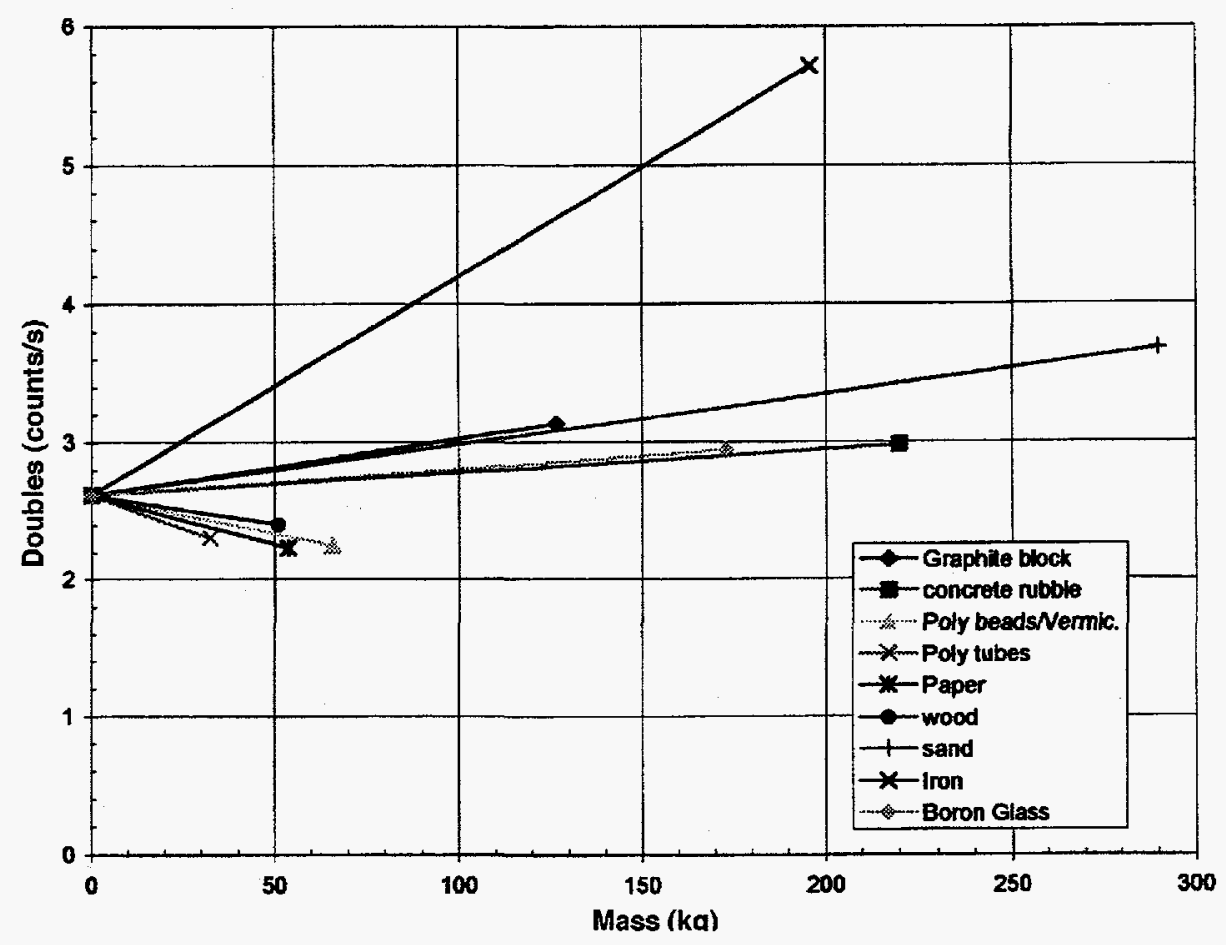

Fig. 31. Doubles background rates as a function of matrix type and mass in the 200-L drums. 


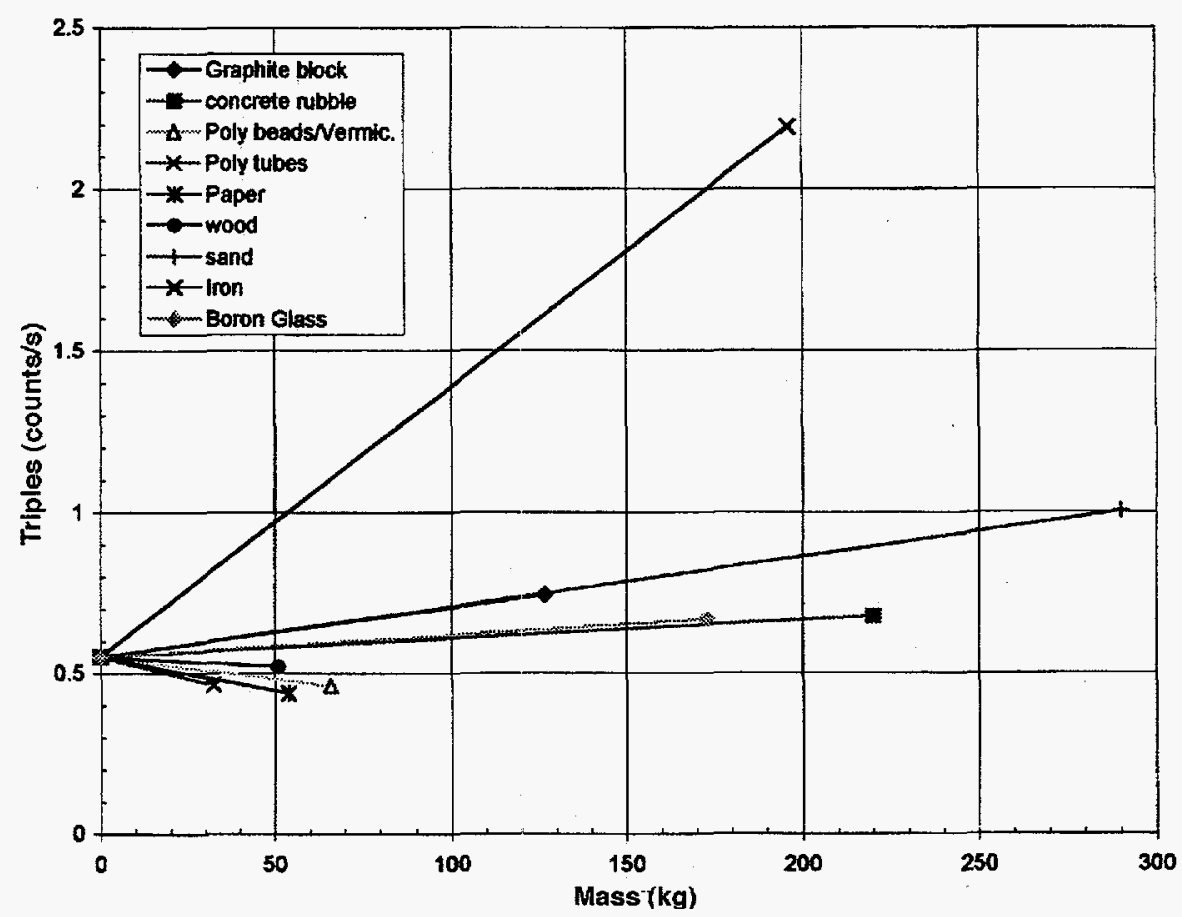

Fig. 32. Triples background rates as a function of matrix type and mass in the drums.

\section{SUMMARY}

When we combine the original MCNP design calculations with the subsequent evaluation, we can make the following recommendations.

1. Include the drum matrix effects in future optimization studies.

2. Increase the distance between the face of the HDPE and the ${ }^{3} \mathrm{He}$ tubes by $0.826 \mathrm{~cm}$ $\left(0.325 \mathrm{in}\right.$.). If the iron rollers remains in the bottom of HENC, remove one ${ }^{3} \mathrm{He}$ tube from the bottom detector bank.

3. Consider removing the drum rotator in HENC and making the AS a one stop location under the drum (same as WDAS-2 and -3).

4. Separate the electromechanical functions including the rollers, draw bridge, doors, and rotators from the data collection/analysis software to improve the reliability.

5. Remove software controls that block the use of the detector system when various switches and parameters are out of sequence or range. Just give warning flags in the printout. 
6. The efficiency after adding $\sim 0.6 \mathrm{~cm}$ of HDPE to the walls was $30.5 \%$ for ${ }^{252} \mathrm{Cf}$ and $32 \%$ for ${ }^{240} \mathrm{Pu}$ using the old ${ }^{252} \mathrm{Cf}$ reference source (CR-6). The ${ }^{240} \mathrm{Pu}$ efficiency decreases to $31 \%$ with the more recently calibrated ${ }^{252} \mathrm{Cf}$ sources.

7. In high background locations such as Los Alamos, use 10-s time bins; however, for lower background locations, use 30 -s time bins.

8. For the Los Alamos locations, use 2.4 sigma QC test levels for NAS software and 3.0 sigma levels for NCC software.

9. Use the singles background from a $\sim 10$-min measurement and calculate the $\mathrm{D}$ and $\mathrm{T}$ rates from the known ratios to $S$. Enter the $\mathrm{D}$ and $\mathrm{T}$ background values manually into the software.

10. For plutonium masses above $\sim 0.4 \mathrm{~g}{ }^{240} \mathrm{Pu}$, use the multiplicity results to supplement the AS results.

11. Refer to Appendix A for the calibration after moving the HENC to TA-54 at Los Alamos.

12. Appendix B presents the Performance Demonstration Program Round 2 test results.

13. Refer to Appendix B for the system parameters that are loaded in the software. 


\section{REFERENCES}

1. D. B. Brochu and R. D. McElroy, "Preliminary Analysis of the High Efficiency Counter Characteristic," private communication from D. B. Brochu, Canberra Industries, Meriden, CT (September 1996).

2. HENC Hardware Manual, under preparation from Canberra Industries, Meriden, CT (to be published in 1997).

3. Model 5430 Neutron Assay Software Technical Manual, 5430-TEC, V1.0 (August 1996).

4. M. Krick, "Windows NCC Version 1.10," in "Safeguards and Security Program, July 1September 30, 1996, Quarterly Activity Summay, FY 96 Summary Report," D. Rutherford, S. Hurdle, and K. Redle, Comps., Los Alamos National Laboratory document LA-UR-96-3936 (November 1996), pp. 28-29.

5. M. C. Miller, H. O. Menlove, A. Abdel-Halim, B. Hassan, and A. Kestleman, "The Improved Inventory Sample Counter INVS Mod-III," Los Alamos National Laboratory report LA12112-M (ISPO-329) (May 1991).

6. M. S. Krick and J. E. Swansen, "Neutron Multiplicity and Multiplication Measurements," Nucl. Instr. Meth. 219 (1984) 384.

7. M. Pickrell, "Combined Neutron/Gamma-Ray NDA Instrument," in "Safeguards and Security Program, July 1-September 30, 1996, Quarterly Activity Summay, FY 96 Summary Report," D. Rutherford, S. Hurdle, and K. Redle, Comps., Los Alamos National Laboratory document LA-UR-96-3936 (November 1996), pp. 54-60. 


\section{APPENDIX A}

\section{HENC RECALIBRATION AT TA-54}

The HENC was moved from TA-35 to TA-54 at Los Alamos for routine use in the measurement of waste drums. During the movement, the $\mathrm{CH}_{2}$ sheets $(0.6 \mathrm{~cm}$ thick) that were added to the sample cavity were moved from the inside of the sample cavity liner to the detector wall. This provided a small increase to the efficiency of $\sim 2 \%$ as determined by counting the same ${ }^{252} \mathrm{Cf}$ source (CR-6) and PDP plutonium standards at both locations.

To determine the plutonium calibration at the TA- 54 location, a set of standards were measured. To obtain a radial averaged response, the standards were counted at three radial positions including the center, one-half radius, and a $25-\mathrm{cm}$ radius. The sources were positioned at the mid height of an empty drum.

Table A-I lists the standards and the calibration data. The plutonium oxide was uniformly mixed into diatomaceous earth. The isotopics for the standards are given in Table A-II. The calculated $\alpha$ for the pure oxide was 0.787 ; however, the mixing with the diatomaceous earth increased the effective $\alpha$ to $\sim 1.80$. This results in a high singles calibration.

The doubles and triples calibration are shown in Fig. A-1 where the slopes are 56.35 and 5.73, respectively. The singles calibration is shown in Fig. A-2 where the slope is 886.1. Table A-III gives a comparison of the backgrounds and calibration constants at TA-35 and TA-54.

The calibration slopes are the same for both the NAS and NCC software codes. However, the backgrounds are slightly different for the two codes because of the differences in the QC test to reduce the cosmic-ray spallation events. The NCC code makes use of the triples rates, whereas, the NAS code does not.

The HENC system can be used with either software code and both codes are loaded in the computer.

TABLE A-I. HENC Calibration Data for PDP Standards at TA-54.

\begin{tabular}{|c|c|c|c|c|c|c|c|}
\hline Sample & $\begin{array}{l}\text { Time } \\
(\mathrm{s})\end{array}$ & $\begin{array}{c}\mathrm{m}_{\text {Pu240 eff }} \\
(\mathrm{g})\end{array}$ & $\begin{array}{l}\text { Singles } \\
\text { (counts/s) }\end{array}$ & $\begin{array}{c}\text { Doubles } \\
\text { (counts/s) }\end{array}$ & $\sigma_{\text {Doubles }}$ & $\begin{array}{c}\text { Triples } \\
\text { (counts/s) }\end{array}$ & $\mathrm{D} / \mathrm{m}_{\mathrm{Pu2} 240 \mathrm{eff}}$ \\
\hline PDP $0.5 \mathrm{~g}+0.1 \mathrm{~g}$ & 2097 & 0.03612 & 32.4 & 0.40 & 0.22 & 0.447 & 59.38 \\
\hline PDP $3.0 \mathrm{~g}$ & $3 \times 600$ & 0.1806 & 161.0 & 10.03 & 0.23 & 0.924 & 55.55 \\
\hline PDP $10.0 \mathrm{~g}$ & $3 \times 600$ & 0.602 & 532.5 & 33.83 & 0.55 & 3.342 & 56.20 \\
\hline PDP $10 \mathrm{~g}+3 \mathrm{~g}$ & $3 \times 600$ & 0.7826 & 694.1 & 44.19 & 0.60 & 4.592 & 56.47 \\
\hline $\begin{array}{l}{ }^{252} \mathrm{Cf} \text { CR-6 (3/11/97) } \\
\text { (centered in drum) }\end{array}$ & 600 & NA & 2008.2 & 626.49 & 2.31 & 116.267 & NA \\
\hline
\end{tabular}




\begin{tabular}{|c|c|}
\hline TABLE A-II. & $\begin{array}{c}\text { Isotopics for LANL } \\
\text { PDP Standards. }\end{array}$ \\
\hline \hline & $\begin{array}{c}\text { Weight } \\
(\%)\end{array}$ \\
\hline Isotope & 0.0145 \\
${ }^{238} \mathrm{Pu}$ & 93.76 \\
${ }^{239} \mathrm{Pu}$ & 5.945 \\
${ }^{240} \mathrm{Pu}$ & 0.223 \\
${ }^{241} \mathrm{Pu}$ & 0.0559 \\
${ }^{242} \mathrm{Pu}$ & 0.0873 \\
${ }^{241} \mathrm{Am}$ & \multicolumn{2}{|c|}{ (as of 7/15/95) } \\
\hline
\end{tabular}

TABLE A-III. Background and Calibration Constants at TA-35 and TA-54.

\begin{tabular}{|l|c|c|}
\hline \multicolumn{1}{|c|}{ Item } & TA-35 & TA-54 $^{\mathrm{a}}$ \\
\hline \hline$\underline{\text { NCC }}$ & & \\
Singles bkg (empty drum) & 23.65 & 28.0 \\
Doubles bkg (empty drum) & 2.61 & 3.0 \\
Triples bkg (empty drum) & 0.551 & 0.65 \\
Empty Drum & & \\
Singles calibration slope (PDP) & 865 & 886 \\
Doubles calibration slope & 53.8 & 56.35 \\
Triples calibration slope & 5.83 & 5.73 \\
& & \\
\hline
\end{tabular}

aThe $\mathrm{CH}_{2}$ liner was moved to the detector slab wall. 


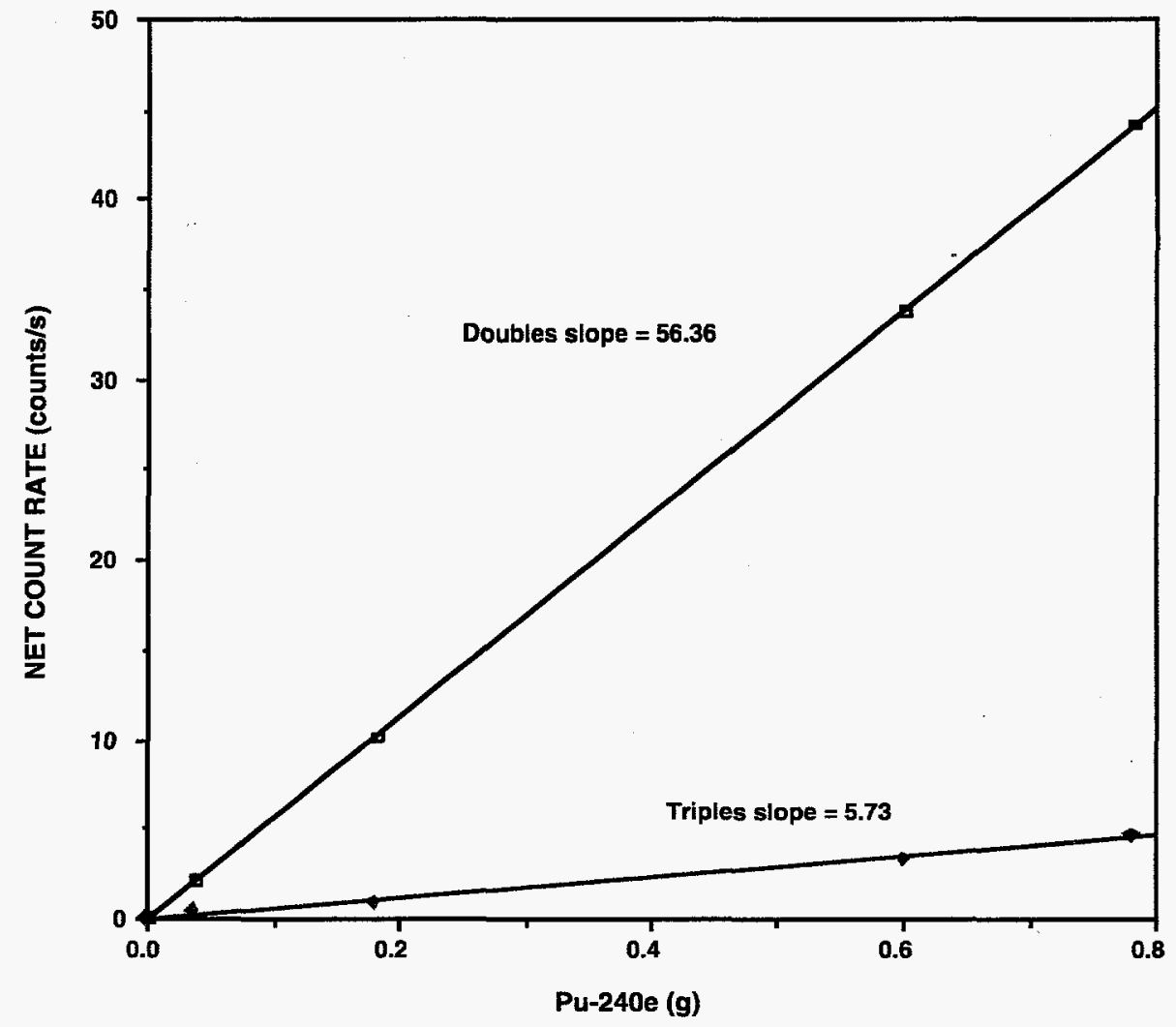

Fig. A-1. Doubles and triples calibration at TA-54 using PDP standards. The data points correspond to the radial average positioning.

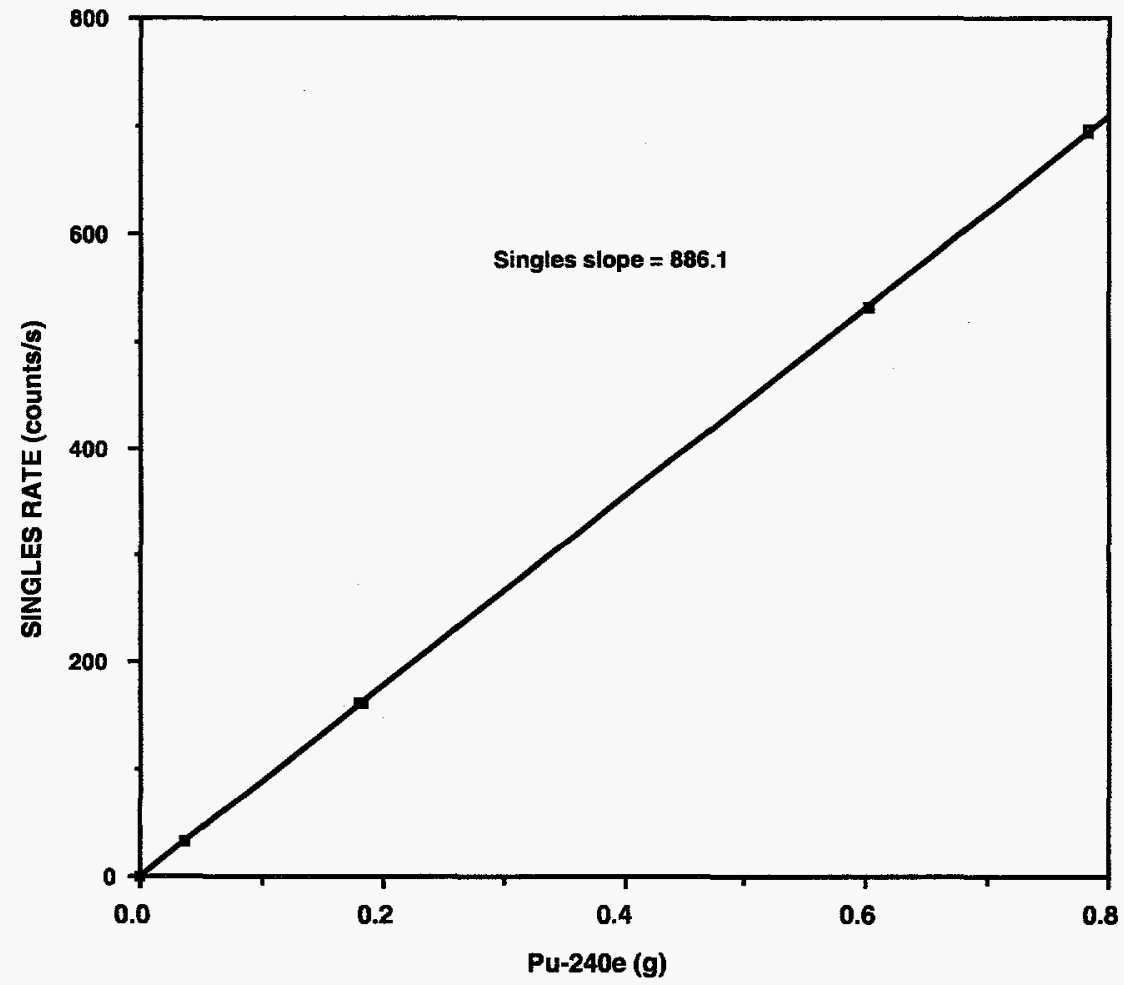

Fig. A-2. Singles calibration (radial averaged) for the diatomaceous earth standards at TA-54. 


\section{APPENDIX B}

\section{HENC CALIBRATION FOR PDP DRUMS}

The two PDP test drums (PDP-002 and PDP-003) were measured using two software codes that have identical data collection and analysis algorithms. The first code was Canberra's neutron assay system (NAS) software that used an OS-2 operating system. The second code was the Los Alamos neutron coincidence counter (NCC) software that is Windows based.

For the PDP drum measurements, the codes were loaded with identical calibration and deadtime parameters. The PDP drums were measured November 20-21, 1996, using the NAS code and November 21-22, 1996, using the NCC code. The NCC measurement results are presented here.

The PDP drums were measured using $10 \mathrm{~min}$ of passive counting followed by 3 min of ${ }^{252} \mathrm{Cf}$ AS counting for making matrix corrections. The measurement data were taken in 10-s time bins to aid in the rejection of cosmic-ray spallation background neutrons. A statistical QC test was used to reject outlier data points resulting from the cosmic-ray events.

The isotopics were assumed to be $6 \%{ }^{240} \mathrm{Pu}$-eff. and the calibration constant of 53.8 counts/s $\mathrm{g}^{240} \mathrm{Pu}$-eff. was used for all of the measurements. MOX pellets and a ${ }^{240} \mathrm{Pu}$ oxide powder sample were used for the calibration.

Table B-I gives the results of the six repeat measurements for each of the drums. The measurement routine was identical to what would be used for an unknown sample drum. The drum was completely discharged and reloaded for each of the cycles.

The average measurement results gave:

$$
0.906 \pm 0.047 \mathrm{~g} \text { Pu for PDP-002 }
$$

$$
\begin{aligned}
& \text { and } \\
& 9.00 \pm 0.10 \mathrm{~g} \text { Pu for PDP-003, }
\end{aligned}
$$

where the uncertainties are 1 sigma value based only on counting statistics. The uncertainty in the matrix correction was $\sim 5 \%$.

A more complete analysis of the data using the singles, doubles, and triples ratio is given below. The agreement using the three different calibration curves shows that the results are accurate.

\section{PDP DRUM ASSAY USING SINGLES, DOUBLES, AND TRIPLES}

The HENC system gives the multiplicity data in addition to the normal coincidence data and the samples can be assayed using the singles and triples rates as well as the doubles rates. We calibrated the HENC for singles and triples counting. If we get agreement for the doubles (D) and triples (T) assays, we can conclude that the matrix correction is correct.

The singles rate is alpha dependent so we used the PDP1-3.0 standard to simulate the alpha increase in a diatomaceous earth standard. The neutron counting rate was 865 counts $/ \mathrm{s} / \mathrm{g}$ eff. compared with 304 counts $/ \mathrm{s} / \mathrm{g}{ }^{240} \mathrm{Pu}$-eff. for a zero alpha sample. The isotopic based alpha (oxide) for PDP1-3.0 was 0.787 and the measured value of alpha was 1.85. For a benign "alpha matrix" such as an oxide, the expected count rate for $1 \mathrm{~g}$ of ${ }^{240} \mathrm{Pu}$ would be

$$
S=304(1+\alpha)=304(1.787)=543 \text { counts } / \mathrm{s} ;
$$

however, the measured rate was

$$
S=304(1+1.85)=865 \text { counts } / \mathrm{s} .
$$


Thus, the diatomaceous earth increased the totals rate by a factor of 1.59 .

The AS correction factor was measured using drums loaded with a wide range of matrix materials. The AS correction factor (CF) is small except for drums with a high hydrogen content. The AS correction is routinely made for the doubles rate and the singles CF and triples CF can be derived from the doubles correction as follows:

$$
\begin{aligned}
& \mathrm{CF}(\text { singles })=\mathrm{CF}(\text { doubles })^{0.18} \\
& \mathrm{CF}(\text { triples })=\mathrm{CF}(\text { doubles })^{1.8}
\end{aligned}
$$

Table B-II gives the measurement results for PDP-002 and PDP-003 drums for S, D, and T counts and the results are displayed in Fig. B-1. The statistics for the average triples rate for the low mass sample was marginal at $\sim 20 \%$, so the $25 \%$ deviation from the true mass is not significant.

We see that all three assay results agree for both matrix loadings so we can conclude that our matrix correction was accurate and our alpha assumption was correct. For samples that have a high plutonium content, we can use the required agreement between the doubles and triples assay to make an accurate matrix correction.

TABLE B-I. PDP Drum Results Using NCC Software.

\begin{tabular}{|ll|l|l|l|l|l|}
\hline \hline & $\begin{array}{c}\text { Real } \\
\text { (counts/s) }\end{array}$ & $\begin{array}{c}\text { Reals } \\
\text { sigma }\end{array}$ & $\begin{array}{c}\text { AS } \\
\text { Corr. }\end{array}$ & $\begin{array}{l}\text { Pu } \\
(\mathrm{g})\end{array}$ & $\begin{array}{c}\text { Sigma } \\
(\mathrm{g})\end{array}$ & $\%$ \\
\hline \hline PDP-002 & & & & & & \\
$(11 / 27 / 96)$ & 2.511 & 0.125 & 1.409 & 1.083 & 0.056 & 5.2 \\
& 2.315 & 0.128 & 1.397 & 0.99 & 0.057 & 5.8 \\
& 1.961 & 0.121 & 1.34 & 0.803 & 0.051 & 6.3 \\
& 2.015 & 0.123 & 1.407 & 0.868 & 0.054 & 6.2 \\
& 2.117 & 0.123 & 1.413 & 0.915 & 0.054 & 5.9 \\
& 1.869 & 0.121 & 1.358 & 0.777 & 0.052 & 6.7 \\
Av. & 2.131 & & & & & \\
& & & & 0.906 & 0.047 & 5.2 \\
PDP-003 & & & & & & \\
$(11 / 26 / 96)$ & 23.87 & 0.466 & 1.232 & 9.002 & 0.201 & 2.2 \\
& 24.55 & 0.454 & 1.226 & 9.21 & 0.203 & 2.2 \\
& 24.01 & 0.439 & 1.224 & 8.99 & 0.191 & 2.2 \\
& 23.78 & 0.435 & 1.199 & 8.72 & 0.195 & 2.2 \\
& 24.30 & 0.449 & 1.236 & 9.191 & 0.203 & 2.2 \\
& 23.67 & 0.441 & 1.223 & 8.855 & 0.201 & 2.2 \\
& & & & & & \\
Av. & 24.03 & & & 9.00 & 0.010 & 0.9 \\
\hline
\end{tabular}




\begin{tabular}{|c|c|c|c|c|c|}
\hline & 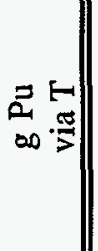 & 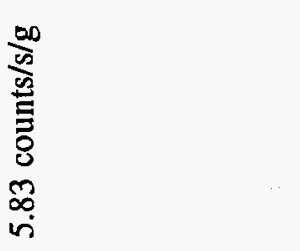 & $\bar{్}$ & & $\begin{array}{ll} \pm & n \\
0 & 0 \\
0 & 0\end{array}$ \\
\hline & 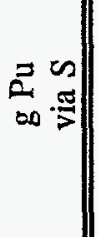 & 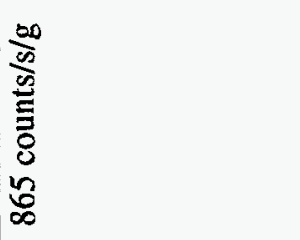 & 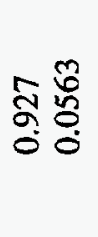 & & 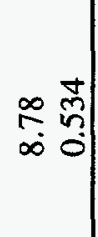 \\
\hline & 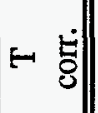 & & సे & & 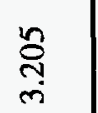 \\
\hline & थ & & $\underset{\substack{\infty \\
⿱ 亠 巾}}{\mathfrak{q}}$ & & ֶై \\
\hline & 足 & 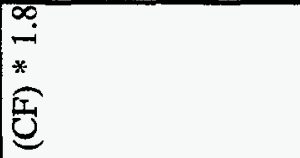 & $\stackrel{\substack{\infty \\
\hdashline}}{-}$ & & $\stackrel{\tilde{m}}{-i}$ \\
\hline 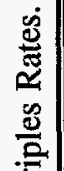 & 里 & 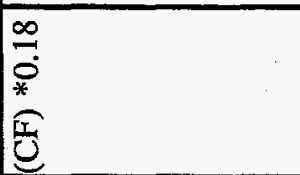 & $\underset{8}{-1}$ & & $\underline{8}$ \\
\hline $\begin{array}{l}n \\
0 \\
\bar{\Xi} \\
\text { gิ }\end{array}$ & - : & 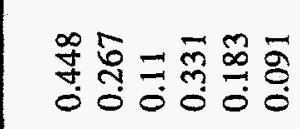 & $\stackrel{\substack{\infty \\
\dddot{\infty}}}{0}$ & 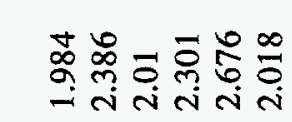 & 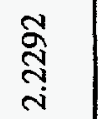 \\
\hline 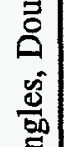 & is & 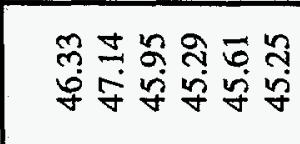 & $\begin{array}{l}\stackrel{\infty}{\Im} \\
\stackrel{\leftrightarrow}{\sim}\end{array}$ & 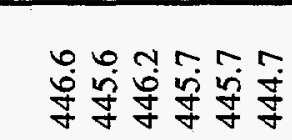 & $\frac{n}{2}$ \\
\hline 章 & 20 & $\begin{array}{l}m \\
0 \\
0 \\
0\end{array}$ & 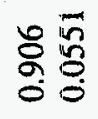 & 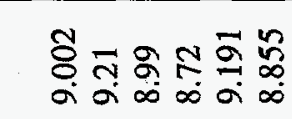 & 8 离 \\
\hline 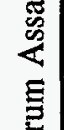 & 20 & 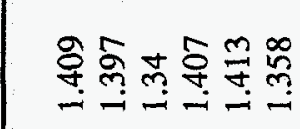 & $\begin{array}{l}m \\
\infty \\
m \\
m\end{array}$ & 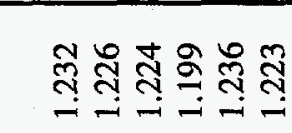 & 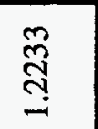 \\
\hline 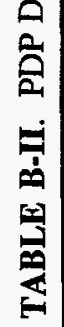 & 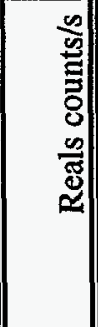 & 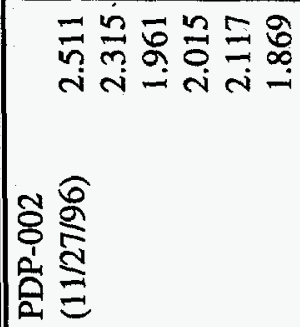 & 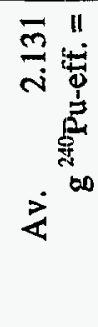 & 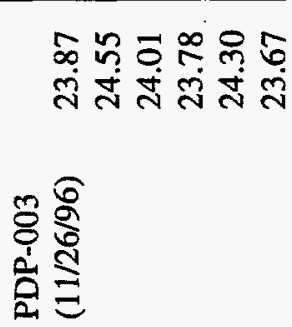 & 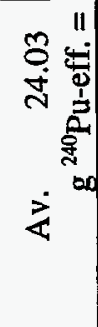 \\
\hline
\end{tabular}


PDP DRUM RESULTS FOA SINGLES, DOUBLES, AND TRIPLES

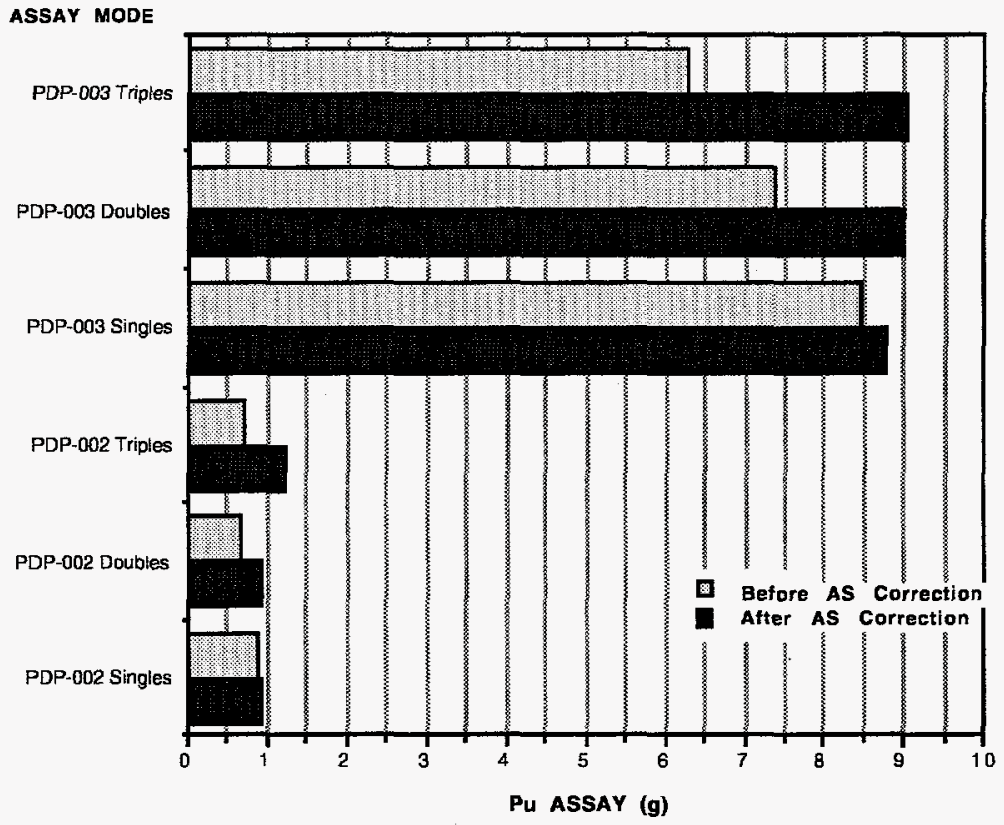

Fig. B-1. PDP cycle 2 test drum (002 and 003) results using $S, D$, and T calibrations. 
APPENDIX C

\section{HENC SOFTWARE PARAMETER SETTINGS}

Prior to using the $\mathrm{HENC}$ for assay verifications, it is necessary to load the parameter settings in the software. After moving the HENC to TA-54, the parameters were loaded into the files with the values shown in the following software screens. 

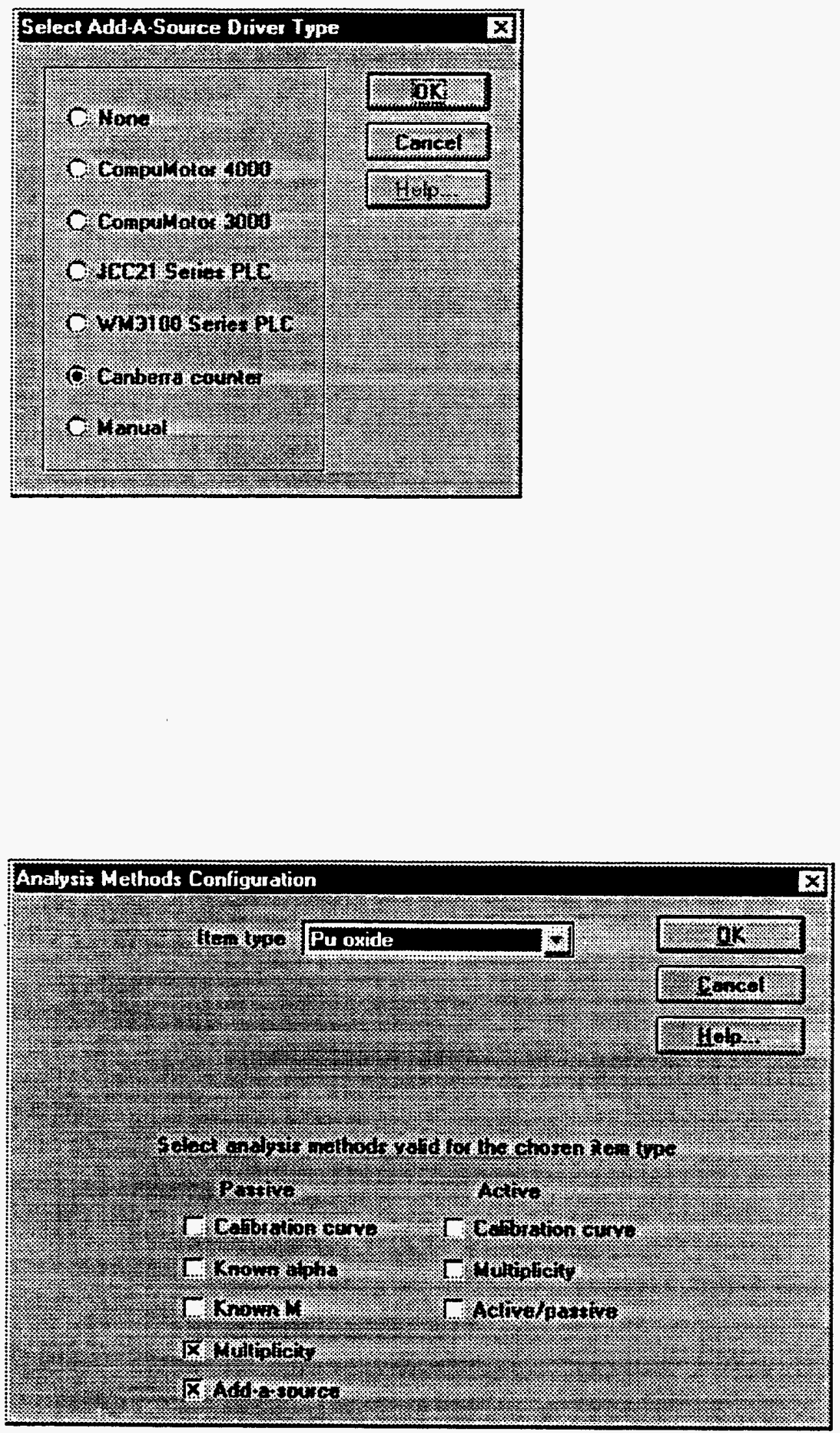

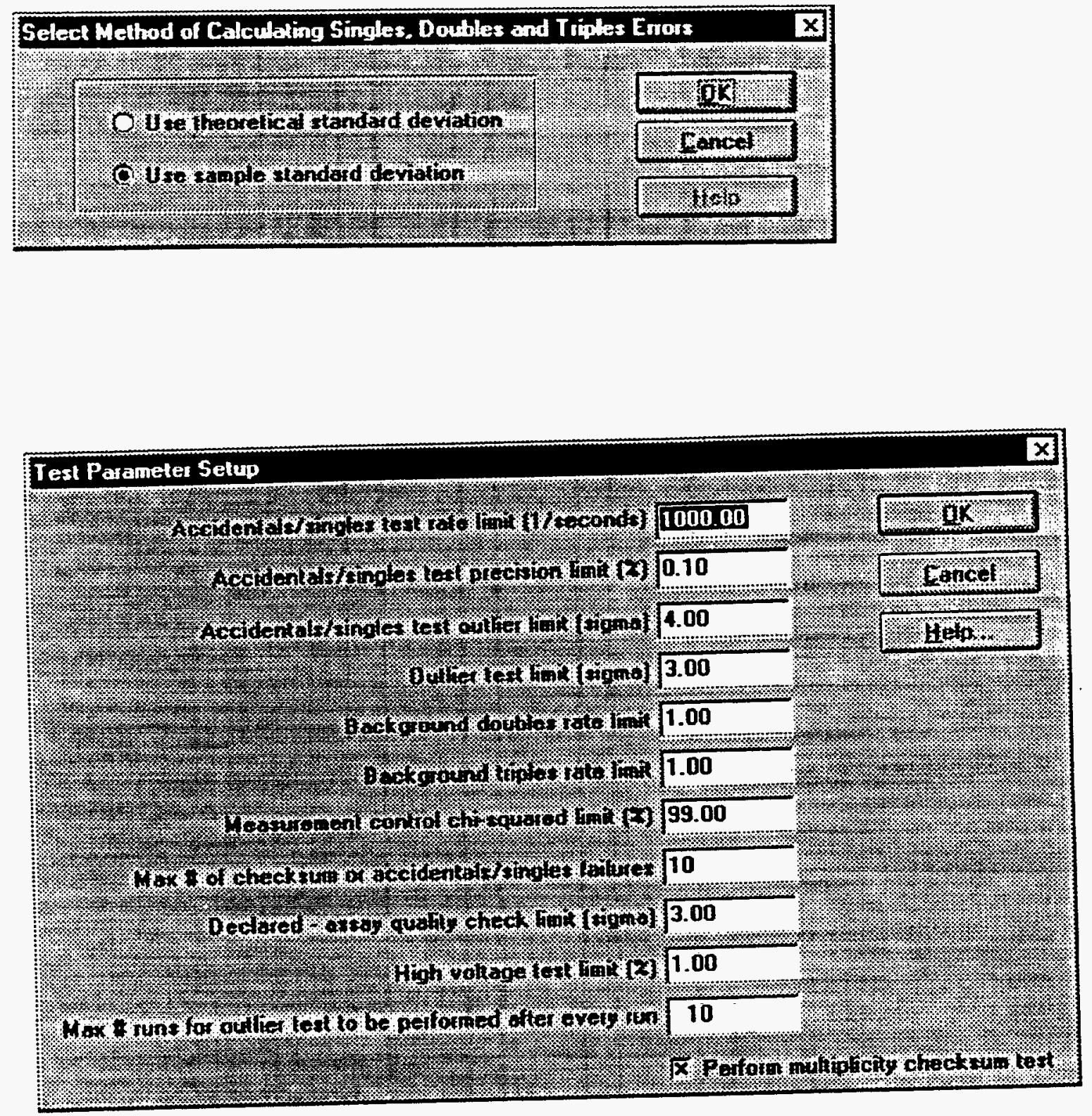

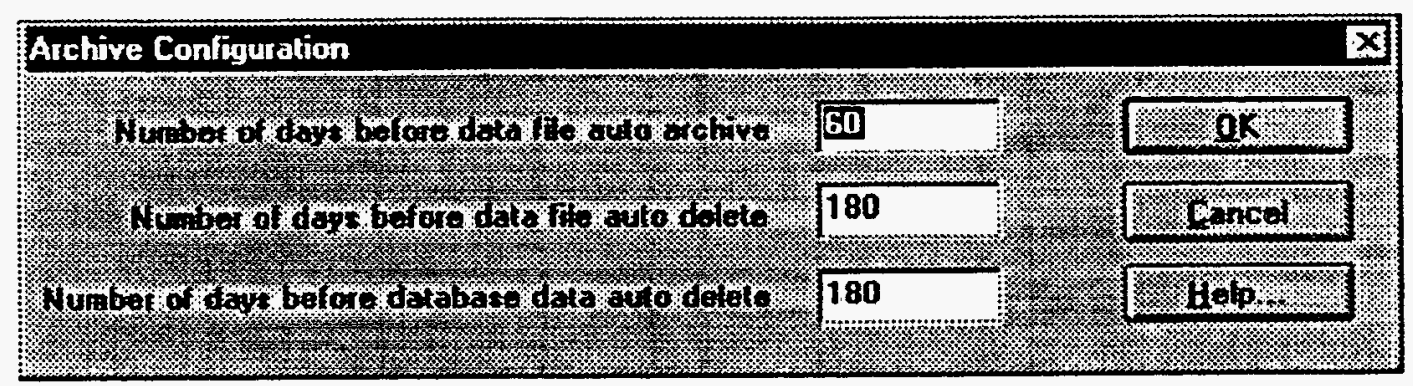




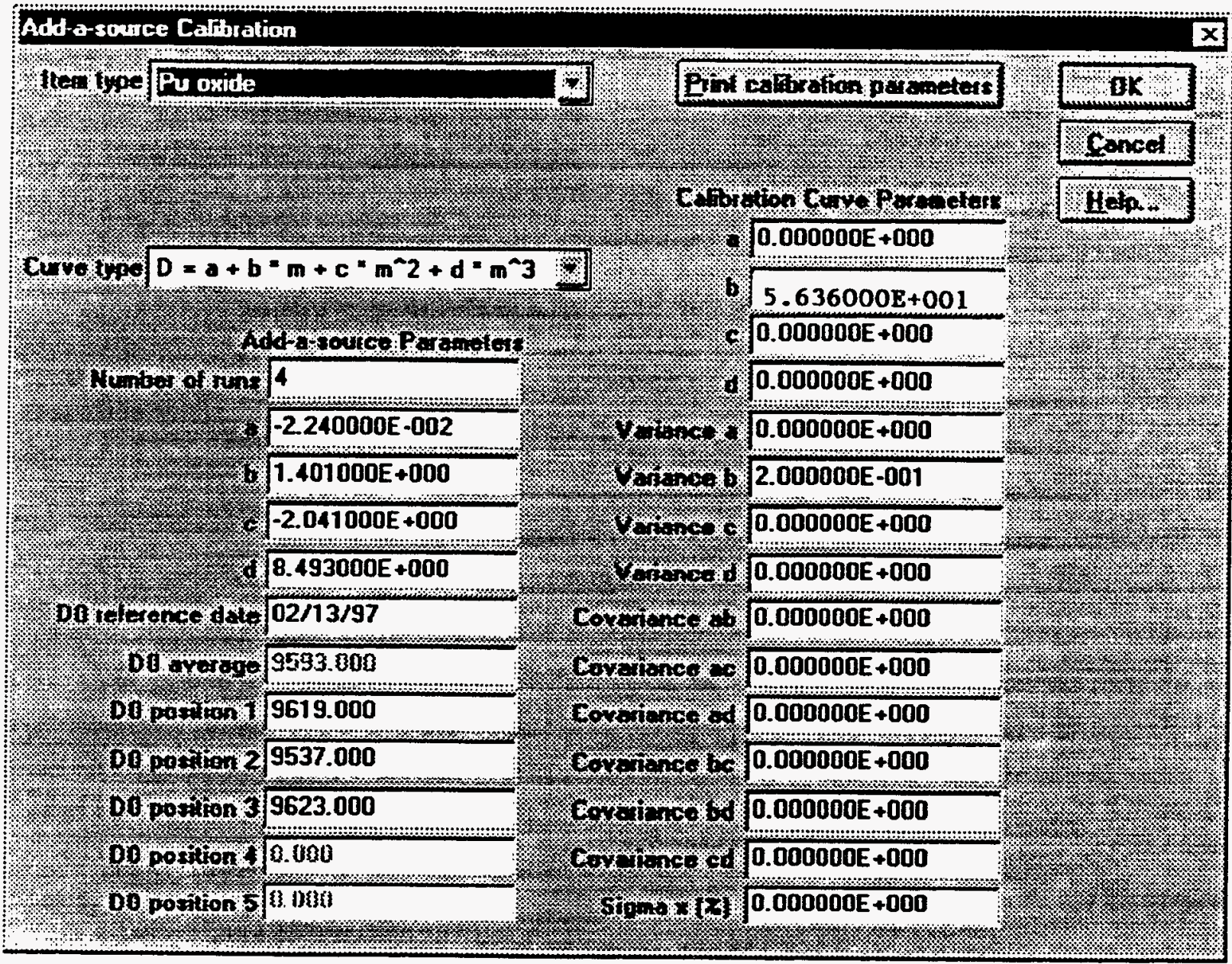

Detector Parameler Setup

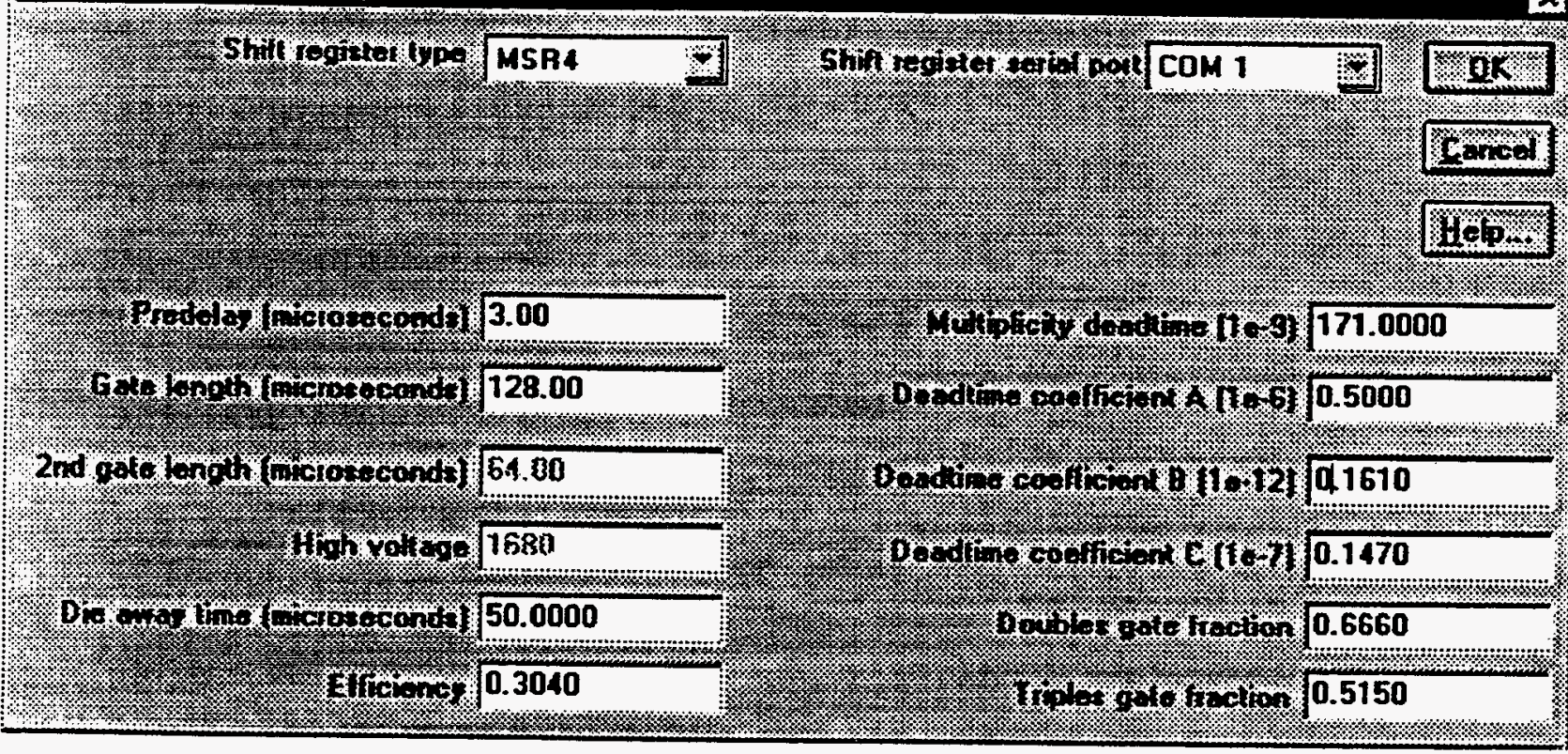




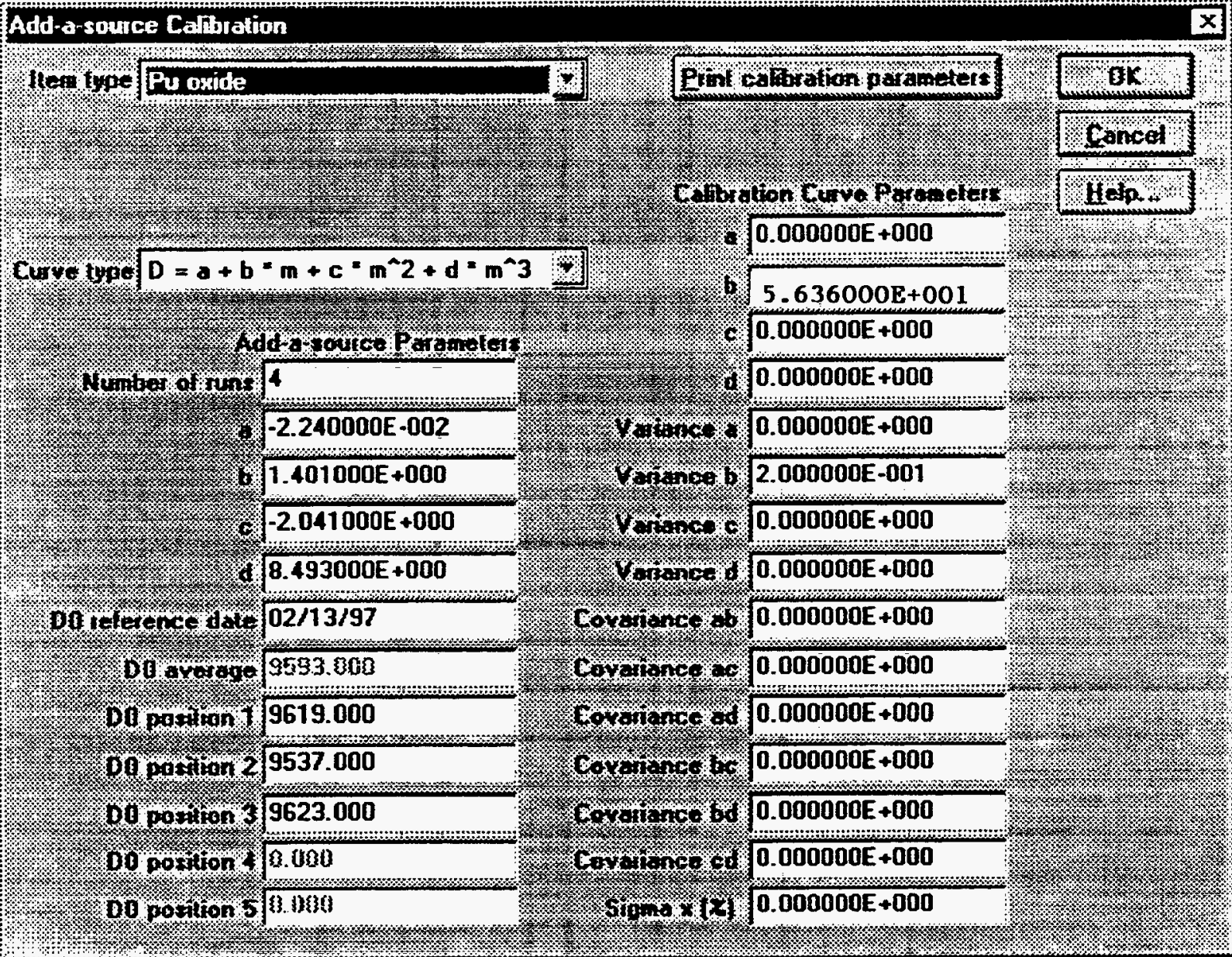

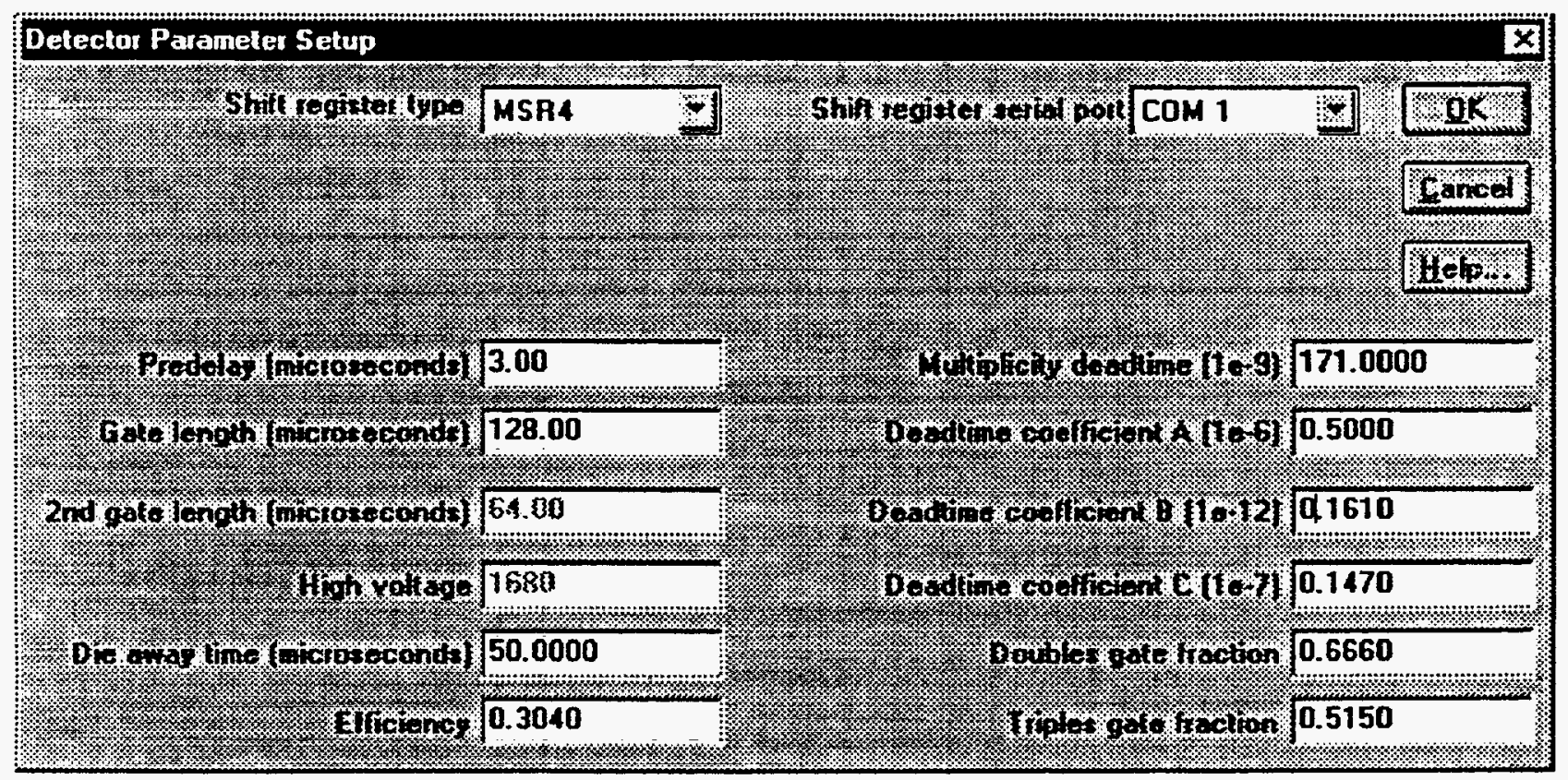

